\title{
Structural basis of DegP-protease temperature-dependent activation
}

\author{
Darius Sulskis ${ }^{1,2}$, Johannes Thoma ${ }^{1,2}$, Björn M. Burmann ${ }^{1,2 *}$ \\ ${ }^{1}$ Department of Chemistry and Molecular Biology, University of Gothenburg, 40530 \\ Göteborg, Sweden \\ ${ }^{2}$ Wallenberg Centre for Molecular and Translational Medicine, University of \\ Gothenburg, 40530 Göteborg, Sweden \\ *bjorn.marcus.burmann@gu.se
}

Protein quality control is an essential cellular function mainly executed by a vast array of different proteases and molecular chaperones. One of the bacterial HtrA (high temperature requirement A) protein family members, the homo-oligomeric DegP-protease, plays a crucial role in the Escherichia coli (E. coli) protein quality control machinery by removing unfolded proteins or preventing their aggregation and chaperoning them to their final folded state within the periplasm. DegP contains two regulatory PDZ domains, which play key roles in substrate recognition and in the transformation of DegP between inactive hexameric and proteolytic active cage-like structures. Here, we analyze the interaction and dynamics of the DegP PDZdomains underlying this transformation by high-resolution NMR spectroscopy complemented with biochemical cleavage assays. We identify an interdomain molecular lock, which controls the interactions between the two PDZ domains, regulated by fine-tuned temperature-dependent protein dynamics, and which is potentially conserved in proteins harboring tandem PDZ domains.

\section{Introduction}

An effective protein quality control (PQC) system consisting of molecular chaperones as well as proteases is essential for each living organism $(1,2)$. Within the periplasmic space of Gramnegative bacteria, this crucial task is carried out mainly by the following three proteins: Skp, SurA, and DegP (3). These proteins play a pivotal role in the quality control of outer membrane proteins (Omp) and protect bacteria from the accumulation and aggregation of misfolded 
proteins within the periplasm. Skp and SurA are responsible for controlling protein folding through their function as holdase chaperones $(4,5)$. In contrast, DegP has been shown to have a tightly-regulated dual activity under different stress conditions in vivo (3): Primarily, it functions as a serine protease to rescue cells during heat stress, but it also possesses chaperoning activity at reduced temperatures (6). DegP was shown to be essential for $E$. coli survival as a $\operatorname{deg} P$ gene knockout is lethal at elevated temperatures $\left(42^{\circ} \mathrm{C}\right)(7)$. However, it was possible to show that DegP protease activity is not a mandatory feature since overexpression of protease-deficient forms of DegP is already sufficient for $E$. coli to recover ( 8 ) under stress conditions, suppressing the lethal phenotypes (9).

On a structural level, DegP consists of a protease domain connected to two adjunct PDZ domains named PDZ1 and PDZ2 after the first proteins PSD-95, Dlg1, and ZO-1 in which this type of domains was observed (10). In its protease-inactive state DegP forms a homohexameric complex (11). Upon activation DegP can re-arrange into dodecameric or 24-meric cage-like forms, which are suggested to encapsulate substrate proteins before proteolytic cleavage (12-14) (Fig. 1A, B). The common building block of the different cage-like structures is a trimer, therefore DegP is assumed to undergo large structural transitions from its hexameric resting state via a trimeric intermediate state towards the higher oligomeric states $(15,16)$. This structural transition itself is supposed to be mediated by modulations of intermolecular PDZ1PDZ2 interactions (17). Moreover, several loops, termed LA, LD, L1, L2, and L3, play an important role in the regulation of the proteolytic function of DegP, having either activating or inhibitory roles $(12,18)$ (fig. S1A, B). Among these, the so-called LA-loop plays an important role as it is believed to stabilize the inactive conformation of DegP by shielding the active site within the protease domain in cellular ground states. In addition, it crucially participates in the modulation of DegP function as mutations in this region directly affect the activation and functionality of the enzyme $(18,19)$. Upon activation, the LA-loop is supposed to facilitate local rearrangements leading to the correct orientation of the catalytic triad ensuring effective proteolysis $(18,19)$.

Nevertheless, the exact underlying mechanism and eventual structural adaptions remain only partially understood as previous structural studies could only reveal the respective endpoints of the different oligomeric assemblies. The current model suggests that peptides containing a hydrophobic carboxy-terminal tail initially bind to the PDZ1-domain, thereby triggering subsequent structural re-arrangements, which in turn activate DegP (20). Contrary, the PDZ2- 
domain inhibits protease activity as long as DegP disassembles into trimers and subsequently transforms into the cage-like structures (17).

To address the underlying structural adaptions upon temperature activation of DegP, we investigated full-length DegP as well as its isolated PDZ1-PDZ2 domains at the atomic level using high-resolution NMR spectroscopy. Based on local chemical shift perturbations we identified an intermolecular methionine-tyrosine interaction controlling the transition from hexameric to trimeric DegP. Detailed analysis of the inherent protein dynamics revealed a finely tuned temperature-dependent allosteric network within PDZ1 modulated by the relief of the interaction with PDZ2. Biochemical characterization of the effect of this interdomain lock on the proteolytic function identified this temperature sensor as the first step in the activation cascade of DegP, but not sufficient for complete protease activation. Remarkably, the crucial tyrosine-methyl bearing residues are conserved within HtrA proteins, in perfect agreement with the mechanism of inhibitory transient oligomerization recently identified for human HtrA2 (21), indicating a widespread fundamental activation mechanism modulated via an intermolecular lock between the PDZ domains.

\section{Results}

\section{Solution NMR of full-length DegP}

Currently, only static high-resolution structures of DegP by X-crystallography (13) and medium-resolution structures by cryo-electron microscopy (cryo-EM) (22) are available, providing an incomplete picture of the functional cycle of DegP. While these structures provide important insight into the organization of the different oligomeric states of DegP, the underlying structural transitions could not be deduced from them. Therefore, we investigated DegP by high-resolution NMR-spectroscopy to obtain detailed insight into its structural and dynamical properties, which give rise to the different oligomeric states and coordinate the transition from the inactive to the active states of DegP. Due to its large size $(\sim 150 \mathrm{kDa}$ as a trimeric building block) and the existence of different oligomeric forms (Fig. 1A, B), DegP presents a challenging system for solution NMR studies. Here, we present the first $\left[{ }^{15} \mathrm{~N},{ }^{1} \mathrm{H}\right]-$ NMR spectra of uniformly-labeled $\left[U_{-}^{2} \mathrm{H},{ }^{15} \mathrm{~N}\right]-\mathrm{DegP} \mathrm{P}^{\mathrm{S} 210 \mathrm{~A}}$, which has the active site serine mutated to prevent self-proteolysis (sequence numbering follows the mature protein 1-448 excluding the 26 residues long periplasmic targeting sequence) (fig. S1C-E). The spectrum obtained at $25^{\circ} \mathrm{C}$ contained only a very limited number of resonances located exclusively in the central region of the spectrum, indicative of disordered and unstructured regions such as 
loops, in line with the large size of the protein (fig. S1C). In contrast, increasing the temperature to $37^{\circ} \mathrm{C}$ and subsequently, to $50^{\circ} \mathrm{C}$ resulted in well-dispersed spectra containing approximately 120 resonances (fig. S1D, E). The dispersion of these peaks [10-6 ppm in the ${ }^{1} \mathrm{H}$-dimension] showed that a folded domain of the full-length DegP was observable under these conditions, indicating its rather flexible attachment to the rest of the protein. In the next step, we used the known trimerization mutant $\operatorname{DegP}^{\mathrm{S} 210 \mathrm{~A}, \mathrm{Y} 444 \mathrm{~A}}$ (23), which resulted in further spectral improvement (Fig. 1C and fig. S1F) and allowed us to sequence-specifically assign large parts of the two carboxy-terminal PDZ domains (150 out of a total of 188 PDZ1-PDZ2 resonances) using standard TROSY (transverse relaxation-optimized spectroscopy)-type 3D experiments. The obtained secondary chemical shifts indicated that the structure in solution is to a large extent in agreement with the secondary structure elements observed previously within the different crystal structures (fig. S1E-G). The observation of a large set of resonances of the DegP PDZ domains indicates that these domains are not in direct contact with other parts of the protein and tumble independently in solution. Furthermore, the increased spectral quality at elevated temperatures suggested that full-length DegP might transition between different oligomeric states, pointing to an inherent temperature switch for DegP activation.

In order to determine the oligomeric state of full-length $\mathrm{DegP}^{\mathrm{S} 210 \mathrm{~A}}$ in solution, we initially tried to use the TRACT experiment (24) to probe the DegP size at the elevated temperatures (data not shown). However, due to the lack of signals at lower temperatures, this approach could not be used at temperatures below $37^{\circ} \mathrm{C}$. Moreover, the inherent overestimation of flexible regions in the TRACT experiment prevented in-depth analysis (24). To circumvent these issues, we specifically labeled the methyl groups of the methyl bearing isoleucine residues, which yielded high-quality spectra already at $25^{\circ} \mathrm{C}$, and measured pulsed-field gradient diffusion experiments on the methyl groups (25). The obtained translational diffusion coefficients showed a clear temperature dependence (Fig. 1D). With increasing temperature, the values increased from $3.4 \cdot 10^{-7} \mathrm{~cm}^{2} \mathrm{~s}^{-1}$ at $25^{\circ} \mathrm{C}$ to $4.82 \cdot 10^{-7} \mathrm{~cm}^{2} \mathrm{~s}^{-1}$ and $4.95 \cdot 10^{-7} \mathrm{~cm}^{2} \mathrm{~s}^{-1}$ at $43^{\circ} \mathrm{C}$ and $50^{\circ} \mathrm{C}$, respectively (Fig. 1D-F). Comparing these values to known literature values clearly indicates that DegP is in a hexameric state $(\mathrm{MW}=300 \mathrm{kDa})$ at $25^{\circ} \mathrm{C}$ whereas at $43^{\circ} \mathrm{C}$ and higher the protein is mainly in a trimeric state $(\mathrm{MW}=150 \mathrm{kDa})($ fig. $\mathrm{S} 1 \mathrm{~J})$. At $37^{\circ} \mathrm{C}$ we obtained diffusion coefficients that were slightly elevated compared to $25^{\circ} \mathrm{C}$ (Fig. 1D-F) indicating the partial presence of a trimeric species as an initial step of the structural transition, which is estimated to be about 20 $25 \%$ based on the increase in the diffusion coefficient. Our observation of a temperature dependent disassembly of the DegP hexamer is in complete agreement with earlier size 
exclusion studies indicating the formation of trimeric $\operatorname{DegP}^{\mathrm{S} 201 \mathrm{~A}}$ ( $\sim 80 \%$ populated) at heat shock temperatures of $42^{\circ} \mathrm{C}(17)$. To further verify this observation we probed the effects of the point mutation $\operatorname{DegP} \mathrm{P}^{\mathrm{S} 210 \mathrm{~A}, \mathrm{Y} 444 \mathrm{~A}}$. In contrast to $\mathrm{DegP}^{\mathrm{S} 210 \mathrm{~A}}$ this variant eluted from a sizeexclusion column as a mixture of trimer and hexamer already at $8^{\circ} \mathrm{C}$ (fig. S1D). To address the temperature dependent modulation of the oligomeric states for this variant, we also employed NMR diffusion measurements. With increasing temperature, the values only showed a slight variation, increasing from $4.64 \cdot 10^{-7} \mathrm{~cm}^{2} \mathrm{~s}^{-1}$ at $25^{\circ} \mathrm{C}$ to $4.81 \cdot 10^{-7} \mathrm{~cm}^{2} \mathrm{~s}^{-1}$ and $4.99 \cdot 10^{-7} \mathrm{~cm}^{2} \mathrm{~s}^{-1}$ at $37^{\circ} \mathrm{C}$ and $50^{\circ} \mathrm{C}$, respectively (Fig. $1 \mathrm{E}, \mathrm{F}$ and table $\mathrm{S} 1$ ). In comparison to $\mathrm{DegP}^{\mathrm{S} 210 \mathrm{~A}}$, these values indicate that already at $25^{\circ} \mathrm{C}$ the majority of this variant is in the trimeric state. Importantly, the observation of trimerization upon mutating Y444 to alanine and the possible temperature dependent release of the PDZ domains in wild-type DegP cannot be directly explained by the known hexameric DegP structure (Fig. 1A) (13). In fact, within the larger oligomeric states, a domain lock is observed on the interface formed by Y444 and M280 (Fig. 1B) (22). To address whether this Y444-M280 interaction occurred as well in solution within the hexamer to trimer transition, we also tested the effect of mutating the corresponding methionine. Size-exclusion chromatography revealed the existence of distinct trimeric and hexameric species for the $\operatorname{DegP} \mathrm{P}^{\mathrm{S} 210 \mathrm{~A}, \mathrm{M} 280 \mathrm{~A}}$ variant, in line with the hypothesis of an $\mathrm{Y} 444$ M280 interaction modulating the transition of the oligomeric states (Fig. 1D). To gain additional insight into the nature of the interaction between these two crucial residues we additionally tested the more conservative mutation variant $\mathrm{DegP}^{\mathrm{S} 210 \mathrm{~A}, \mathrm{M} 280 \mathrm{I}}$. In contrast, this variant showed no distinct states in the size exclusion chromatography, but rather a single elution peak in between the trimeric and the hexameric state, indicating a fast trimer-hexamer equilibrium suggesting a weakened complex formation compared the $\mathrm{DegP}^{\mathrm{S} 210 \mathrm{~A}}$, which forms an obligate hexamer under the tested conditions (fig. S1F). In agreement with this observation, we obtained also a slightly altered hexamer-trimer transition when studying this DegPS210A,M280I variant by NMR-diffusion (fig. S1H-I).

\section{Isolated PDZ1-PDZ2 bi-domains in solution}

Based on the initial observation of the highly flexible PDZ-domains within the full-length DegP and their possible contribution to the inherent temperature switch, we subsequently focused on the isolated PDZ1-PDZ2 domains. High-quality resonance assignment data of the PDZ1-PDZ2 domain construct allowed an almost complete sequence-specific assignment of the observed resonances in the $\left[{ }^{15} \mathrm{~N},{ }^{1} \mathrm{H}\right]-\mathrm{NMR}$ spectrum (fig. S2), yielding $87 \%$ backbone and 95\% aliphatic side-chain assignment. The missing amino acids were part of the interdomain 
linker (356-366) or were located in flexible loops within PDZ1. This observed exchange broadening can be explained by enhanced amide-proton exchange rates at $50^{\circ} \mathrm{C}$ within these unstructured regions (26). Using the combined ${ }^{13} \mathrm{C} \alpha$ and ${ }^{13} \mathrm{C} \beta$ chemical shifts of the protein backbone, we identified the secondary structure elements of the PDZ1-PDZ2 domain construct in solution. The observed structural elements, five $\alpha$-helices and ten $\beta$-sheets, are in agreement with the apparent secondary structure elements of the available crystal structures (fig. S2C, D). However, we observed some difference within PDZ2, where the short helical turn $\alpha_{4}$ was slightly shifted and the $\beta$-strand $\beta_{8}$ also lacked the characteristic secondary chemical shifts. Nevertheless, the presence of the short $\beta$-strands, $\beta_{6}$ and $\beta_{7}$, in the linker region between the two PDZ domains, suggests that the domains are not completely decoupled, even at the elevated temperature of $50^{\circ} \mathrm{C}$.

As we had observed large temperature-dependent effects within the spectra of full-length DegP, we also assigned the PDZ1-PDZ2 construct at $25^{\circ} \mathrm{C}$ and investigated its secondary structure propensities (fig. S3). The ${ }^{13} \mathrm{C}$ secondary chemical shifts were almost identical to the ones obtained at $50^{\circ} \mathrm{C}$, indicating that no temperature-dependent structural adaptions occurred within the PDZ domains. Nevertheless, a distinct lack of resonances was observed for residues within the amino- and carboxy-terminus of the PDZ1-PDZ2 domain construct in the $25^{\circ} \mathrm{C}$ data set: the resonances for residues M268, G269, L276, A277, M280, R286, G287, S291, N435, I436, G439, D440, and I443-M447 were broadened beyond detection in a $\left[{ }^{15} \mathrm{~N},{ }^{1} \mathrm{H}\right]-\mathrm{NMR}$ spectrum, in line with the presence of a dynamic intermolecular interaction between different PDZ1-PDZ2 molecules on the NMR intermediate timescale, i.e. with kinetic rates ranging from 1000 to $10 \mathrm{~s}^{-1}(27)$.

\section{Probing the interactions between PDZ1 and PDZ2}

To follow up on the temperature-dependent line-broadening effect observed for the PDZ1PDZ2 domain construct in solution, we characterized the PDZ1-PDZ2 interaction in further detail. Previous cryo-EM data indicated that the PDZ1-PDZ2 domains are essential for assembling as well as interlocking the DegP 12-meric and 24-meric cages and that removal of the PDZ2 domain prevents cage formation, altogether leading to primarily trimeric protein (17). Therefore, we prepared individual constructs of the PDZ1 and the PDZ2 domain and confirmed the sequence specific resonance assignments (fig. S4). In order to map possible interaction areas between these two isolated domains at different temperatures, we titrated the $\mathrm{PDZ} 1$ and the PDZ2 domains towards each other at four different temperatures $\left(25-50^{\circ} \mathrm{C}\right)$. 
These temperatures represent the hexameric, the $\sim 20 \%$ trimeric, as well as the fully trimeric state within the full-length $\mathrm{DegP}^{\mathrm{S} 210 \mathrm{~A}}$ protein, as indicated by the NMR diffusion data (Fig. 1D-F). The observed spectral changes showed that the extreme amino-terminal and carboxyterminal regions of the PDZ1-PDZ2 domains interact strongly at $25^{\circ} \mathrm{C}$ and the chemical shift perturbations (CSPs) lessened with increasing temperature, with M280 showing the largest effect (Fig. 2 and fig. S5). Remarkably, completely in line with our previous observations for the larger DegP constructs, the affected resonances did not correspond to any interfaces on the available hexameric crystal structure (Fig. 1A), but were observed within the 12 meric X-ray and the 24-meric cryo-EM structure (Fig. 1B and 2E), indicating the possibility of a stabilizing sulfur- $\pi$ aromatic or methyl- $\pi$ aromatic motif $(28,29)$. Moreover, a distinct set of residues showed larger chemical shift perturbations along with an enhanced intensity loss at $25^{\circ} \mathrm{C}$ compared to higher temperatures (Fig. 2C, D). Specifically, besides M280 Y444 was the residue most affected, implying that these two residues might provide the molecular switch locking the hexameric resting state at lower temperatures, completely in line with our observations by size-exclusion chromatography and NMR diffusion for the different fulllength protein variants (Fig. 1D-F). To validate this hypothesis, we constructed the corresponding mutants $\left(\mathrm{PDZ}^{\mathrm{M} 280 \mathrm{~A}}, \mathrm{PDZ}^{\mathrm{Y} 444 \mathrm{~A}}\right)$ and evaluated if the interaction between the domains was abolished. The titration experiments clearly showed that the interaction was completely abolished if either M280 or Y444 was mutated (fig. S6A, B), highlighting the involvement of both amino acids in forming the intermolecular lock. The same characteristic effect, although to a slightly lesser extent, was observed for the sub-set of peaks involved in the interaction for the $\mathrm{PDZ}^{\mathrm{M} 280 \mathrm{I}}$ variant, indicating that the complex was less stable (fig. S6C).

To quantify the interaction between the individual wild-type PDZ domains we used Bio-Layer Interferometry (BLI) steady-state analysis at $25^{\circ} \mathrm{C}$ resulting in a dissociation constant $\left(K_{\mathrm{D}}\right)$ of $7.8 \pm 0.9 \mu \mathrm{M}$ for the binding of PDZ1 towards biotinylated-PDZ2 (Fig. 2F and fig. S4C). We did not test the interaction vice versa with biotinylated PDZ1 in detail, because initial tests yielded a dissociation constant weakened by a factor of $\sim 20$, indicating that the binding interface on PDZ1 is perturbed by the close proximity of the Biotin-label and the identified interaction site (data not shown).

\section{The M280-Y444 interaction locks the hexameric state}

To further analyze the basis of the M280-Y444 interaction we initially checked the temperature effects on the resonance lines of the side-chains within the PDZ1-PDZ2 construct. For Y444 we observed a $\mathrm{C} \alpha$ resonance line-broadening to a similar extent than observed initially for the 


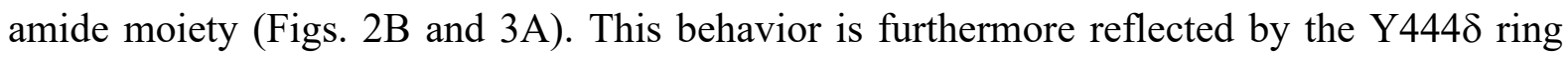
resonances, which lose about $60 \%$ of their intensity at $25^{\circ} \mathrm{C}$ compared to $50^{\circ} \mathrm{C}$ in contrast to the $\mathrm{Y} 444 \varepsilon$ resonances, which show stable intensity over the tested temperature range (Fig. 3B). Subsequently, we investigated the effects on the M280 side, where we focused on its methionine-e-methyl group, which we assigned by employing the mutation variant PDZ1$\mathrm{PDZ2}^{\mathrm{M} 280 \mathrm{~A}}$ (Fig. 3C). Probing the M280 $\varepsilon$ resonance at different temperatures revealed the presence of two distinct states, which we termed open $\left(50^{\circ} \mathrm{C}\right)$ and locked $\left(25^{\circ} \mathrm{C}\right)$ (Fig. 3D). In the transition temperatures of $37^{\circ} \mathrm{C}$ and $43^{\circ} \mathrm{C}$, respectively, we could observe two distinct peaks for the open and locked conformations, which are in the slow exchange regime, milliseconds to seconds, on the NMR timescale. Integrating the peak intensities at the different temperatures revealed that at $37^{\circ} \mathrm{C}$ the open and locked conformation coexist in a $1: 1$ ratio, whereas at $43^{\circ} \mathrm{C}$ or higher the open conformation dominates, and at $25^{\circ} \mathrm{C}$ the locked one, respectively (Fig. 3E). In order to quantify the interconversion between the open and the locked state, we used NMR exchange spectroscopy (Fig. 3F,G) $(31,32)$. We estimated the rate for the interconversion between the different states of $k_{\mathrm{ex}}=0.33 \mathrm{~s}^{-1}$ from the open to the locked state, although this has to be considered as a rough estimate as the overlap of the second cross peak impaired a more detailed analysis. Interestingly, the observation of an opening-mechanism on this slow exchange timescale is in line with recently reported data on a trimer-hexamer equilibrium for the related human HtrA2 (21).

To obtain a more detailed picture of the involved residues in the stabilization of this interdomain lock we analyzed nuclear Overhauser enhancement spectroscopy (NOESY) crosspeaks in a temperature-dependent manner (fig. S7). This analysis revealed that the participating residues, L276, M280, F289 within PDZ1 as well as V431, Y444, L446 within PDZ2 are involved in stable NOE networks in their respective domains over the temperature range $37^{\circ} \mathrm{C}-$ $50^{\circ} \mathrm{C}$. Due to the line-broadening of the participating atoms no intermolecular NOEs could be detected at $25^{\circ} \mathrm{C}$, but the distinctive signal intensity loss clearly showed the regions involvement in this temperature lock by forming a hydrophobic patch, in agreement with the interface identified in the structures of the larger DegP assemblies earlier (Fig. 2H) (22). Interestingly, we also observed temperature-dependent line-broadening for the methyl moieties of L272, which indicates its contribution to the interaction network. However, based on the crystal structure of the $\operatorname{DegP}_{12}(23)$, this residue is not expected to be located directly within the binding patch, indicating a slight rearrangement of this part of the protein, potentially due to the isolated PDZ1-PDZ2 construct used. 


\section{Backbone dynamics of the PDZ1-PDZ2 construct reveal a fine-tuned temperature adaption}

In order to understand the molecular basis and eventual structural or functional consequences of the M280 mediated temperature-switch in more detail, we next evaluated the inherent backbone dynamics of the PDZ1-PDZ2 domain construct over a broad range of timescales employing NMR relaxation measurements (32). To investigate the motions on the fasttimescale (pico- to nanosecond) the steady-state ${ }^{15} \mathrm{~N}\left\{{ }^{1} \mathrm{H}\right\}$-NOE (hetNOE) and the ${ }^{15} \mathrm{~N}$ longitudinal $\left(R_{1}\right)$ relaxation rates were measured. We observed a planar profile for the folded segments with average hetNOE values of 0.78 and $R_{1}$-rates of $1.82 \mathrm{~s}^{-1}$, respectively, indicating a stable protein fold (Fig. 4A and fig. S8A). As expected, for the loop regions and the termini we observed values indicative of increased flexibility, namely lower hetNOE values and higher $R_{1}$-rates.

Subsequently, we analyzed the contributions of motions in the micro- to millisecond regime. For these slow timescale motions, we analyzed the ${ }^{15} \mathrm{~N}$ transverse relaxation rates. First, we measured the $R_{2}$-rates derived from the $R_{1 \rho}$ rates $\left(R_{2(\mathrm{R} 1 \rho)}\right)$, which report on the motions on the lower micro-second timescale, because under the used spin-lock radio frequency (RF) field of $2,000 \mathrm{~Hz}$ all exchange contributions $\left(R_{\mathrm{ex}}\right)$ slower than $80 \mu$ s would be leveled out (Fig. $4 \mathrm{~B}$ and fig. S8B). In line with the previous analysis of the fast timescale motions, we observed a largely planar profile for the folded segments. In addition, we observed slightly enhanced transversal relaxation rates for the loop regions and for helix $\alpha_{1}$ as well as the carboxy-terminal strand $\beta_{10}$, containing M280 and Y444, respectively. Furthermore, we measured the transverse relaxation of the slowly relaxing ${ }^{15} \mathrm{~N}\left[{ }^{1} \mathrm{H}\right]$ doublet component $\left(R_{2 \beta}\right)$, revealing exchange contributions $\left(R_{\mathrm{ex}}\right)$ on the higher micro- to millisecond timescale (33), which resulted in similar profiles as observed for $R_{2(\mathrm{R} 1 \rho) \text {. In summary, the transversal relaxation rates indicate the existence of local }}$ conformational exchange contributions in the regions involved in the interdomain lock.

Next, we assessed the obtained relaxation rates globally in a temperature dependent manner (Fig. 4C-F). Whereas we observed no differences in the hetNOE values over the tested temperature range, we could observe temperature dependent modulations for $R_{1}$ and $R_{2(\mathrm{R} 1 \rho)}$ resulting consequently in changes in the rotational correlation time $\tau_{\mathrm{c}}(\mathrm{Fig}$. 4F). These observed changes in $\tau_{c}$ can be attributed to the following factors: changes in temperature and consequently solvent viscosity via the Stokes Einstein equation lead to a change by a factor of 1.74, eventual decoupling of the individual domains, and/or transient intermolecular 
interactions. To delineate if other contributions besides the temperature dependent modulation play a role for the observed changes in $\tau_{c}$, we calculated the theoretical diffusion coefficients and compared them to our experimental data (Fig. 4D). There was a very good agreement at the higher temperatures, ruling out a meaningful contribution by domain decoupling under these conditions, whereas at $25^{\circ} \mathrm{C}$ the experimental and theoretical values deviate (the experimental values indicate a larger molecule size), pointing towards the formation of a transient interdomain interaction. This observation is therefore in complete agreement with a temperature dependent transition as initially observed within the hexamer-trimer transition for full-length DegP $\mathrm{P}^{\mathrm{S} 210 \mathrm{~A}}$ by NMR diffusion measurements (Fig. 1D-F). To obtain a more detailed picture of the roles of individual amino acids involved in the PDZ1-PDZ2 interaction we employed the Lipari-Szabo model-free approach (34). This analysis using an axially symmetric diffusion model $D_{\| / \perp}$ ranging from $1.25-1.35$ (table S2) over the used temperature range revealed distinct temperature-dependent differences for the two domains (Fig. 4A) for the nanosecond timescale order parameters $\mathrm{S}^{2}$, reporting on the fast motions of the $\mathrm{N}-\mathrm{H}$ vector. Whereas the core of PDZ1 (e.g. central $\beta$-sheet) was showing only slightly temperature modulated $\mathrm{S}^{2}$ values of $\sim 0.7$, the core of PDZ2 showed lower values, with a minimum achieved at $43^{\circ} \mathrm{C}$ with $\sim 0.6$ for its central $\beta$-sheet (Fig. $5 \mathrm{~A}$ and fig. S8C). The exchange rate contributions, $R_{\mathrm{ex}}$, additionally determined by the Lipari Szabo approach (34), are indicative for possible effects of conformational exchange on the micro- to millisecond timescale. In agreement with the initially determined transversal relaxation rates, we observed enhanced $R_{\mathrm{ex}}-$ rates for the residues residing in helix $\alpha_{1}$ and parts of the $\beta$-sheet core of PDZ1 pointing towards dynamical adaptions enabling client interaction (Fig. 5B and fig. 8C). Assessing the $R_{\text {ex }}$-rates in a temperature-dependent manner reveals that at $25^{\circ} \mathrm{C}$ possible conformational exchange contributions are minimized, especially around $\mathrm{M} 280$, whereas from $37^{\circ} \mathrm{C}$ onwards micro- to millisecond motions manifest (Fig. 5B, C). Based on the observed behavior the picture emerges, that the extend of motions of M280 is coupled to the release of the inter domain lock and in this way directly modulates the degree of motions within the whole PDZ1 domain (Fig. 5D and fig. S8 C, D). Nevertheless, the observation that domain opening and enhanced backbone dynamics occur on different timescales indicates distinct separate underlying processes, such as domain release and substrate binding.

As the domain release apparently had a direct effect on the dynamics of the PDZ1, we wondered what might be the driving force for locking the domains in the inactive form. As for example, molecular chaperones were previously shown to recognize locally frustrated regions 
(35, 36), we hypothesized that local frustration within parts of the PDZ1-PDZ2 domains (37) might be the driving force for the observed intermolecular PDZ1-PDZ2 interaction (Fig. 5E). Indeed, the most frustrated region as evidenced by the large number of highly frustrated contacts within the PDZ1-PDZ2 construct resides in helix $\alpha_{1}$ harboring M280. As local frustration arises from conflicts between the constrained connectivity of amino acids, like hydrophobic amino acids in close proximity to highly charged residues, resulting in energetically unfavorable local regions, this observation indicates that the M280-Y444 lock reduces this energetically unfavorable state in cellular ground states. In line with this reasoning, both the sub-nanosecond order parameter $\mathrm{S}^{2}$ as well as the exchange contributions $R_{\mathrm{ex}}$ determined via the Lipari-Szabo approach indicate the least extent of motions at the lower temperatures. In contrast under heat shock conditions at $43^{\circ} \mathrm{C}$ the largest degree of inherent motions is observed, pointing to a preparation of the PDZ1 for substrate interaction by modulating these dynamic properties in a temperature-dependent manner.

\section{Dynamics of the methyl side-chains}

To derive the origin of the enhanced local exchange contributions of helix $\alpha_{1}$, that provide the basis for modulating the PDZ1-PDZ2 interaction, we exploited the increased sensitivity of methyl groups to gain insight into side-chain dynamics. We chose specific labeling of isoleucine, leucine, and valine methyl groups as these amino acids are well-dispersed among the PDZ-domains providing specific probes. First, we measured $\left[{ }^{1} \mathrm{H},{ }^{13} \mathrm{C}\right]-\mathrm{NMR}$ spectra at different temperatures between $25^{\circ} \mathrm{C}$ and $50^{\circ} \mathrm{C}$ (fig. S9A, D). Comparing the spectra at $50^{\circ} \mathrm{C}$ and $25^{\circ} \mathrm{C}$ revealed that a subset of the resonances underwent severe line-broadening (e.g.

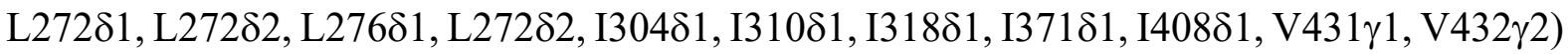
accompanied by chemical shift perturbations (fig. S9A-F). Whereas the latter can be attributed to a slight change in compactness of the protein core, which is also evidenced by the decreased extent of global backbone dynamics at the lower temperature (Fig. 5D), the lack of signal intensity for a subset of methyl groups indicates the presence of an intermolecular interaction. To assess the nature of the underlying motions we first determined the product of the sidechain order parameters and the correlation time of the overall molecular tumbling $\left(\mathrm{S}^{2} \cdot \tau_{\mathrm{C}}\right)$ for an isoleucine-labeled as well as a leucine, valine-labeled PDZ1-PDZ2 sample, providing insight into the extent of the amplitude of motions of the methyl axis in the picosecond regime (Fig. 6A, B). The obtained residue-wise profiles at $37^{\circ} \mathrm{C}$ indicate a large degree of flexibility 
for the studied methyl-groups. Whereas groups residing in the core of the PDZ2-domain show overall a lesser extend of motions on this timescale, reflected by an average $S^{2} \cdot t_{C}=4.2 \pm 1.6$ ns, methyl groups in the core of the PDZ1 uniformly show a higher degree of flexibility with $\mathrm{S}^{2} \cdot \mathrm{t}_{\mathrm{C}}=3.0 \pm 1.3 \mathrm{~ns}$.

As several methyl resonances appeared to be involved in conformational exchange processes, we next quantified these by employing multiple quantum Carr-Purcell-Meiboom-Gill (CPMG) relaxation dispersion measurements (38), sensing motions on the micro- to millisecond timescale. Measuring CPMG experiments at temperatures ranging from $25-50^{\circ} \mathrm{C}$ revealed that the residues experiencing micro- to millisecond motions reside mainly within the PDZ1

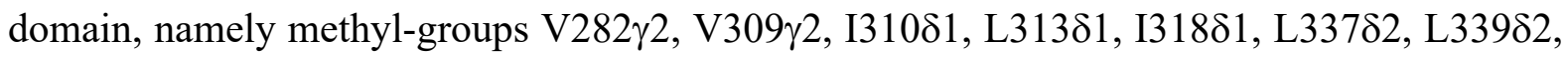

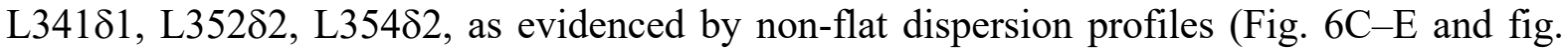
S9G). Quantitative global analysis of the dispersion data showed that this motion occurred on a $0.2 \mathrm{~ms}\left(25^{\circ} \mathrm{C}\right)$ or $0.4 \mathrm{~ms}\left(37^{\circ} \mathrm{C}\right)$ timescale under inactive conditions and $1 \mathrm{~ms}\left(42^{\circ} \mathrm{C}\right)$ or $2 \mathrm{~ms}$ $\left(50^{\circ} \mathrm{C}\right)$ timescale under activating heat shock conditions (Fig. 6E). The observation of the increased timescale of the side-chain motions under increased temperatures indicates pronounced modulations of inherent side-chain dynamics, which is directly coupled to the release of helix $\alpha_{1}$, suggesting contributions of the local frustration driving this dynamical behavior (Fig. 5E).

Having established the inherent flexibility on the micro- to millisecond timescale of mainly the PDZ1 domain likely crucial for substrate recognition, we next set out to probe these effects on the isoleucine methyl probes within the full-length $\mathrm{DegP}^{\mathrm{S} 210 \mathrm{~A}}$. Based on the side-chain assignment of the isolated PDZ1-PDZ2-domain construct (fig. S2E), we were able to unambiguously transfer the assignment of all eleven resonances within the $\operatorname{DegP}^{\mathrm{S} 210 \mathrm{~A}}$ fulllength construct (Fig. 6A, B). In order to study the transformation from the low temperature hexameric-state to the high-temperature trimeric-state within full-length $\operatorname{DegP}^{\mathrm{S} 210 \mathrm{~A}}$, we measured $\left[{ }^{1} \mathrm{H},{ }^{13} \mathrm{C}\right]-\mathrm{NMR}$ spectra over the complete temperature range from $25^{\circ} \mathrm{C}$ to $50^{\circ} \mathrm{C}$ (Fig.

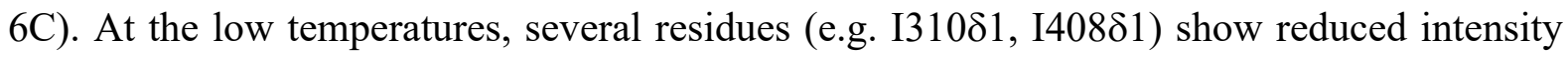
comparable to the situation observed for the PDZ1-PDZ2 construct. Using the measured intensities for $\mathrm{I} 310 \delta 1$ and $\mathrm{I} 408 \delta 1$ from $25^{\circ} \mathrm{C}$ to $50^{\circ} \mathrm{C}$ together with transition state theory, we extracted thermodynamic values for the transition from the locked to the open state. Fitting the data to a 2-state model yielded an activation enthalpy of $\Delta \mathrm{H}=241.7 \pm 88 \mathrm{~kJ} \mathrm{~mol}^{-1}$ and entropy of $\Delta \mathrm{S}=0.78 \pm 0.14 \mathrm{~kJ} \mathrm{~mol}^{-1} \mathrm{~K}^{-1}$ with a transition midpoint at $36.8 \pm 1.3^{\circ} \mathrm{C}$. The obtained activation enthalpy is perfectly in line with the obtained values for a general methyl- 
phenylalanine or a comparable methionine-phenylalanine interaction motifs of $50-100 \mathrm{~kJ} \mathrm{~mol}^{-}$ ${ }^{1}(39,40)$, providing further indication of the Met-Tyr motif stabilizing the intermolecular PDZ1-PDZ2 interaction.

Similar to the initial observations for the $\left[{ }^{1} \mathrm{H},{ }^{15} \mathrm{~N}\right]-\mathrm{NMR}$ spectra (fig. S1), the $\left[{ }^{1} \mathrm{H},{ }^{13} \mathrm{C}\right]-\mathrm{NMR}$ spectra of the isoleucine labeled $\operatorname{DegP}^{\mathrm{S} 210 \mathrm{~A}}$ also did not yield high-quality spectra for the protease domain of full-length DegP (Fig. 6). This suggests that a high-amount of inherent dynamics exists for this domain (backbone as well as methyl groups), which could already be observed to cause poor quality NMR spectra for some oligomeric proteases earlier $(41,42)$, and therefore likely reflects the regulatory role of the variety of different loops involved in the regulation of DegP protease function (fig. S1A, B). In agreement with this reasoning is the observation of spectra of similar quality for the $\left[{ }^{1} \mathrm{H},{ }^{13} \mathrm{C}\right]-\mathrm{NMR}$ spectra of isoleucine labeled DegP $P^{\mathrm{S} 210 \mathrm{~A}, \mathrm{Y} 444 \mathrm{~A}}$ and DegP $\mathrm{P}^{\mathrm{S} 10 \mathrm{~A}, \mathrm{M} 280 \mathrm{I}}$ over the tested temperature range (fig. S10A-C). Whereas these spectra differ in terms of quality for the resonances of the two PDZ domains, with DegP ${ }^{\mathrm{S} 210 \mathrm{~A}, \mathrm{Y} 444 \mathrm{~A}}$ providing the highest quality spectra, reflecting its obligate trimeric form over the whole temperature range assessed, no distinctive differences for isoleucine residues originating from the protease domain could be observed.

\section{DegP trimers display increased proteolytic activity}

To investigate if DegP trimerization has a direct influence on the proteolytic function, we tested the effect on previously reported DegP model substrates: fluorescent $\mathrm{p} 23$ peptide as well as $\beta$ casein. In initial test experiments, we were not able to observe any significant differences for the DegP variants cleaving the fluorescent p23 peptide (fig. S11), which can likely be attributed to the proposed function of this peptide as a DegP activator (23). On the other hand, the used DegP mutants, DegP ${ }^{\mathrm{Y} 444 \mathrm{~A}}$, DegP ${ }^{\mathrm{M} 280 \mathrm{~A}}$, and $\operatorname{DegP}^{\mathrm{M} 280 \mathrm{I}}$ did cleave $\beta$-casein more rapidly compared to DegP in a coupled assay using a non-activating fluorescent reporter peptide (14) (Fig. 8A). The observation of sigmoidal curves for all tested DegP variants indicates the necessity of a second activation step, besides breakage of the PDZ1-PDZ2 interaction, for its proteolytic function, likely pointing to the positive cooperative allosteric activation of the LALoop upon $\beta$-casein binding to PDZ1 $(12,18,23)$. Interestingly, the DegP ${ }^{\mathrm{M} 280 \mathrm{I}}$ variant showed an intermediate behavior in our essays, suggesting a partially functioning interdomain lock, albeit being surprisingly active at $25^{\circ} \mathrm{C}$ compared to $37^{\circ} \mathrm{C}$. 
Analyzed by SDS-PAGE, DegP $\mathrm{P}^{\mathrm{M} 280 \mathrm{~A}}$ and $\mathrm{DegP}^{\mathrm{Y} 444 \mathrm{~A}}$ variants completed cleavage of a 30-times molar excess (considering a DegP hexamer) of $\beta$-casein within 30 min, whereas DegP and $\operatorname{DegP}^{\mathrm{M} 280 \mathrm{I}}$ required up to 1 hour to process $\beta$-casein (Fig. $8 \mathrm{~B}, \mathrm{C}$ ). It should be noted that it should be possible for DegP $\mathrm{P}^{\mathrm{M} 280 \mathrm{I}}$ to form 12- and 24-meric cages due to interactions between the long methyl-bearing isoleucine side-chains and the aromatic $\pi$-system of Y444 (29). This feature could be confirmed by size-exclusion chromatography, where DegP and DegP $\mathrm{P}^{\mathrm{M} 20 \mathrm{I}}$ formed almost exclusively cage-like structures, reflecting DegP cages in the presence of the $\beta$ casein substrate, whereas the capability to assemble these cages was largely diminished in $\operatorname{DegP}^{\mathrm{M} 280 \mathrm{~A}}$ and DegP $\mathrm{P}^{\mathrm{Y} 44 \mathrm{~A}}$ indicating the importance of the PDZ1-PDZ2 interdomain stabilizing the large assemblies (Fig. 8D).

Additional NMR titrations provided evidence for our initial reasoning, that $\mathrm{p} 23$ primarily binds to the PDZ1 domain and thus likely triggers the allosteric changes needed for proteolytic activation via the LA-loop in complete agreement with previous crystallographic studies (23) (fig S10A-D). $\beta$-casein on the other hand had a more global effect on both domains at half equimolar ratio, reflecting its larger size $(24 \mathrm{kDa})$ and consequently larger binding interface compared to the p23 peptide (fig. S11D). At lower ratios, the largest chemical shift perturbations were observed for the PDZ1 domain, in agreement with its role as the main substrate recognition region and indicating an auxiliary role for the PDZ2 in substrate recognition (fig. S11D, E). Finally, the non-activating reporter peptide did not lead to any significant spectral changes, indicative of binding to the protease domain (43) and thus highlighting the need for allosteric activation of DegP through substrate binding to the PDZ1 domain, a characteristic feature of a variety of $\operatorname{HtrA}$ proteins $(11,14,20,44,45)$.

\section{Discussion}

Despite being studied extensively and the existence of several high-resolution crystal structures of DegP in its different states multiple questions remain about how its structural transitions are achieved. Within the known structures of the hexameric state, the $\operatorname{DegP}_{12}$ and $\operatorname{DegP}_{24}$ structures, an intermolecular PDZ1-PDZ2 interaction always coordinates the arrangements of the DegP trimer building-blocks to stabilize the larger oligomeric assemblies (12). Thereby, the structures indicated a different arrangement of the PDZ-domains for the hexameric state compared to the larger oligomeric states (Fig. 1A). However, our solution NMR results presented here shows that in solution DegP is locked in the hexameric state via the same M280Y444 interaction as observed initially within the larger oligomeric states, indicating that this 
interaction is crucial for modulating the different oligomeric states within DegPs functional cycle. Although the participation of Y444 was already suggested based on the characterized DegP $210 \mathrm{~A}, \mathrm{Y444 \textrm {A }}$ mutant (14), our data revealed that the M280 is not only participating in this interaction but effectively modulating the temperature-dependent opening of this interdomain lock.

Studying backbone in combination with methyl-group side-chain dynamics over the transition temperature range revealed inherent dynamics within the core of the PDZ1 domain (V282, V309, I310, L313, I318, L337, L339, L341, L352, L354), which are likely allosterically triggered by the domain release. The conformational transition of M280 between its locked and open state is on a different timescale therefore only indirectly modulating these inherent faster dynamics. Our data indicate that this interaction is stabilized likely via a sulfur- $\pi$ interaction of the M280 and Y444 side-chains, a motif lately receiving recognition as an important stabilizer of protein interactions $(28,39)$. Although we cannot completely rule out a methyl- $\pi$ interaction, the fact that a sulfur- $\pi$ is believed to be the stronger interaction $(39,40)$ and our observation that the conservative mutation M280I leads to a destabilization of the inter-domain lock suggests a sulfur- $\pi$ interaction.

Taken together our backbone and side-chain dynamical data draw a detailed picture of how the temperature-dependent breakage of the interdomain lock fine-tunes the inherent dynamics of PDZ1 to ensure efficient substrate interaction (Fig. 9). Whereas the lack of backbone motions at $25^{\circ} \mathrm{C}$ directly explains the consequence of the locked conformation at low temperatures, likely driven by a reduction of the local frustration in M280 bearing helix $\alpha_{1}$ in cellular ground states, the situation changes with increasing temperatures, where we begin to observe extensive inherent dynamics. The amplitude of motions at $37^{\circ} \mathrm{C}$ (Figs. 5A and 6D) reveals a fine-tuned dynamical compensation, which can easily adapt to slight changes in temperature to either lock the interaction (at a lower temperature) or unlock the interaction and consequently activate also the protease function of DegP (at a higher temperature). Whereas under heat-shock conditions the extensive inherent dynamics on the micro- to millisecond timescale within PDZ1 indicate a domain optimized for substrate interaction facilitating subsequent proteolytic cleavage by the protease domain. This finding poses the very interesting question whether and how the proposed large DegP-cages can form at elevated temperatures. Therefore, under heat-shock conditions the formation of the larger DegP states might not be supported by the stabilization of the PDZ1-PDZ2 lock, even though cages are supposed to form between $25-48^{\circ} \mathrm{C}(23)$. Alternatively, upon cage-formation there could be an allosteric feedback loop from the protease 
domain back towards the PDZ1 domain, with the resulting compensation of the frustrated area around $\alpha_{1}$ once again forming the main driving force for a stable complex formation via the M280-Y444 domain-lock (Fig. 9). The exact nature of the existence and/or the stabilization of the interdomain lock at elevated temperatures clearly needs further research as most studies so far focused on lower temperatures $(12,15,17,23)$.

On a more broader scope, the involved carboxy-terminal Y444 remarkably is found in several HtrA proteins known to exploit a similar locking mechanism (fig. S12A-E) (12, 21, 46, 47), Furthermore, the involved residues in DegP, M280 and Y444, are also highly conserved within different HtrA-proteins carrying two PDZ-domains, with the tyrosine showing a slightly higher conversation score than the methionine (fig. S12F, G). Our finding might therefore be indicative of a more wide-spread mechanism not only restricted to HtrA-proteins as it is already known that carboxy-terminal aromatic/hydrophobic residues in a variety of mammalian multiPDZ domain proteins govern their formation of homo- and heterodimers suggesting a possible evolutionary conserved mechanism of stabilizing PDZ-PDZ interactions $(48,49)$.

\section{Materials and Methods}

\section{Cloning of different DegP domain constructs}

The pDS4 plasmid contains wild-type DegP (E. coli K12 strain) lacking its amino-terminally signaling sequence within a pET28b-vector backbone yielding DegP with an amino-terminal $\mathrm{His}_{6}$-Tag (purchased from GenScript). The individual PDZ domains, the PDZ1-PDZ2 construct as well as the SUMO-tag were amplified by PCR from pDS4 and pET28_SUMO_Hsc70 (a kind gift of B. Bukau (Heidelberg)) (50) plasmids, respectively. The different DegP-PDZ constructs and the SUMO-tag were fused by standard PCR methods and cloned into a pET28a(-) vector via the $\mathrm{Ncol}$ and Xhol restriction sites by standard cloning techniques yielding PDZ constructs fused to an amino-terminal $\mathrm{His}_{6}$-SUMO-tag. Plasmids and primers used in this study can be found in table S3.

\section{Protein expression and Purification of PDZ1-PDZ2 domains}

pDS10 (DegP $\left.{ }^{261-354}\right)$, pDS11 (DegP ${ }^{359-448}$ ), and pDS12 (DegP ${ }^{261-448}$ ) plasmids were chemically transformed into $E$. coli BL21 Star ${ }^{\mathrm{TM}}$ ( $\lambda$ DE3) cells. The transformed cells were grown at $37^{\circ} \mathrm{C}$ in 1 I LB medium containing $50 \mu \mathrm{g} / \mathrm{ml}$ kanamycin until an $\mathrm{OD}_{600} \approx 0.5$ was reached. Expression was induced by the addition of 0.4 mM IPTG and the cells were left to grow overnight at $25^{\circ} \mathrm{C}$. 
Cells were harvested by centrifugation at $8,000 * \mathrm{~g}$ for $20 \mathrm{~min}$ at $4^{\circ} \mathrm{C}$ and subsequently resuspended in $25 \mathrm{ml}$ of lysis buffer $(25 \mathrm{mM}$ HEPES/ $\mathrm{NaOH}, 0.5 \mathrm{M} \mathrm{NaCl}, 10 \mathrm{mM}$ Imidazole, $\mathrm{pH}$ 7.5). The resuspended cells were incubated on ice with one Complete EDTA-free protease inhibitor (Roche) tablet as well as with $100 \mathrm{U}$ of DNAse (ArcticZymes) for $30 \mathrm{~min}$ and subsequently lysed with a Q700 sonicator (Qsonica) (10 s on, 30 s off, $30 \%$ power). Cell debris was removed by centrifugation at $18000^{*} \mathrm{~g}$ for $45 \mathrm{~min}$ at $4^{\circ} \mathrm{C}$ and the supernatant was applied to a $\mathrm{Ni}^{2+}$-Sepharose 6 Fast Flow (GE Healthcare) loaded gravity column, followed by step-wise elution with $20 \mathrm{ml}$ of lysis buffer supplemented with $100 \mathrm{mM}$ and $500 \mathrm{mM}$ imidazole, respectively. Fractions containing the target proteins were dialyzed against PBS (pH 7.4) and the $\mathrm{His}_{6}$-SUMO-tag was removed by enzymatic cleavage using human SENP1 protease at $4^{\circ} \mathrm{C}$ overnight (Addgene \#16356) (51). The cleaved proteins were applied again to a $\mathrm{Ni}^{2+}$-column and the flow-through was collected. The proteins were concentrated using Amicon centrifugal filters (5k MWCO or 10k MWCO, Millipore) and purified further by size exclusion chromatography (Superdex 75 Increase, GE Healthcare) in NMR buffer ( $25 \mathrm{mM}$ potassium phosphate, 1 mM EDTA 1 mM TCEP, pH 7.0).

For His6-tagged full-length DegP variants, an additional unfolding/refolding step was introduced. To this end, after cell lysis and centrifugation, the supernatant was loaded to a HisTrap HP 5 ml column (GE Healthcare) equilibrated with lysis buffer supplemented with 6 M Guanidinium chloride. For on-column refolding, the bound protein was washed with a $6-0$ M Guanidinium chloride linear gradient (15 CV, $0.5 \mathrm{ml} / \mathrm{min}$ ) overnight and subsequently eluted with a step elution of $100 \mathrm{mM}$ and $500 \mathrm{mM}$ imidazole. In the next step, DegP was purified by size exclusion chromatography (Superdex 200 Increase, GE Healthcare) in NMR buffer.

\section{Isotope labeling}

We obtained $\left[U_{-}^{15} \mathrm{~N}\right]$ and $\left[U_{-}{ }^{15} \mathrm{~N},{ }^{13} \mathrm{C}\right]$ labeled PDZ-domain constructs by growing the expression cells in $\mathrm{M9}$ minimal media (52), supplemented with $\left({ }^{15} \mathrm{NH}_{4}\right) \mathrm{Cl}$ and $D-\left({ }^{13} \mathrm{C}\right)$-glucose, respectively. For full-length DegP, the cells were in addition grown in $\mathrm{D}_{2} \mathrm{O}$-based $\mathrm{M} 9$ minimal medium, yielding $\left[\mathrm{U}_{-}^{2} \mathrm{H},{ }^{15} \mathrm{~N}\right]$ and upon the usage of $D-\left({ }^{13} \mathrm{C},{ }^{2} \mathrm{H}\right)$-glucose $\left[\mathrm{U}^{-2} \mathrm{H},{ }^{15} \mathrm{~N},{ }^{13} \mathrm{C}\right]$ proteins, respectively. For specific methyl group labeling, we either supplemented $\mathrm{D}_{2} \mathrm{O}$-based $\mathrm{M} 9$ minimal medium with $D-\left({ }^{12} \mathrm{C},{ }^{2} \mathrm{H}\right)$-glucose and isoleucine precursor (2-Ketobutyric acid-4-

${ }^{13} \mathrm{C}, 3,3-\mathrm{d}_{2}$ sodium salt hydrate) 1 hour prior to induction resulting in $\left[U-{ }^{2} \mathrm{H}\right.$, Ile- $\left.\delta_{1}{ }^{-}{ }^{13} \mathrm{CH}_{3}\right]$ or in a similar manner with $D-\left({ }^{12} \mathrm{C},{ }^{2} \mathrm{H}\right)$-glucose and leucine, valine precursor [2-Keto-3-methyl- $\mathrm{d}_{3}-3$ - 
$\mathrm{d}_{1}-4-{ }^{13} \mathrm{C}$-butyrate $]$ resulting in non-stereospecific $\left[\mathrm{U}-{ }^{2} \mathrm{H}\right.$, Leu/Val- $\left.{ }^{13} \mathrm{CH}_{3} /{ }^{12} \mathrm{CD}_{2}\right]$ labeled DegPvariants. All isotopes were purchased from Sigma Aldrich/Merck.

\section{NMR spectroscopy}

NMR measurements were performed on Bruker Avance III HD $700 \mathrm{MHz}$ or $800 \mathrm{MHz}$ spectrometers, running Topspin 3.5/3.6 and equipped with a cryogenically cooled tripleresonance probe. All experiments were performed in NMR buffer $(25 \mathrm{mM}$ potassiumphosphate, $1 \mathrm{mM}$ EDTA, $1 \mathrm{mM}$ TCEP pH 7.0).

For the sequence-specific backbone resonance assignment experiments of DegP $\$ 210 \mathrm{~A}$ constructs and the different PDZ-domain constructs the following experiments were recorded: 2D $\left[{ }^{15} \mathrm{~N},{ }^{1} \mathrm{H}\right]-$ TROSY-HSQC (53) and for full-length DegP $5210 \mathrm{~A}, \mathrm{Y444A}$ the following TROSY-type 3D experiments 3D trHNCA, 3D trHNCACB, and 3D trHNCO (54) whereas for the different PDZ-domain constructs standard through-bond 3D HNCA, 3D HNCACB, 3D HNCO, $3 \mathrm{D}$ CBCA(CO)NH (55) experiments were used. Aliphatic side-chain resonance assignment for the PDZ1-PDZ2-construct was performed based on 2D $\left[{ }^{13} \mathrm{C},{ }^{1} \mathrm{H}\right]-\mathrm{HSQC}$ spectra with/without constant time $(\mathrm{CT})$ version, as well as 3D $(\mathrm{H}) \mathrm{CC}(\mathrm{CO}) \mathrm{NH}, \mathrm{H}(\mathrm{CC})(\mathrm{CO}) \mathrm{NH}$, and $\mathrm{HCCH}-\mathrm{TOCSY}-$ experiments (55). In addition, the following NOESY-type experiments with the indicated mixing times were performed: $3 \mathrm{D} \mathrm{H}_{\mathrm{all}}-\mathrm{H}_{\text {aro }}-\mathrm{C}_{\text {aro }}$ with $120 \mathrm{~ms}$ mixing time, $3 \mathrm{D} \mathrm{H}_{\text {all }}-\mathrm{H}_{\text {ali }}-\mathrm{C}_{\text {ali }}$ with 120 ms mixing time (55), 3D ${ }^{13} \mathrm{C}_{\mathrm{m}}{ }^{-13} \mathrm{C}_{\mathrm{m}}{ }^{1} \mathrm{H}_{\mathrm{m}}$ SOFAST NOESY with $50 \mathrm{~ms}$ mixing time (56). Assignment experiments were performed at $50^{\circ} \mathrm{C}$ if not indicated otherwise.

For the quantitative analysis of signal intensities, the amplitudes were corrected by differences in the ${ }^{1} \mathrm{H}-90^{\circ}$ pulse-length, the number of scans, and the dilution factor (57). NMR data were processed with a combination of NMRPipe (58) and mddNMR2.6 (59) as well as analyzed with CARA (60).

For titration experiments, 2D $\left[{ }^{15} \mathrm{~N},{ }^{1} \mathrm{H}\right]$-TROSY-HSQC experiments were acquired with 4 scans and $2048 \times 256$ complex points in the direct and indirect dimensions, respectively. The chemical shift changes of the amide moiety were calculated as follows:

$$
\Delta \delta(H N)=\sqrt{\left(\Delta \delta^{1} H\right)^{2}+\left(\Delta \delta^{15} N / 5\right)^{2}}
$$

The chemical shift changes of the methyl groups were calculated as follows:

$$
\Delta \delta(H C)=\sqrt{\left(\Delta \delta^{1} H\right)^{2}+\left(\Delta \delta^{13} C / 4\right)^{2}}
$$


Secondary chemical shifts were calculated relative to the random coil values using the prediction software POTENCI (61). Further, a weighting function with weights 1-2-1 for residues $(i-1)-i-(i+1)$ was applied to the raw data $(5,35)$.

\section{NMR backbone dynamics}

For the analysis of the dynamic properties of the different DegP constructs, the following relaxation experiments were measured: ${ }^{15} \mathrm{~N}\left\{{ }^{1} \mathrm{H}\right\}-\mathrm{NOE}(62), T_{1}\left({ }^{15} \mathrm{~N}\right)(62), T_{1 \rho}\left({ }^{15} \mathrm{~N}\right)(63)$, and TROSY for rotational correlation times (TRACT) for determining $T_{2 \alpha}\left({ }^{15} \mathrm{~N}\right)$ and $T_{2 \beta}\left({ }^{15} \mathrm{~N}\right)(24)$ at $700 \mathrm{MHz}(16.4 \mathrm{~T})$ proton $\left({ }^{1} \mathrm{H}\right)$ frequency. Non-linear least square fits of relaxation data were done with MATLAB (MathWorks) and the Dynamics Center 2.5 (Bruker Biospin). $R_{2(\mathrm{R} 1 \rho)}\left({ }^{15} \mathrm{~N}\right)$ values were derived from $T_{1 \rho}(64)$ using equation 3 :

$$
R_{2}=\frac{R_{1} \rho}{\sin ^{2} \theta}-\frac{R_{1}}{\tan ^{2} \theta}
$$

with $\theta=\tan ^{-1}(\omega / \Omega)$, where $\omega$ is the spin-lock field strength $(2 \mathrm{kHz})$ and $\Omega$ is the offset from the ${ }^{15} \mathrm{~N}$ carrier frequency.

Error bars for $R_{1}\left({ }^{15} \mathrm{~N}\right), R_{1 \rho}\left({ }^{15} \mathrm{~N}\right), R_{2 \alpha}\left({ }^{15} \mathrm{~N}\right)$, and $R_{2 \beta}\left({ }^{15} \mathrm{~N}\right)$ were calculated by a Monte Carlo simulation embedded within Dynamics Center 2.5 (Bruker, Biospin), and for $R_{2(R 1 \rho)}\left({ }^{15} \mathrm{~N}\right)$ by error propagation. Error bars for the ${ }^{15} \mathrm{~N}\left\{{ }^{1} \mathrm{H}\right\}$-NOE were calculated from the spectral noise. Analysis of the obtained relaxation rates was performed with Tensor2 (65) using an anisotropic diffusion tensor on the NMRbox web server (66). Missing atoms and hydrogens in the PDB structure (30U0) were added using PDBFixer (67). Tmeperature dependent rotation correlation times $\left(\tau_{c}\right)$ were estimated by using HYDRONMR version 7c (68) via NMRBox at 700 $\mathrm{MHz}$ (16.4 T) magnetic field strength using a standard AER (atomic element radius) value of 3.3 $\AA$, a $1.02 \AA \mathrm{N}-\mathrm{H}$ bond length, a CSA of $-160 \mathrm{ppm}$, with the refined PDZ1-PDZ2 crystal structure (PDB-ID: 30U0). For the temperature dependent changes in viscosity of the water, the standard values were obtained from the NIST website (https://webbook.nist.gov/chemistry/fluid/).

\section{NMR side-chain dynamics}

Experiments were performed on either a $\left[\mathrm{U}_{-}{ }^{2} \mathrm{H}, \mathrm{Ile}-\delta_{1}{ }^{-}{ }^{13} \mathrm{CH}_{3}\right]-\mathrm{PDZ1}-\mathrm{PDZ2}$ or a $\left[\mathrm{U}^{-}{ }^{2} \mathrm{H}\right.$, Leu- $\delta_{1,2^{-}}$ Val- $\left.\gamma_{1,2}{ }^{13} \mathrm{CH}_{3}\right]$-PDZ1-PDZ2 sample at a temperature of $37^{\circ} \mathrm{C}$ in $99.9 \% \mathrm{D}_{2} \mathrm{O}$ based NMR buffer. Side-chain methyl order parameters $\left(\mathrm{S}^{2}\right.$ axis $)$ were determined by cross-correlated relaxation experiments $(69,70)$. Single- (SQ) and triple-quantum (TQ) ${ }^{1} \mathrm{H}-{ }^{13} \mathrm{C}$ experiments were collected at a series of delay times. Ratios of the peak intensities were fitted for eight values ranging 
between 2 and 24 ms using the following equation where $T$ is the relaxation delay time and $\delta$ a factor to account for coupling due to relaxation with external protons:

$$
\left|\frac{I_{a}}{I_{b}}\right|=\frac{3}{4} \frac{\eta \tan h\left(\sqrt{\eta^{2}+\delta^{2}} T\right)}{\sqrt{\eta^{2}+\delta^{2}-\delta \tan h\left(\sqrt{\eta^{2}+\delta^{2}} T\right)}}
$$

$\mathrm{S}^{2}$ axis values were determined using equation 5 , using their fitted $\eta$ values and the separately determined rotational correlation time adjusted for the change in viscosity in $100 \% \mathrm{D}_{2} \mathrm{O}\left(\tau_{c}\right)$ of 14.4 ns at $37^{\circ} \mathrm{C}$ :

$$
\eta \approx \frac{9}{10}\left(\frac{\mu_{0}}{4 \pi}\right)\left[P_{2}\left(\cos \Theta_{a x i s, H H}\right)\right]^{2} \frac{S_{a x i s}^{2} \gamma_{H}^{4} \hbar^{2} \tau_{c}}{r_{H H}^{6}}
$$

Where $\mu_{0}$ is the vacuum permittivity constant, $\gamma_{H}$ the gyromagnetic ratio of the proton spin, $r_{H H}$ is the distance between pairs of methyl protons $(1.813 \AA), \mathrm{S}^{2}$ axis is the generalized order parameter describing the amplitude of motion of the methyl 3-fold axis, $\Theta_{\text {axis, } \mathrm{HH}}$ is the angle between the methyl symmetry axis and a vector between a pair of methyl protons $\left(90^{\circ}\right)$, and $P_{2}(x)=1 / 2\left(3 x^{2}-1\right)$. Finally, the product of the methyl order parameter and the overall correlation time constant, $S^{2}{ }_{a x i s} \bullet \tau_{c}$, was determined.

Multiple quantum (MQ) methyl relaxation dispersion experiments (38) were recorded as a series of 2D data sets using constant time relaxation periods $(T)$ of $30 \mathrm{~ms}(800 \mathrm{MHz}(18.8 \mathrm{~T})$; $25^{\circ} \mathrm{C}, 37^{\circ} \mathrm{C}, 43^{\circ} \mathrm{C}$, and $50^{\circ} \mathrm{C}$ ) and CPMG (Carr-Purcell-Meiboom-Gill) frequencies ranging from

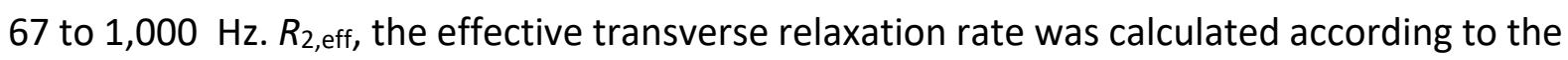
following equation:

$$
R_{2, \text { eff }}=-\left(\frac{1}{T}\right) \ln \left(\frac{I}{I_{0}}\right)
$$

where $I\left(\right.$ or $\left.I_{0}\right)$ are the intensities with and without the presence of a constant-time relaxation interval of duration $T$, during which a variable number of ${ }^{13} \mathrm{C} 180^{\circ}$ pulses are applied leading to $V_{\mathrm{CPMG}}=1 /(2 \delta)$, where $\delta$ is the time between successive pulses. Dispersion data were fitted numerically to a two-site exchange model using the program ChemEx (available at https://github.com/gbouvignies/chemex/releases).

\section{NMR magnetization exchange}

2D methyl magnetization exchange experiments were recorded to quantify the exchange between the locked (I) and open (o) state of the Met280- ${ }^{13} \mathrm{C} \varepsilon^{1} \mathrm{H} \varepsilon$ methyl group as outlined by Farrow et al. (30). The ${ }^{13} \mathrm{C}$-EXSY-SOFAST-HMQC experiments (31) were recorded with varying delays between 50 and $1,000 \mathrm{~ms}$ at $37^{\circ} \mathrm{C}$. To ensure equilibration of the initial magnetization 
a long relaxation delay (1s) was chosen. The signal intensities of the observed three peaks of $\mathrm{M} 280-{ }^{13} \mathrm{C} \varepsilon^{1} \mathrm{H} \varepsilon$, namely, the auto peak of the locked conformation, $I_{\|}$, and the auto peak of the open conformation $l_{\text {oo }}$ as well as the cross peak originating from the transition from the locked to the open state, $I_{\mathrm{o}}$ was determined. Due to signal overlap the second cross-peak, $I_{\mathrm{ol}}$, could not be determined from the spectra, therefore it was assumed in a first order approximation that it follows a similar build-up than $/$ o. All data points were simultaneously fitted to the following theoretical equations:

$$
\begin{gathered}
I_{l l}(T)=\frac{I_{l}(0)\left\{-\left(\lambda_{2}-x_{l}\right) e^{-\lambda_{1} T}+\left(\lambda_{1}-x_{l}\right) e^{-\lambda_{2} T}\right\}}{\lambda_{1}-\lambda_{2}} \\
I_{o o}(T)=\frac{I_{o}(0)\left\{-\left(\lambda_{2}-x_{o}\right) e^{-\lambda_{1} T}+\left(\lambda_{1}-x_{o}\right) e^{-\lambda_{2} T}\right\}}{\lambda_{1}-\lambda_{2}} \\
I_{l o}(T)=\frac{-I_{l}(0) k_{l o}\left(e^{-\lambda_{1} T}-e^{-\lambda_{2} T}\right)}{\lambda_{1}-\lambda_{2}} \\
I_{o l}(T)=\frac{-I_{o}(0) k_{o l}\left(e^{-\lambda_{1} T}-e^{-\lambda_{2} T}\right)}{\lambda_{1}-\lambda_{2}}
\end{gathered}
$$

Where $\lambda_{1,2}, x_{1}$, and $x_{0}$ are defined according to the following relationships:

$$
\begin{gathered}
\lambda_{1,2}=\frac{\left(x_{l}+x_{o}\right) \pm \sqrt{\left(x_{l}-x_{l o}\right)^{2}+4 k_{l o} k_{o l}}}{2} \\
x_{l}=R_{1 l}+k_{l o} \\
x_{o}=R_{1 o}+k_{o l}
\end{gathered}
$$

and the rate of transition from the locked to the open conformations, $k_{10}$, the rate of transition vice versa, $k_{\mathrm{ol}}$, the longitudinal relaxation rate in the locked conformation, $R_{11}$, as well as the longitudinal relaxation rate of the open conformation, $R_{10}$, were fitted. $l_{1}(0)$ and $I_{0}(0)$ denote the initial amounts of longitudinal carbon magnetization associated with the locked and the open conformations at the beginning of the mixing periods.

\section{NMR Diffusion}

Translational diffusion coefficients were measured by recording a series of $1 \mathrm{D}{ }^{13} \mathrm{C}$-edited spectra at different temperatures, using a pulse scheme $\left({ }^{13} \mathrm{C}\right.$-edited BPP-LED) that is similar to a ${ }^{15} \mathrm{~N}$-edited BPP-LED experiment with ${ }^{15} \mathrm{~N}$ and ${ }^{13} \mathrm{C}$ pulses interchanged (25). To compensate for the different J-coupling of the methyl-groups compared to the amide groups, a gradient duration $\mathrm{d}$ of $3.2 \mathrm{~ms}$ was used instead of $4.8 \mathrm{~ms}$ used in the ${ }^{15} \mathrm{~N}$-filtered version. In addition, a diffusion delay $T$ of $400 \mathrm{~ms}$ and a $\tau$ of $0.1 \mathrm{~ms}$ were used. The strength of the encoding/decoding was increased stepwise. Transverse gradients instead of z-gradients were employed to minimize convection effects (71). The resulting ${ }^{1} \mathrm{H}$ signal was integrated over the 
methyl ${ }^{1} \mathrm{H}$ frequency range to obtain intensities as a function of encoding/decoding gradient strength. To adjust for the temperature dependent changes in viscosity it was adjusted based on published values for $\mathrm{D}_{2} \mathrm{O}$-based buffers (72). In order to construct the calibration curve given in fig. S1J the following published translational diffusion coefficients, measured at $25^{\circ} \mathrm{C}$, were used: Immunoglobin binding domain of streptococcal protein G, GB1 (MW = $6.2 \mathrm{kDa}$ ) (73), lysozyme (MW = $14.1 \mathrm{kDa})$ and Interleukin-10 (MW = $37.2 \mathrm{kDa})(74)$, bacterial HsIV (MW $=230 \mathrm{kDa}), 1 / 2$ proteasome from $T$. acidophilum, $\alpha 7 \alpha 7(\mathrm{MW}=360 \mathrm{kDa})$, and the $\alpha 7$ single ring variant of the proteasome $(\mathrm{MW}=180 \mathrm{KDa})(75)$.

\section{Bio-Layer Interferometry (BLI)}

$\mathrm{BLI}$ experiments were performed on an Octet RED96 system (Fortébio) at $25^{\circ} \mathrm{C}$ as outlined in detail before (76). Briefly, the respective ligands were biotinylated using the biotinylation kit EZ-Link NHS-PEG4-Biotin (Thermo Fisher Scientific). The biotin label was resolved in $\mathrm{H}_{2} \mathrm{O}$ and directly added to the protein solution in a final molar ratio of $1: 1$ in $25 \mathrm{mM} \mathrm{MES}, \mathrm{pH} 6.0$ to ensure preferential labeling of the amino-terminal $\alpha$-amino group, followed by gentle mixing at room temperature for $45 \mathrm{~min}$. Unreacted biotin was removed with Zeba Spin Desalting Columns (7 MWCO, Thermo Fisher Scientific). Biotin-labeled proteins were immobilized on the streptavidin (SA) biosensors (Fortébio) and the biosensors were subsequently blocked with EZ-Link Biocytin (Thermo Fisher Scientific). Analytes were diluted and applied in a dosedependent manner to the biosensors immobilized with the biotinylated ligand. Bovine serum albumin (BSA) powder (Sigma-Aldrich) and Tween-20 were added to final concentrations of $0.1 \%$ and $0.05 \%$, respectively, to avoid non-specific interactions. Parallel experiments were performed for reference sensors with no analyte bound and the signals were subsequently subtracted during data analysis. The association period was set to $30 \mathrm{~s}$ and dissociation to 40 s. Data measurements and analysis were performed by using the Data acquisition 10.0 and the Data analysis HT 10.0 (Fortébio) software, respectively.

\section{Proteolytic cleavage assay}

The fluorescent reporter peptides Abz-KASPVSLGYNO2D and p23 (AbzGNWVSAAKFETYR ${ }^{N O 3}$ SKNTQDYGILQI), originally described in (43) and (23), respectively, were purchased from GenScript and prepared by dissolving in the lyophilized peptides directly in PBS (p23) or DMSO (Abz-KASPVSLGYNO2D). Cleavage assays were monitored using a FLUOstar Optima plate reader (BMG LABTECH), using an excitation wavelength of $320 \mathrm{~nm}$ and an emission wavelength of $440 \mathrm{~nm}$, respectively, in 96-well black clear bottom microplates 
(Corning ${ }^{\circledR}$ ). All experiments were prepared in PBS and contained either $0.2 \mu \mathrm{M}$ of the respective DegP enzyme (monomer concentration) and $7.5 \mu \mathrm{M}$ of p23 peptide or $10 \mu \mathrm{M}$ of the enzyme with $50 \mu \mathrm{M} \beta$-Casein (Sigma-Aldrich) and $100 \mu \mathrm{M}$ of the Abz-KASPVSLGYNO2D reporter peptide. All assays were performed as triplicates.

$\beta$-Casein degradation was, in addition, assessed via SDS-PAGE by incubating $1 \mu \mathrm{M}$ DegP with $5 \mu \mathrm{M}$ of $\beta$-Casein in PBS at $25^{\circ} \mathrm{C}$ or $37^{\circ} \mathrm{C}$. At specific time intervals of $0 \mathrm{~min}, 5 \mathrm{~min}, 10 \mathrm{~min}$, $20 \mathrm{~min}, 30 \mathrm{~min}, 60 \mathrm{~min}$, and $90 \mathrm{~min}$, respectively. Samples were taken out, mixed with sample loading dye, and subsequently heat-denatured at $95^{\circ} \mathrm{C}$ for 10 minutes, before loading them onto SDS-PAGE gels. The samples were subsequently analyzed by SDS-PAGE using 4-20\% Mini-Protean TGX-SDS-Gels (Bio-Rad). 


\section{References}

1. F. U. Hartl, A. Bracher, M. Hayer-Hartl, Molecular chaperones in protein folding and proteostasis. Nature. 475, 324-332 (2011).

2. D. Balchin, M. Hayer-Hartl, F. U. Hartl, In vivo aspects of protein folding and quality control. Science. 353 (2016), doi:10.1126/science.aac4354.

3. J. G. Sklar, T. Wu, D. Kahne, T. J. Silhavy, Defining the roles of the periplasmic chaperones SurA, Skp, and DegP in Escherichia coli. Genes Dev. 21, 2473-2484 (2007).

4. J. Thoma, B. M. Burmann, S. Hiller, D. J. Müller, Impact of holdase chaperones Skp and SurA on the folding of $\beta$-barrel outer-membrane proteins. Nat. Struct. Mol. Biol. 22, 795-802 (2015).

5. B. M. Burmann, C. Wang, S. Hiller, Conformation and dynamics of the periplasmic membrane-protein-chaperone complexes OmpX-Skp and tOmpA-Skp. Nat. Struct. Mol. Biol. 20, 1265-1272 (2013).

6. O. Subrini, J. M. Betton, Assemblies of DegP underlie its dual chaperone and protease function. FEMS Microbiol. Lett. 296, 143-148 (2009).

7. J. Skórko-Glonek, A. Wawrzynow, K. Krzewski, K. Kurpierz, B. Lipinska, A. Wawrzynw, Site-directed mutagenesis of the HtrA (DegP) serine-protease, whose proteolytic activity is indispensable for Escherichia coli survival at elevated-temperatures. Gene. 163, 47-52 (1995).

8. R. Misra, M. Castillokeller, M. Deng, Overexpression of protease-deficient DegP(S210A) rescues the lethal phenotype of Escherichia coli OmpF assembly mutants in a $\operatorname{deg} P$ background. J. Bacteriol. 182, 4882-4888 (2000).

9. M. CastilloKeller, R. Misra, Protease-deficient DegP suppresses lethal effects of a mutant OmpC protein by its capture. J. Bacteriol. 185, 148-154 (2003). 
10. M. B. Kennedy, Origin of PDZ (DHR, GLGF) domains. Trends Biochem. Sci. 20, 350 (1995).

11. T. Clausen, M. Kaiser, R. Huber, M. Ehrmann, HTRA proteases: regulated proteolysis in protein quality control. Nat. Rev. Mol. Cell Biol. 12, 152-162 (2011).

12. T. Krojer, J. Sawa, E. Schäfer, H. R. Saibil, M. Ehrmann, T. Clausen, Structural basis for the regulated protease and chaperone function of DegP. Nature. 453, 885-890 (2008).

13. T. Krojer, M. Garrido-Franco, R. Huber, M. Ehrmann, T. Clausen, Crystal structure of $\operatorname{DegP}(\mathrm{HtrA})$ reveals a new protease-chaperone machine. Nature. 416, 455-459 (2002).

14. S. Kim, R. A. Grant, R. T. Sauer, Covalent linkage of distinct substrate degrons controls assembly and disassembly of DegP proteolytic cages. Cell. 145, 67-78 (2011).

15. N. J. Thompson, M. Merdanovic, M. Ehrmann, E. Van Duijn, A. J. R. Heck, Substrate occupancy at the onset of oligomeric transitions of DegP. Structure. 22, 281-290 (2014).

16. S. Li, R. Wang, D. Li, J. Ma, H. Li, X. He, Z. Chang, Y. Weng, Thermal-triggerd proteinquake leads to disassembly of DegP hexamer as an imperative activation step. Sci. Rep. 4, 4834 (2015).

17. J. Jiang, X. Zhang, Y. Chen, Y. Wu, Z. H. Zhou, Z. Chang, S.-F. Sui, Activation of DegP chaperone-protease via formation of large cage-like oligomers upon binding to substrate proteins. Proc. Natl. Acad. Sci. U. S. A. 105, 11939-11944 (2008).

18. D. Figaj, A. Gieldon, A. Polit, A. Sobiecka-Szkatula, T. Koper, M. Denkiewicz, B. Banecki, A. Lesner, J. Ciarkowski, B. Lipinska, J. Skorko-Glonek, The LA loop as an important regulatory element of the HtrA (DegP) protease from Escherichia coli structural and functional studies. J. Biol. Chem. 289, 15880-15893 (2014).

19. T. Krojer, J. Sawa, R. Huber, T. Clausen, HtrA proteases have a conserved activation 
mechanism that can be triggered by distinct molecular cues. Nat. Struct. Mol. Biol. 17, 844-852 (2010).

20. S. Kim, I. Song, G. Eom, S. Kim, A small periplasmic protein with a hydrophobic Cterminal residue enhances DegP proteolysis as a suicide activator. J. Bacteriol. 200, 112 (2018).

21. Y. Toyama, R. W. Harkness, T. Y. T. Lee, J. T. Maynes, L. E. Kay, Oligomeric assembly regulating mitochondrial HtrA2 function as examined by methyl-TROSY NMR. Proc. Natl. Acad. Sci. 118, e2025022118 (2021).

22. H. Malet, F. Canellas, J. Sawa, J. Yan, K. Thalassinos, M. Ehrmann, T. Clausen, H. R. Saibil, Newly folded substrates inside the molecular cage of the HtrA chaperone DegQ. Nat. Struct. Mol. Biol. 19, 152-157 (2012).

23. S. Kim, R. T. Sauer, Cage assembly of DegP protease is not required for substratedependent regulation of proteolytic activity or high-temperature cell survival. Proc. Natl. Acad. Sci. U. S. A. 109, 7263-7268 (2012).

24. D. Lee, C. Hilty, G. Wider, K. Wüthrich, Effective rotational correlation times of proteins from NMR relaxation interference. J. Magn. Reson. 178, 72-76 (2006).

25. J. J. Chou, J. L. Baber, A. Bax, Characterization of phospholipid mixed micelles by translational diffusion. J. Biomol. NMR. 29, 299-308 (2004).

26. K. Wüthrich, NMR assignments as a basis for structural characterization of denatured states of globular proteins. Curr. Opin. Struct. Biol. 4, 93-99 (1994).

27. H. M. McConnell, Reaction rates by nuclear magnetic resonance. J. Chem. Phys. 28, 430-431 (1958).

28. C. C. Valley, A. Cembran, J. D. Perlmutter, A. K. Lewis, N. P. Labello, J. Gao, J. N. Sachs, The methionine-aromatic motif plays a unique role in stabilizing protein structure. $J$. 
Biol. Chem. 287, 34979-34991 (2012).

29. M. J. Plevin, D. L. Bryce, J. Boisbouvier, Direct detection of $\mathrm{CH} / \pi$ interactions in proteins. Nat. Chem. 2, 466-471 (2010).

30. N. A. Farrow, O. Zhang, J. D. Forman-Kay, L. E. Kay, A heteronuclear correlation experiment for simultaneous determination of ${ }^{15} \mathrm{~N}$ longitudinal decay and chemical exchange rates of systems in slow equilibrium. J. Biomol. NMR. 4, 727-734 (1994).

31. G. Mas, J. Y. Guan, E. Crublet, E. C. Debled, C. Moriscot, P. Gans, G. Schoehn, P. Macek, P. Schanda, J. Boisbouvier, Structural investigation of a chaperonin in action reveals how nucleotide binding regulates the functional cycle. Sci. Adv. 4, 1-9 (2018).

32. A. G. Palmer, C. D. Kroenke, J. P. Loria, Nuclear magnetic resonance methods for quantifying microsecond-to-millisecond motions in biological macromolecules. Methods Enzymol. 339, 204-238 (2001).

33. N.-A. Lakomek, J. Ying, A. Bax, Measurement of ${ }^{15} \mathrm{~N}$ relaxation rates in perdeuterated proteins by TROSY-based methods. J. Biomol. NMR. 53, 209-221 (2012).

34. G. Lipari, A. Szabo, Model-Free approach to the interpretation of nuclear magnetic resonance relaxation in macromolecules. 2. Analysis of experimental results. J. Am. Chem. Soc. 104, 4559-4570 (1982).

35. L. Morgado, B. M. Burmann, T. Sharpe, A. Mazur, S. Hiller, The dynamic dimer structure of the chaperone Trigger Factor. Nat. Commun. 8, 1992 (2017).

36. L. He, T. Sharpe, A. Mazur, S. Hiller, A molecular mechanism of chaperone-client recognition. Sci. Adv. 2, 1-12 (2016).

37. R. G. Parra, N. P. Schafer, L. G. Radusky, M. Y. Tsai, A. B. Guzovsky, P. G. Wolynes, D. U. Ferreiro, Protein Frustratometer 2: a tool to localize energetic frustration in protein molecules, now with electrostatics. Nucleic Acids Res. 44, W356-W360 (2016). 
38. D. M. Korzhnev, K. Kloiber, V. Kanelis, V. Tugarinov, L. E. Kay, Probing slow dynamics in high molecular weight proteins by methyl-TROSY NMR spectroscopy: Application to a 723-residue enzyme. J. Am. Chem. Soc. 126, 3964-3973 (2004).

39. A. K. Lewis, K. M. Dunleavy, T. L. Senkow, C. Her, B. T. Horn, M. A. Jersett, R. Mahling, M. R. McCarthy, G. T. Perell, C. C. Valley, C. B. Karim, J. Gao, W. C. K. Pomerantz, D. D. Thomas, A. Cembran, A. Hinderliter, J. N. Sachs, Oxidation increases the strength of the methionine-aromatic interaction. Nat. Chem. Biol. 12, 860-866 (2016).

40. A. Fujii, H. Hayashi, J. W. Park, T. Kazama, N. Mikami, S. Tsuzuki, Experimental and theoretical determination of the accurate $\mathrm{CH} / \pi$ interaction energies in benzene-alkane clusters: Correlation between interaction energy and polarizability. Phys. Chem. Chem. Phys. 13, 14131-14141 (2011).

41. R. Sprangers, A. Gribun, P. M. Hwang, W. A. Houry, L. E. Kay, Quantitative NMR spectroscopy of supramolecular complexes: Dynamic side pores in ClpP are important for product release. Proc. Natl. Acad. Sci. U. S. A. 102, 16678-16683 (2005).

42. S. Vahidi, Z. A. Ripstein, J. B. Juravsky, E. Rennella, A. L. Goldberg, A. K. Mittermaier, J. L. Rubinstein, L. E. Kay, An allosteric switch regulates Mycobacterium tuberculosis ClpP1P2 protease function as established by cryo-EM and methyl-TROSY NMR. Proc. Natl. Acad. Sci. U. S. A. 117, 5895-5906 (2020).

43. M. E. Lee, T. A. Baker, R. T. Sauer, Control of substrate gating and translocation into ClpP by channel residues and ClpX binding. J. Mol. Biol. 399, 707-718 (2010).

44. L. Truebestein, A. Tennstaedt, T. Mönig, T. Krojer, F. Canellas, M. Kaiser, T. Clausen, M. Ehrmann, Substrate-induced remodeling of the active site regulates human HTRA1 activity. Nat. Struct. Mol. Biol. 18, 386-388 (2011).

45. R. V. Mauldin, R. T. Sauer, Allosteric regulation of DegS protease subunits through a 
shared energy landscape. Nat. Chem. Biol. 9, 90-96 (2013).

46. C. Wilken, K. Kitzing, R. Kurzbauer, M. Ehrmann, T. Clausen, Crystal structure of the DegS stress sensor. Cell. 117, 483-494 (2004).

47. J. Sawa, H. Malet, T. Krojer, F. Canellas, M. Ehrmann, T. Clausen, Molecular adaptation of the DegQ protease to exert protein quality control in the bacterial cell envelope. J. Biol. Chem. 286, 30680-30690 (2011).

48. B. J. Hillier, K. S. Christopherson, K. E. Prehoda, D. S. Bredt, W. A. Lim, Unexpected modes of PDZ domain scaffolding revealed by structure of nNOS-syntrophin complex. Science. 284, 812-815 (1999).

49. S. Srivastava, P. Osten, F. S. Vilim, L. Khatri, G. Inman, B. States, C. Daly, S. DeSouza, R. Abagyan, J. G. Valtschanoff, R. J. Weinberg, E. B. Ziff, Novel anchorage of GluR2/3 to the postsynaptic density by the AMPA receptor-binding protein ABP. Neuron. 21, 581591 (1998).

50. R. Schlecht, S. R. Scholz, H. Dahmen, A. Wegener, C. Sirrenberg, D. Musil, J. Bomke, H. M. Eggenweiler, M. P. Mayer, B. Bukau, Functional analysis of Hsp70 inhibitors. PLoS One. 8, 1-12 (2013).

51. J. Mikolajczyk, M. Drag, M. Békés, J. T. Cao, Z. Ronai, G. S. Salvesen, Small Ubiquitinrelated Modifier (SUMO)-specific proteases: Profiling the specificities and activities of human SENPs. J. Biol. Chem. 282, 26217-26224 (2007).

52. J. Sambrook, E. F. Fritsch, T. Maniatis, Molecular cloning: a laboratory manual. Mol. cloning a Lab. manual. (1989).

53. K. Pervushin, R. Riek, G. Wider, K. Wüthrich, Attenuated $T_{2}$ relaxation by mutual cancellation of dipole-dipole coupling and chemical shift anisotropy indicates an avenue to NMR structures of very large biological macromolecules in solution. Proc. 
Natl. Acad. Sci. U. S. A. 94, 12366-12371 (1997).

54. M. Salzmann, K. Pervushin, G. Wider, H. Senn, K. Wüthrich, TROSY in triple-resonance experiments: New perspectives for sequential NMR assignment of large proteins. Proc. Natl. Acad. Sci. U. S. A. 95, 13585-13590 (1998).

55. M. Sattler, J. Schleucher, C. Griesinger, Heteronuclear multidimensional NMR experiments for the structure determination of proteins in solution employing pulsed field gradients. Prog. Nucl. Magn. Reson. Spectrosc. 34, 93-158 (1999).

56. P. Rossi, Y. Xia, N. Khanra, G. Veglia, C. G. Kalodimos, ${ }^{15} \mathrm{~N}$ and ${ }^{13} \mathrm{C}-$ SOFAST-HMQC editing enhances 3D-NOESY sensitivity in highly deuterated, selectively $\left[{ }^{1} \mathrm{H},{ }^{13} \mathrm{C}\right]$-labeled proteins. J. Biomol. NMR. 66, 259-271 (2016).

57. G. Wider, L. Dreier, Measuring protein concentrations by NMR spectroscopy. J. Am. Chem. Soc. 128, 2571-2576 (2006).

58. F. Delaglio, S. Grzesiek, G. W. Vuister, G. Zhu, J. Pfeifer, A. Bax, NMRPipe: A multidimensional spectral processing system based on UNIX pipes. J. Biomol. NMR. 6, 277-293 (1995).

59. V. Jaravine, I. Ibraghimov, V. Y. Orekhov, Removal of a time barrier for high-resolution multidimensional NMR spectroscopy. Nat. Methods. 3, 605-607 (2006).

60. R. L. J. Keller, The Computer Aided Resonance Assignment Tutorial. Cantina Verlag, Goldau (2004).

61. J. T. Nielsen, F. A. A. Mulder, Potenci: Prediction of temperature, neighbor and pHcorrected chemical shifts for intrinsically disordered proteins. J. Biomol. NMR. 70, 141165 (2018).

62. G. Zhu, Y. Xia, L. K. Nicholson, K. H. Sze, Protein dynamics measurements by TROSYbased NMR experiments. J. Magn. Reson. 143, 423-426 (2000). 
63. T. Szyperski, P. Lunginbühl, G. Otting, P. Güntert K. Wüthrich, Protein dynamics studied by rotating frame ${ }^{15} \mathrm{~N}$ spin relaxation-times. J. Biomol. NMR. 3, 151-164 (1993).

64. T. A. Walton, C. M. Sandoval, C. A. Fowler, A. Pardi, M. C. Sousa, The cavity-chaperone Skp protects its substrate from aggregation but allows independent folding of substrate domains. Proc. Natl. Acad. Sci. U. S. A. 106, 1772-1777 (2009).

65. P. Dosset, J. C. Hus, M. Blackledge, D. Marion, Efficient analysis of macromolecular rotational diffusion from heteronuclear relaxation data. J. Biomol. NMR. 16, 23-28 (2000).

66. M. W. Maciejewski, A. D. Schuyler, M. R. Gryk, I. I. Moraru, P. R. Romero, E. L. Ulrich, H. R. Eghbalnia, M. Livny, F. Delaglio, J. C. Hoch, NMRbox: A Resource for biomolecular NMR computation. Biophys. J. 112, 1529-1534 (2017).

67. P. Eastman, M. S. Friedrichs, J. D. Chodera, R. J. Radmer, C. M. Bruns, J. P. Ku, K. A. Beauchamp, T. J. Lane, L. P. Wang, D. Shukla, T. Tye, M. Houston, T. Stich, C. Klein, M. R. Shirts, V.S. Pande, OpenMM 4: A reusable, extensible, hardware independent library for high performance molecular simulation. J. Chem. Theory Comput. 9, 461-469 (2013).

68. J. García De La Torre, M. L. Huertas, B. Carrasco, Calculation of hydrodynamic properties of globular proteins from their atomic-level structure. Biophys. J. 78, 719730 (2000).

69. H. Sun, L. E. Kay, V. Tugarinov, An optimized relaxation-based coherence transfer NMR experiment for the measurement of side-chain order in methyl-protonated, highly deuterated proteins. J. Phys. Chem. B. 115, 14878-14884 (2011).

70. K. Weinhäupl, C. Lindau, A. Hessel, Y. Wang, C. Schütze, T. Jores, L. Melchionda, B. Schönfisch, H. Kalbacher, B. Bersch, D. Rapaport, M. Brennich, K. Lindorff-Larsen, N. 
Wiedemann, P. Schanda, Structural basis of membrane protein chaperoning through the mitochondrial intermembrane space. Cell. 175, 1365-1379 (2018).

71. P. Kiraly, I. Swan, M. Nilsson, G. A. Morris, Improving accuracy in DOSY and diffusion measurements using triaxial field gradients. J. Magn. Reson. 270, 24-30 (2016).

72 C.H. Cho, J. Urquidi, S. Singh, G. Wilse Robinson, Thermal offset viscosities of liquid $\mathrm{H}_{2} \mathrm{O}$, $\mathrm{D}_{2} \mathrm{O}$ and $\mathrm{T}_{2} \mathrm{O}$. J. Phys. Chem. B, 103, 1991-1994 (1999)

73. C. Arquint, A. M. Gabryjonczyk, S. Imseng, R. Böhm, E. Sauer, S. Hiller, E. A. Nigg, T. Maier, STIL binding to Polo-box 3 of PLK4 regulates centriole duplication. Elife. 4, 1-22 (2015).

74. A. S. Altieri, R. A. Byrd, D. P. Hinton, Association of biomolecular systems via pulsed field gradient NMR self-diffusion measurements. J. Am. Chem. Soc. 117, 7566-7567 (1995).

75. L. Shi, L. E. Kay, Tracing an allosteric pathway regulating the activity of the HsIV protease. Proc. Natl. Acad. Sci. U. S. A. 111, 2140-2145 (2014).

76. B. M. Burmann, J. A. Gerez, I. Matečko-Burmann, S. Campioni, P. Kumari, D. Ghosh, A. Mazur, E. E. Aspholm, D. Šulskis, M. Wawrzyniuk, T. Bock, A. Schmidt, S. G. D. Rüdiger, R. Riek, S. Hiller, Regulation of $\alpha$-synuclein by chaperones in mammalian cells. Nature. 577, 127-132 (2020).

77. G. Lipari, A. Szabo, Model-Free Approach to the interpretation of nuclear magnetic resonance relaxation in macromolecules. 1. Theory and range of validity. J. Am. Chem. Soc. 104, 4546-4559 (1982).

78. M. Landau, I. Mayrose, Y. Rosenberg, F. Glaser, E. Martz, T. Pupko, N. Ben-Tal, ConSurf 2005: The projection of evolutionary conservation scores of residues on protein structures. Nucleic Acids Res. 33, 299-302 (2005). 
79. H. Ashkenazy, E. Erez, E. Martz, T. Pupko, N. Ben-Tal, ConSurf 2010: Calculating evolutionary conservation in sequence and structure of proteins and nucleic acids. Nucleic Acids Res. 38, 529-533 (2010).

\section{Acknowledgments}

We thank G. Mas (Basel), P. Schanda (Grenoble), and R. Sprangers (Regensburg) for providing NMR pulse sequences. The Swedish NMR Centre of the University of Gothenburg is acknowledged for spectrometer time. B.M.B. gratefully acknowledges funding from the Wallenberg Centre for Molecular and Translational Medicine, University of Gothenburg, Sweden.

\section{Funding:}

Swedish Research Council (Starting Grant 2016-04721) to B.M.B

Swedish Research Council (Consolidator Grant 2020-00466) to B.M.B

Wallenberg Academy Fellowship (2016.0163) to B.M.B

EMBO Long-Term Fellowship (ALTF 413-2018) to J.T.

\section{Author contributions:}

B.M.B. conceived the study and designed the experiments together with D.Š.. D. ̌́. performed all experimental work. D.Š., J.T., and B.M.B. analyzed and discussed the data. D.Š., J.T., and B.M.B. wrote jointly the paper.

\section{Competing interests:}

The authors declare that they have no competing interests.

\section{Data and materials availability:}

All data needed to evaluate the conclusions in the paper are present in the paper and/or Supplementary Materials. The sequence-specific NMR resonance assignments for the 
bioRxiv preprint doi: https://doi.org/10.1101/2020.07.14.202507; this version posted May 17, 2021. The copyright holder for this preprint (which was not certified by peer review) is the author/funder. All rights reserved. No reuse allowed without permission.

PDZ1-PDZ2 $\left(25^{\circ} \mathrm{C}\right.$ and $50^{\circ} \mathrm{C}$, respectively), PDZ1, and $\mathrm{PDZ} 2$-constructs were deposited in the BMRB under accession codes 50450-50453. 


\section{Figures and Tables}
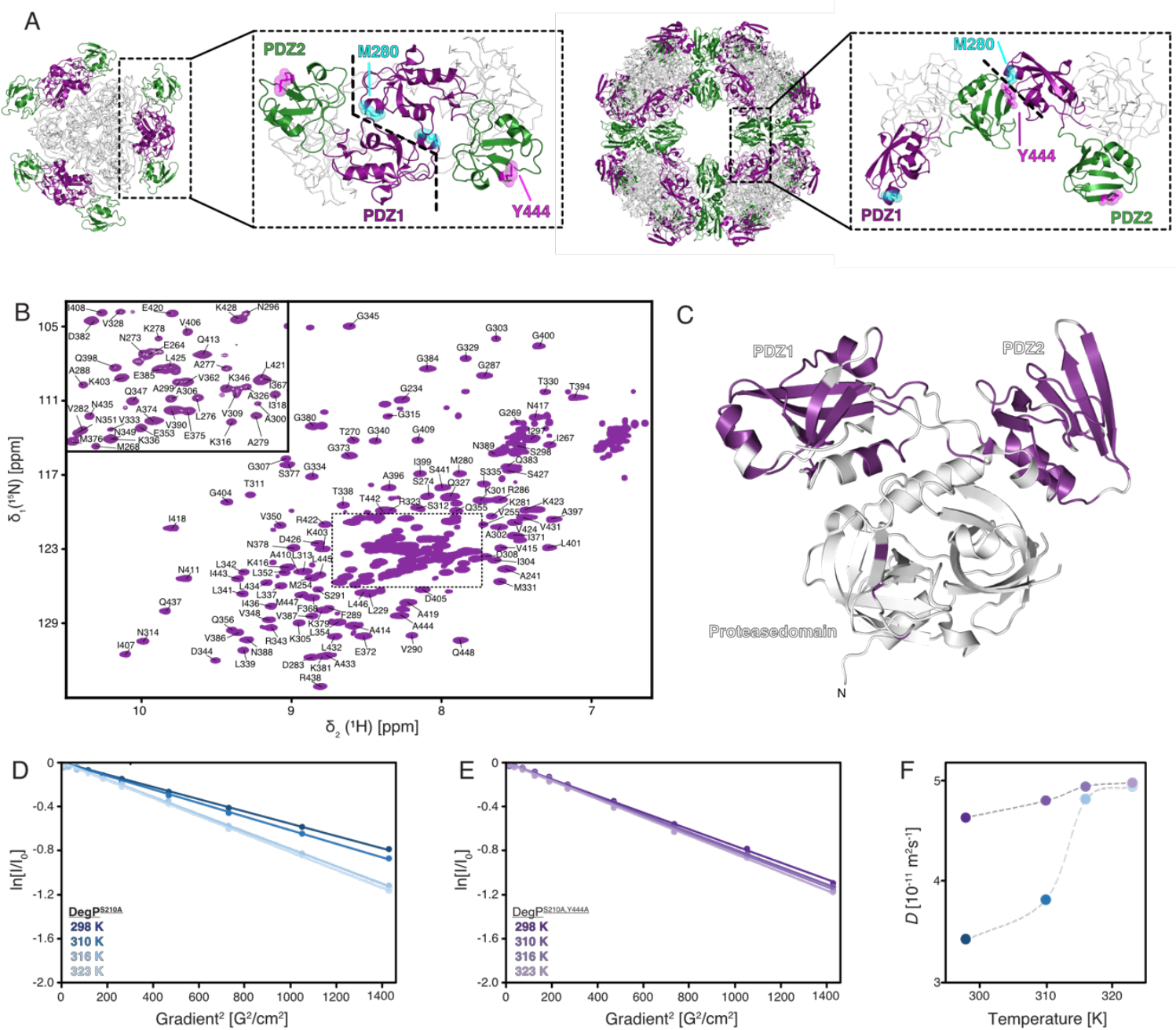

Fig. 1: Full-length DegP $\mathrm{P}^{\mathrm{S210A}}$ in solution. (A) Comparison of the PDZ domains orientation between different monomers in the crystal structures of the hexamer (PDB-ID: 1KY9) and 24-meric cage assembly (PDB-ID: 3OU0). Whereas in the inactive hexameric state this interaction is proposed to be mediated mainly via a direct interaction between two PDZ1s, the PDZ2s are found to be non-constraint at the hexamer edges, however within the proteolytically active 24-mer the interaction between PDZ1 and PDZ2 of different molecules is achieved by a Y444 and M280 interaction indicating stabilization by a sulfur- $\pi$-aromatic or methyl- $\pi$-aromatic motif. (B) $2 \mathrm{D}\left[{ }^{15} \mathrm{~N},{ }^{1} \mathrm{H}\right]-\mathrm{NMR}$ spectrum of $\left[U-{ }^{2} \mathrm{H},{ }^{15} \mathrm{~N},{ }^{13} \mathrm{C}\right]$ DegPS210A,Y444A. The sequence-specific resonance assignment obtained from 3D TROSY-type tripleresonance experiments is indicated. $(\mathbf{C})$ Cartoon representation of a DegP $\mathrm{P}^{\mathrm{S} 210 \mathrm{~A}}$ monomer from the crystal structure of the hexameric assembly of DegP ${ }^{\text {S210A }}$ (PDB-ID: 1KY9) with the sequence-specific resonance assignment indicated in purple. (D, E) Measurement of the molecular diffusion constant with a ${ }^{13} \mathrm{C}$ methyl-filtered diffusion experiment for $\operatorname{DegP}^{\mathrm{S} 210 \mathrm{~A}}(\mathbf{D})$ and $\operatorname{Deg} \mathrm{P}^{\mathrm{S} 210 \mathrm{~A}, \mathrm{Y} 444 \mathrm{~A}}(\mathbf{E})$. The logarithm of the signal intensity is plotted against the squared gradient strength of the applied pulsed-field gradients. The two $\left[U_{-}^{2} \mathrm{H}\right.$, Ile- $\left.\delta_{1-}{ }^{13} \mathrm{CH}_{3}\right]-$ DegP samples were measured at different temperatures as indicated. Solid lines are a linear fit to the data. (F) Obtained molecular diffusion constants plotted against the temperature. The broken lines serve as a guide to the eyes only. 
A

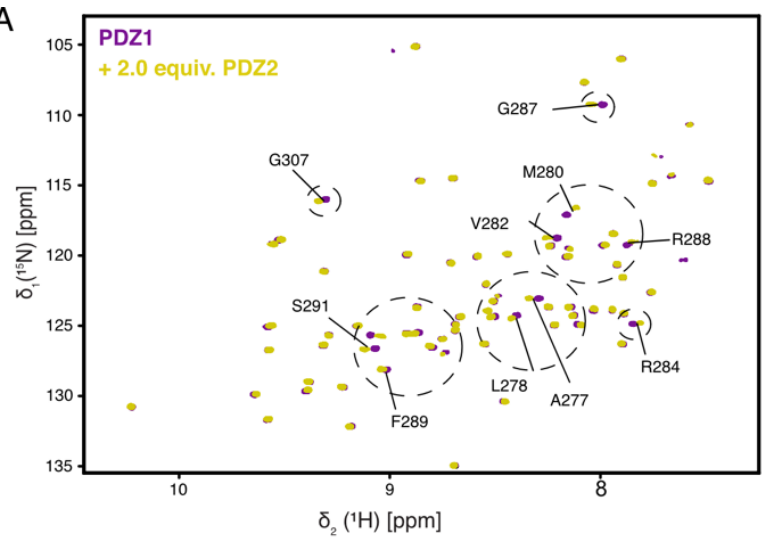

C

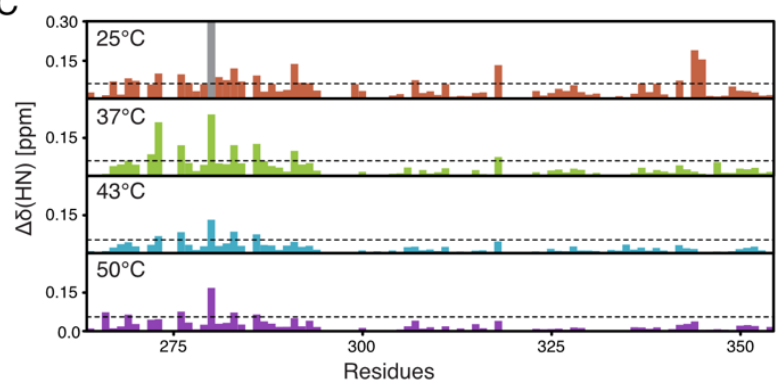

$\mathrm{E}$

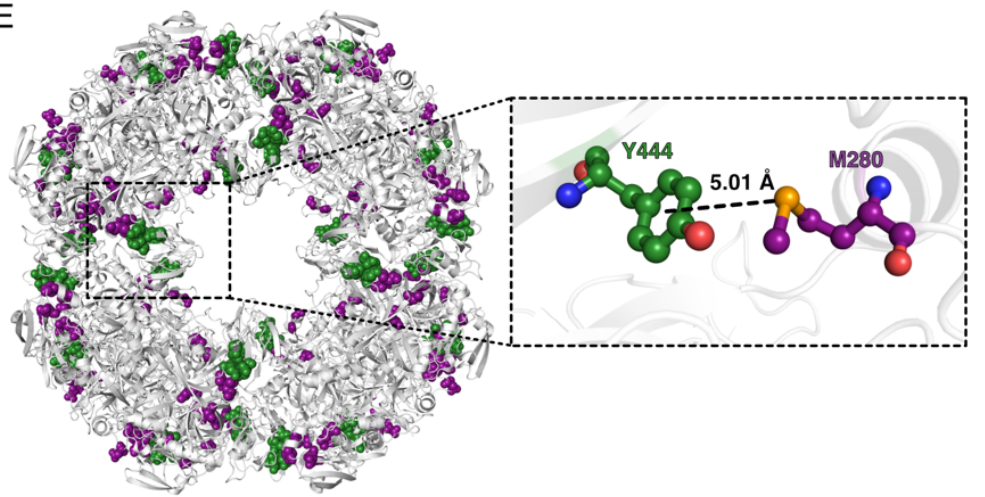

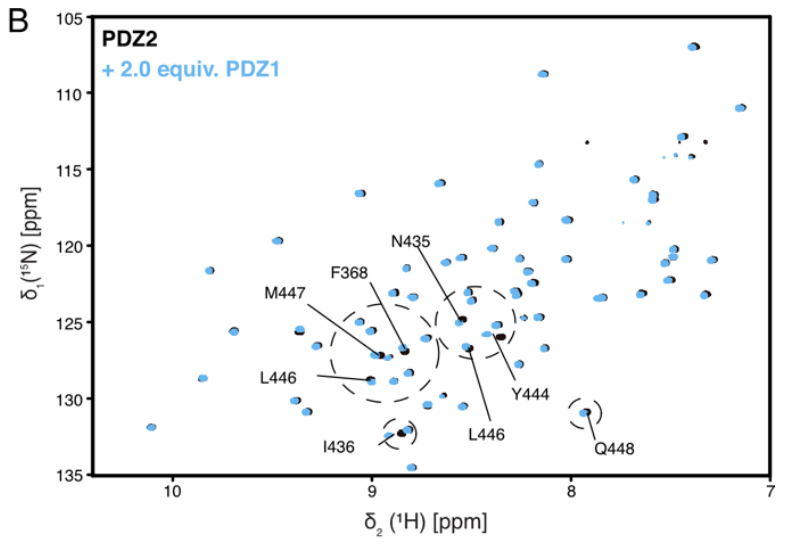

D

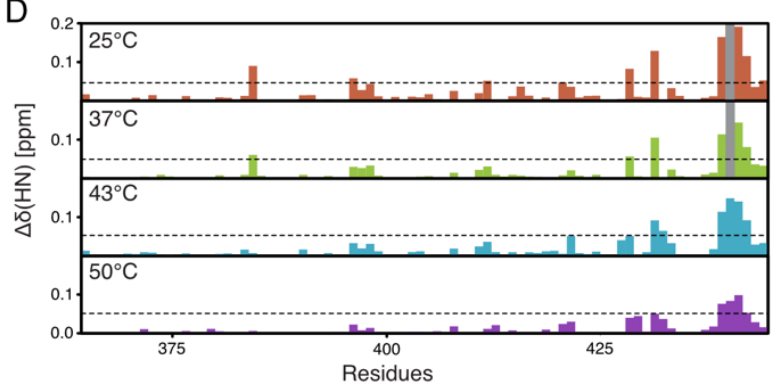

$\mathrm{F}$

Fig. 2: The individual PDZ domains show transient interactions reminiscent of the higher oligomeric DegP-complexes. (A, B) 2D $\left[{ }^{15} \mathrm{~N},{ }^{1} \mathrm{H}\right]-\mathrm{NMR}$ spectra of $\left[U_{-}{ }^{15} \mathrm{~N}\right]-\mathrm{PDZ} 1$ (A, purple) and $[U$ $\left.{ }^{15} \mathrm{~N}\right]-\mathrm{PDZ} 2$ (B, black) as well as after the addition of two molar equivalents of the respective other domain. Titrations were measured at $50^{\circ} \mathrm{C}$. (C, D) Detected chemical shift perturbations at four temperatures ranging from $25^{\circ} \mathrm{C}-50^{\circ} \mathrm{C}$ as indicated by the PDZ1 domain $(\mathbf{C})$ and the PDZ2 domain (D). Severely affected residues experiencing line-broadening are indicated as grey bars in the panels. The dotted lines represent a significance level of $0.05 \mathrm{ppm}$ of the CSPs. (E) Perturbated resonances mapped on the crystal structure of DegP ${ }^{\mathrm{S} 210 \mathrm{~A}}$ 24-mer (PDB-ID: 3OU0). Mainly affected residues, CSPs twice the S.D. on PDZ1, are highlighted in purple (G266, G269, K278, M280, D283, and R286), whereas residues in PDZ2 are highlighted in green (A433, N435, I443, Y444, and L445). The enlargement shows the central M280-Y444 interaction. (F), Kinetic analysis by biolayer interferometry (BLI) of the PDZ1PDZ2 interaction. PDZ1 binding to the biotinylated-PDZ2 domain was probed at $25^{\circ} \mathrm{C}$. Analyte concentrations are indicated in the figure. Non-linear least-square fits to the experimental data are indicated by black lines. 

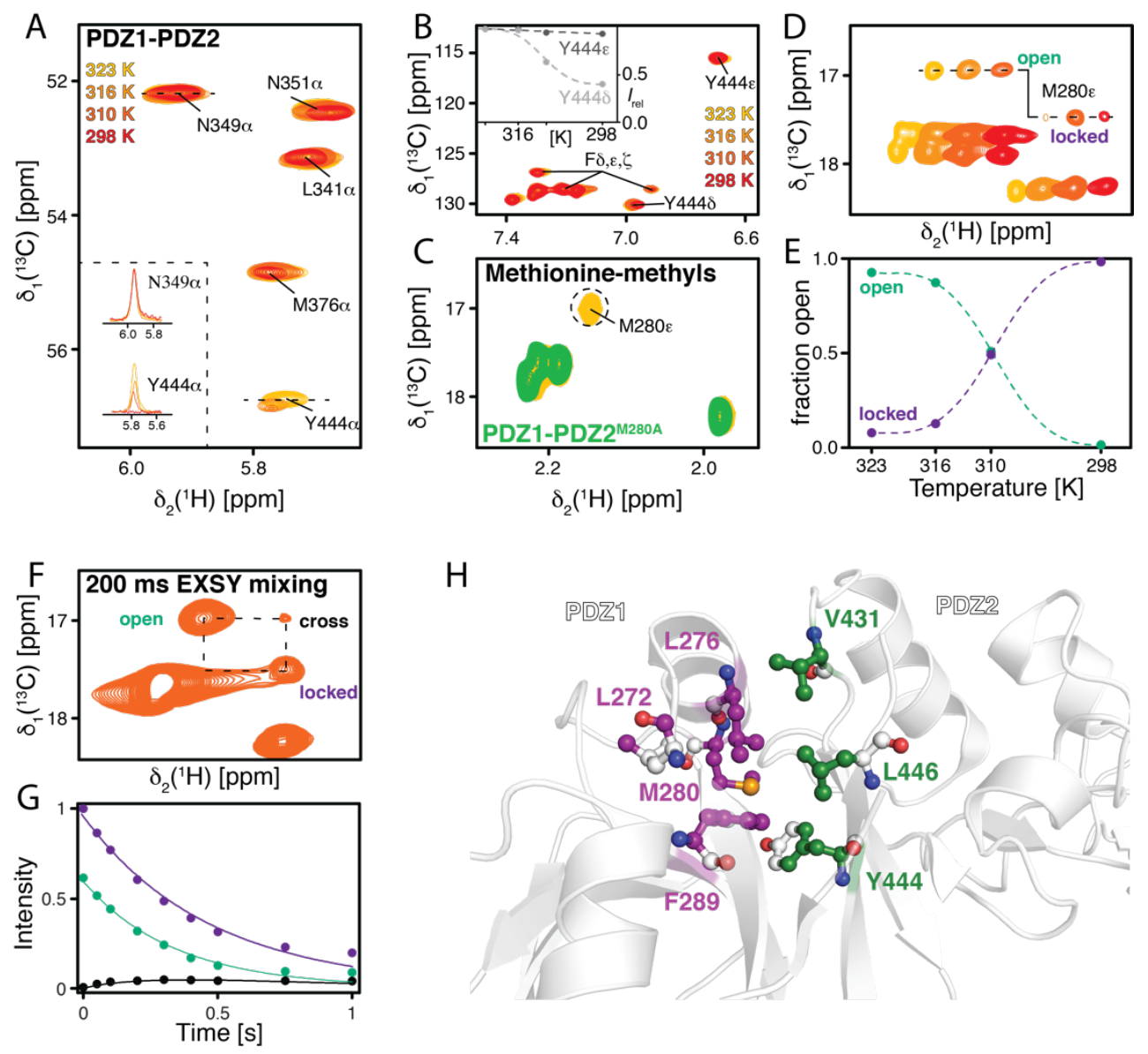

$\mathrm{H}$

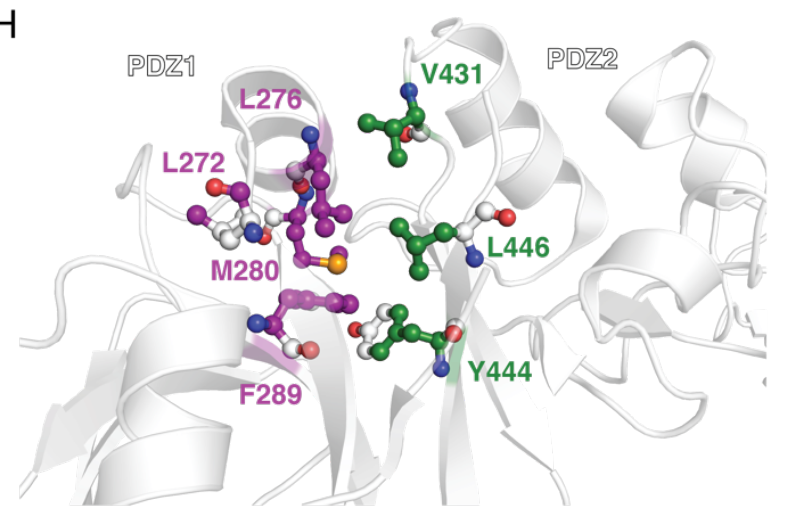

Fig. 3: M280 is locking the PDZ1-PDZ2 interaction within DegP via Y444. (A) Focus on the Ca resonance region around $\mathrm{Y} 444$ of a $2 \mathrm{D}\left[{ }^{13} \mathrm{C},{ }^{1} \mathrm{H}\right]$-NMR spectrum of $\left[U-{ }^{13} \mathrm{C},{ }^{15} \mathrm{~N}\right]-\mathrm{PDZ} 1-\mathrm{PDZ} 2$ at $25^{\circ} \mathrm{C}-$ $50^{\circ} \mathrm{C}$ as indicated. The inset shows the respective $\delta_{2}\left[{ }^{1} \mathrm{H}\right]-1 \mathrm{D}$ cross-sections through the $\mathrm{N} 349 \alpha$ and Y444 $\alpha$ resonances. (B) Methionine methyl region of a $2 \mathrm{D}\left[{ }^{13} \mathrm{C},{ }^{1} \mathrm{H}\right]-\mathrm{NMR}$ spectrum of $\left[U-{ }^{13} \mathrm{C},{ }^{15} \mathrm{~N}\right]-$ $\mathrm{PDZ1}-\mathrm{PDZ} 2$ at $25^{\circ} \mathrm{C}-50^{\circ} \mathrm{C}$ as indicated. Inset shows the signal intensities of the aromatic $\mathrm{Y} 444 \varepsilon$ and $\mathrm{Y} 444 \delta$ resonances in the dependence of the temperature. (C) Overlay of $\left[U-{ }^{13} \mathrm{C},{ }^{15} \mathrm{~N}\right]-\mathrm{PDZ} 1-\mathrm{PDZ} 2^{\mathrm{M} 280 \mathrm{~A}}$ (blue) and PDZ1-PDZ2 (yellow) at $50^{\circ} \mathrm{C}$ used to assign the M280\& resonance. (D) Methionine- $\varepsilon$-methyl region of a $2 \mathrm{D}\left[{ }^{13} \mathrm{C},{ }^{1} \mathrm{H}\right]-\mathrm{NMR}$ spectrum of $\quad\left[U{ }^{13} \mathrm{C},{ }^{15} \mathrm{~N}\right]-\mathrm{PDZ} 1-\mathrm{PDZ} 2$ at $25^{\circ} \mathrm{C}-50^{\circ} \mathrm{C}$ as indicated. Spectra were manually shifted along the ${ }^{1} \mathrm{H}$ dimension to illustrate the transition between open and locked states. (E) Analysis of the open and locked state. Lines are guide to the eyes only. (F) Magnetization exchange spectroscopy showing that the open state (o) and locked state (1) of M280 are in a dynamic equilibrium at $37^{\circ} \mathrm{C}$ as indicated. (G) The exchange rate $\left(k_{\mathrm{ex}}\right)$ is determined from the builtup of the exchange peaks. (H) Observed NMR line-broadening indicates a hydrophobic patch stabilizing the PDZ1-PDZ2 interaction. Atoms involved on PDZ2 side are highlighted in green, whereas residues on PDZ1 side are highlighted in purple. 

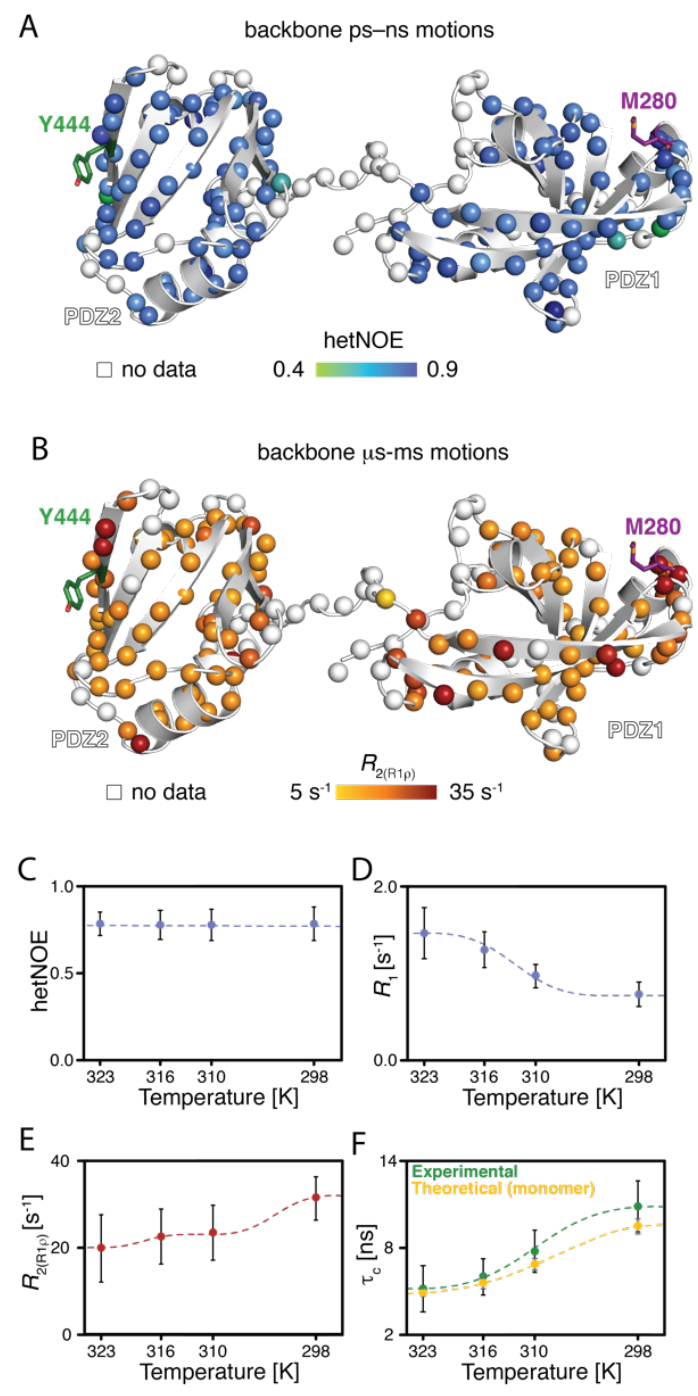

Fig. 4: Backbone dynamics of the PDZ1-PDZ2 construct. (A) Local backbone dynamics on the psns timescale probed by hetNOE measurements at $50^{\circ} \mathrm{C}$. The amide moieties of the PDZ1-PDZ2 construct are shown as spheres and the hetNOE values are indicated by the green to blue gradient. (B) Obtained transversal relaxation $\left(R_{2(\mathrm{R} 1 \rho)}\right)$ rates reporting on microsecond motions at $50^{\circ} \mathrm{C}$, are plotted on the amide moieties and are indicated by the yellow to red gradient. $(\mathbf{C}-\mathbf{E})$ Temperature dependence of the average hetNOE (C) $R_{1}$ (D) and $R_{2}$-rates (E) over the indicated temperature range. Error bars are the S.D. (D) Temperature-dependence of the measured rotational correlation time, $\tau_{\mathrm{c}}$, over the indicated temperature range (green). Theoretical values were calculated for the DegP crystal structure (PDB-ID: 3OU0) with HYDRONMR (68) for a PDZ1-PDZ2 monomer. 
A

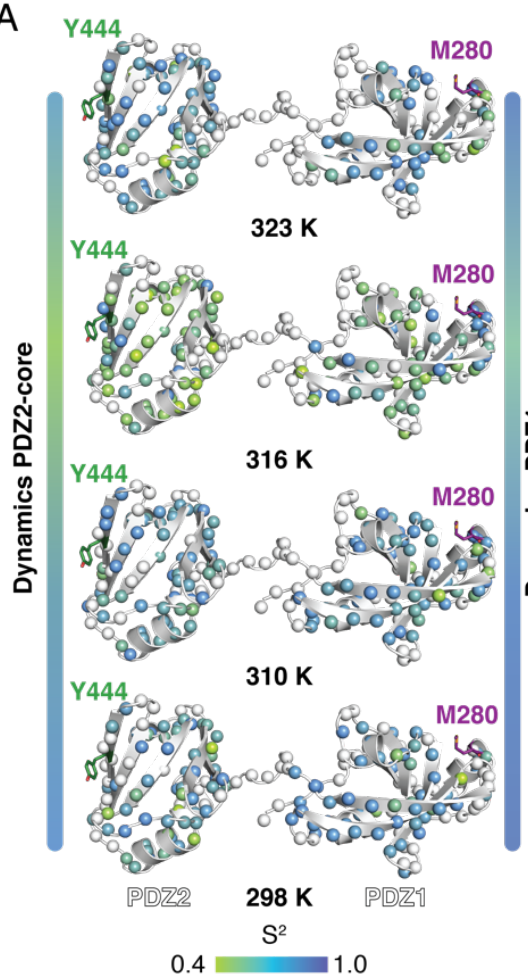

B

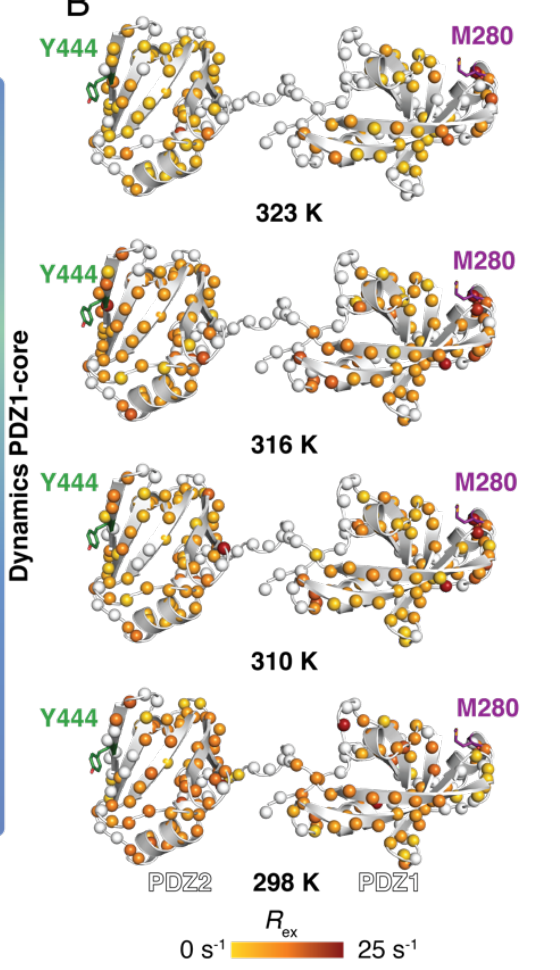

C

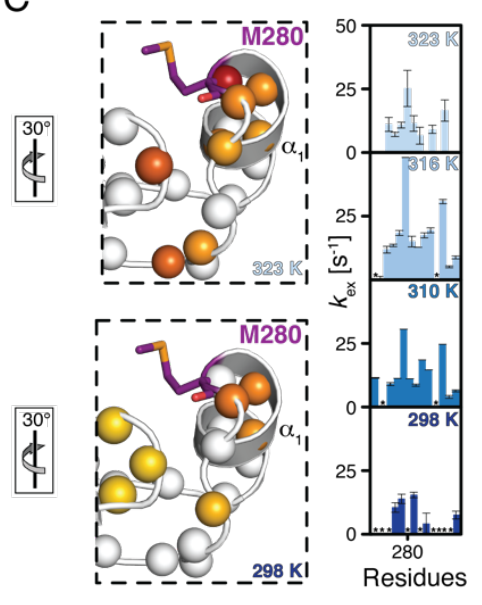

D

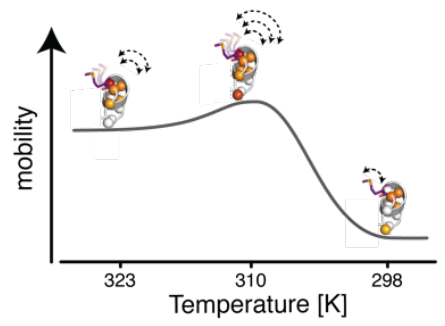

$\mathrm{E}$

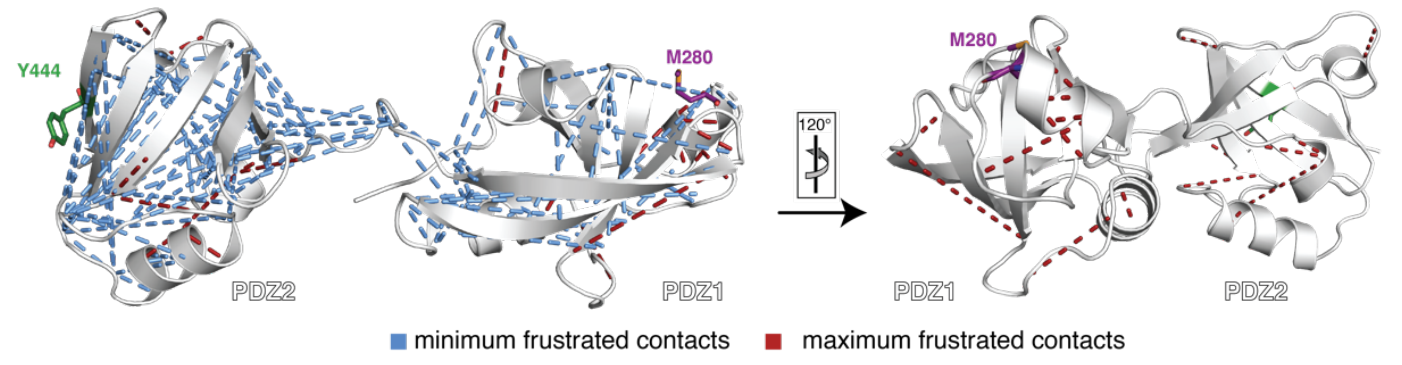

Fig. 5: Backbone dynamics show correlated movements of PDZ1 and helix $\alpha_{1}$ harbouring M280.

(A, B) Temperature dependence of the sub-nanosecond order parameter $\mathrm{S}^{2}(\mathbf{A})$ and the exchange rate $R_{\mathrm{ex}}$ (B), reporting on the flexibility on the micro- to millisecond timescale, calculated using the Lipari-Szabo model-free approach $(34,36)$. (C) Temperature dependence of the $R_{\text {ex }}$-rates and zoom-in on the region around Met280. The rotation relative to panel $\mathbf{B}$ is indicated. The excerpt from the obtained exchange rates in this region is also shown. Residues for which no data could be obtained are indicated with a * The full data set is provided in fig. S8C. (D) Cartoon representation of the temperature-dependence of the inherent mobility as reflected by the possible conformational exchange contributions on the micro to millisecond timescale of helix $\alpha_{1}$ containing M280. (E) Frustration analysis was calculated for the DegP crystal structure (PDB-ID: 3OU0) via the Protein Frustratometer 2 (37). Minimally frustrated interactions are indicated as blue lines, whereas highly frustrated interactions as red lines. 

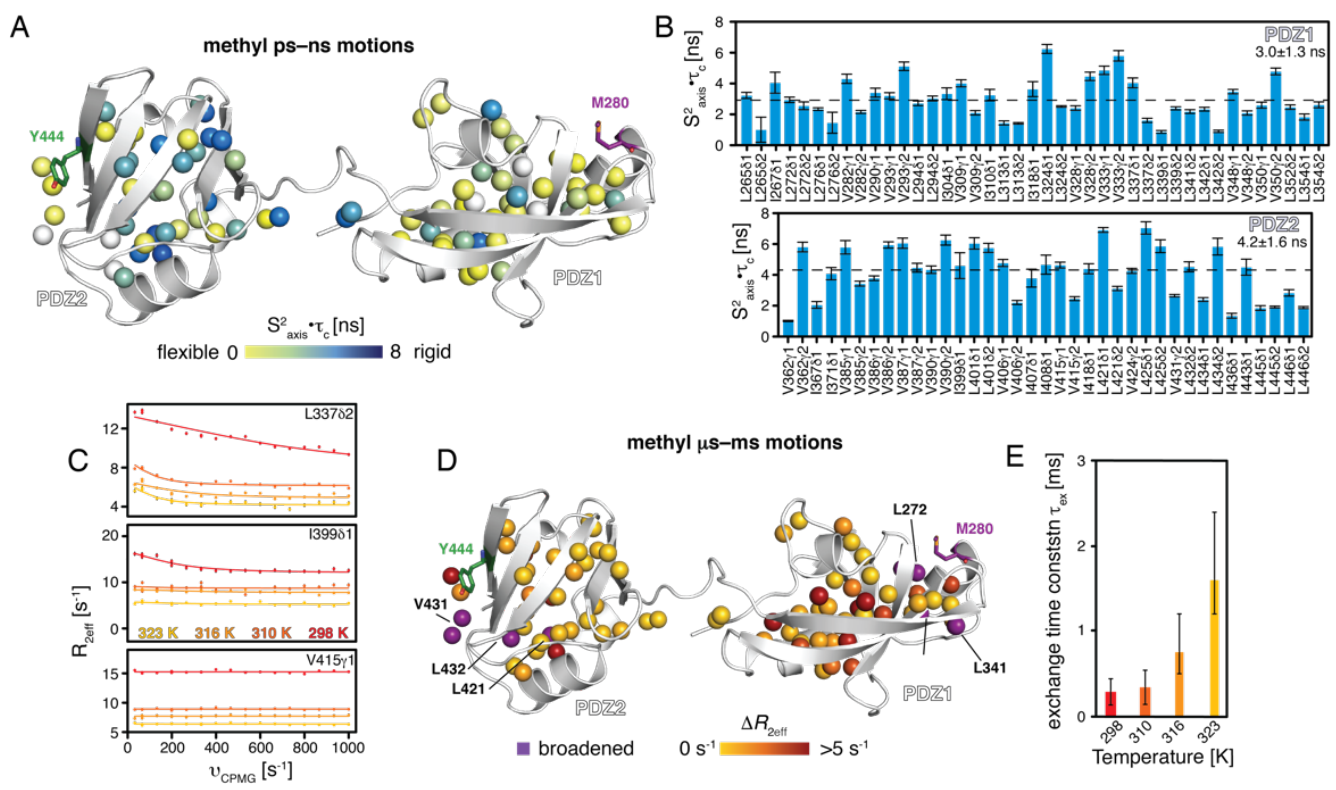

Fig. 6: ILV methyl groups reveal conformational exchange within the PDZ1 core. (A, B) Local methyl-group dynamics on the pico- to nanosecond timescale probed by methyl triple-quantum (TQ) relaxation experiments measurements $(69,70)$ at $37^{\circ} \mathrm{C}$ showing the product of the local order parameter and the overall tumbling constant, $\mathrm{S}^{2}{ }_{\text {axis }}{ }^{*} \tau_{\mathrm{C}}$. The ILV methyl groups of PDZ1-PDZ2 construct are shown as spheres and the obtained $\mathrm{S}^{2}{ }_{\text {axis }}{ }^{\bullet} \tau_{\mathrm{C}}$-values by the green to blue gradient (A). $\mathrm{S}^{2}{ }_{\text {axis }}{ } \tau_{\mathrm{C}}$ values plotted against the sequence (B). (C) Exemplary ${ }^{13} \mathrm{C}$ methyl MQ-CPMG relaxation dispersion profiles at different temperatures as indicated. Non-flat profiles indicate millisecond-dynamics. (D) Structural view of the amplitude of the CPMG relaxation dispersion profiles $\Delta R_{2 \text { eff }}$ at $25^{\circ} \mathrm{C}$. (E) Rate constants of the dynamic process $\left(\tau_{\mathrm{ex}}\right)$ obtained from a global fit of the CPMG relaxation dispersion data. 

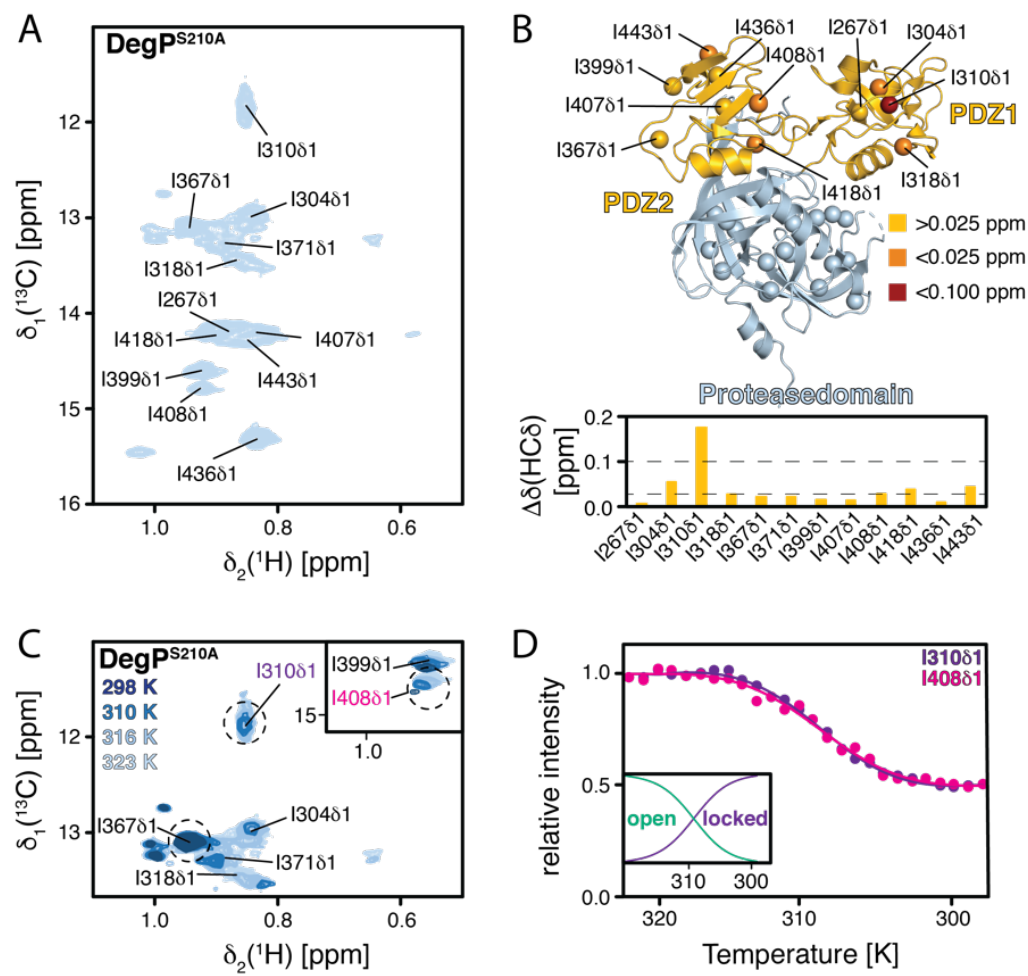

Fig. 7: Isoleucine methyl groups within full-length DegP show also temperaturedependent transition. (A) $2 \mathrm{D}\left[{ }^{13} \mathrm{C},{ }^{1} \mathrm{H}\right]-\mathrm{NMR}$ spectrum of $\left[U-{ }^{2} \mathrm{H}\right.$, Ile- $\left.\delta_{1}{ }^{13} \mathrm{CH}_{3}\right]-\mathrm{Deg} \mathrm{P}^{\mathrm{S} 210 \mathrm{~A}}$ at $50^{\circ} \mathrm{C}$. The indicated resonance assignments were transferred from the assigned PDZ1-PDZ2 construct. (B) Chemical shift changes of the isoleucine methyl groups of DegP compared to the PDZ1-PDZ2 (bottom). The isoleucine methyl groups of one DegP monomer are indicated with spheres (top), and the chemical shift changes compared to the PDZ1-PDZ2 construct are indicated by the yellow to red gradient. (C) Excerpt of the isoleucine methyl region of a $2 \mathrm{D}\left[{ }^{13} \mathrm{C},{ }^{1} \mathrm{H}\right]-\mathrm{NMR}$ spectrum of $\left[\mathrm{U}-{ }^{2} \mathrm{H}\right.$, lle$\left.\delta_{1}{ }^{13} \mathrm{CH}_{3}\right]-$ DegP $\mathrm{P}^{\mathrm{S} 10 \mathrm{~A}}$ at different temperatures as indicated. (D) The temperature dependence of the selected $1310 \delta 1$ and $1408 \delta 1$ signal intensities is shown. Solid lines represent a fit to a 2-state model for the extraction of thermodynamic parameters. The inset shows the respective populations of the open and the locked state, respectively, at the different temperatures. 

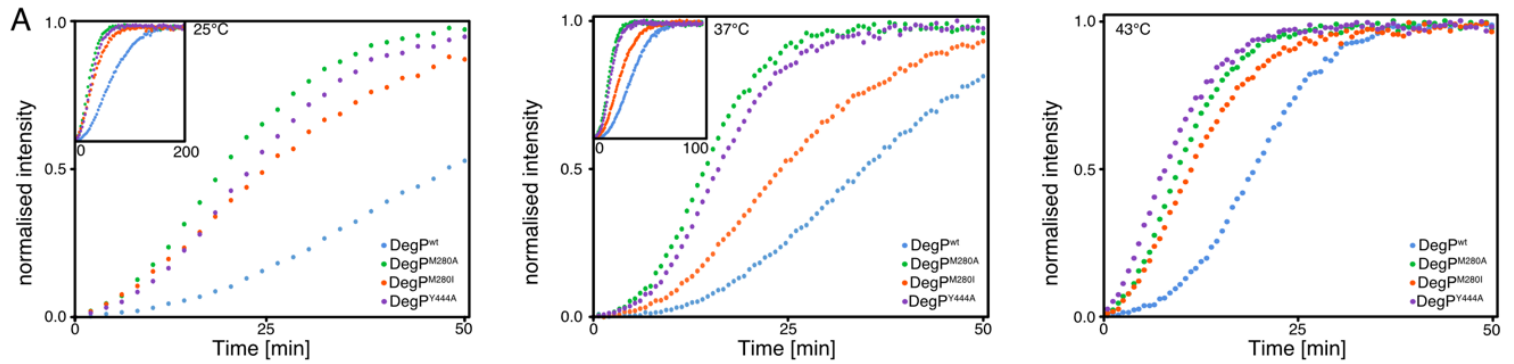

B
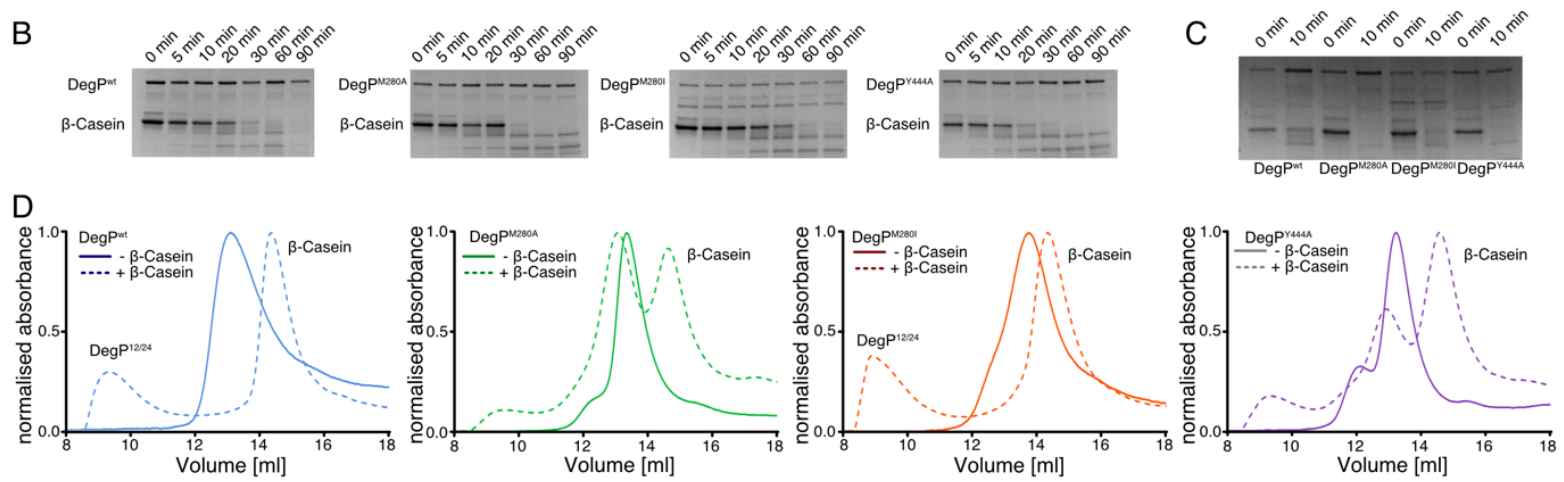

Fig. 8: Assessing the effect of the domain-lock on DegP proteolytic function. (A) DegP (10 $\mu \mathrm{M}$ monomer concentration) proteolysis of $\beta$-casein $(50 \mu \mathrm{M})$ via detection by a fluorescent reporter peptide $(100 \mu \mathrm{M})$ at $25^{\circ} \mathrm{C}, 37^{\circ} \mathrm{C}$, and $43^{\circ} \mathrm{C}$. All experiments were scaled to the experiment at $43^{\circ} \mathrm{C}$. Insets show the respective full data sets at the lower temperatures. Experiments were performed as triplicates yielding identical results.

(B) SDS-PAGE analysis of $\beta$-casein $(5 \mu \mathrm{M})$ cleavage by DegP variants $(1 \mu \mathrm{M}$ monomer concentration) at the indicated time intervals at $25^{\circ} \mathrm{C}$. (C) SDS-PAGE analysis of $\beta$-casein cleavage at the indicated time intervals at $37^{\circ} \mathrm{C}$. Experiments were performed as triplicates yielding identical results. (D) Size-exclusion chromatography elution profiles of DegP and $\beta$-casein mixtures on an S200increase 10/300 column (GE Healthcare). 


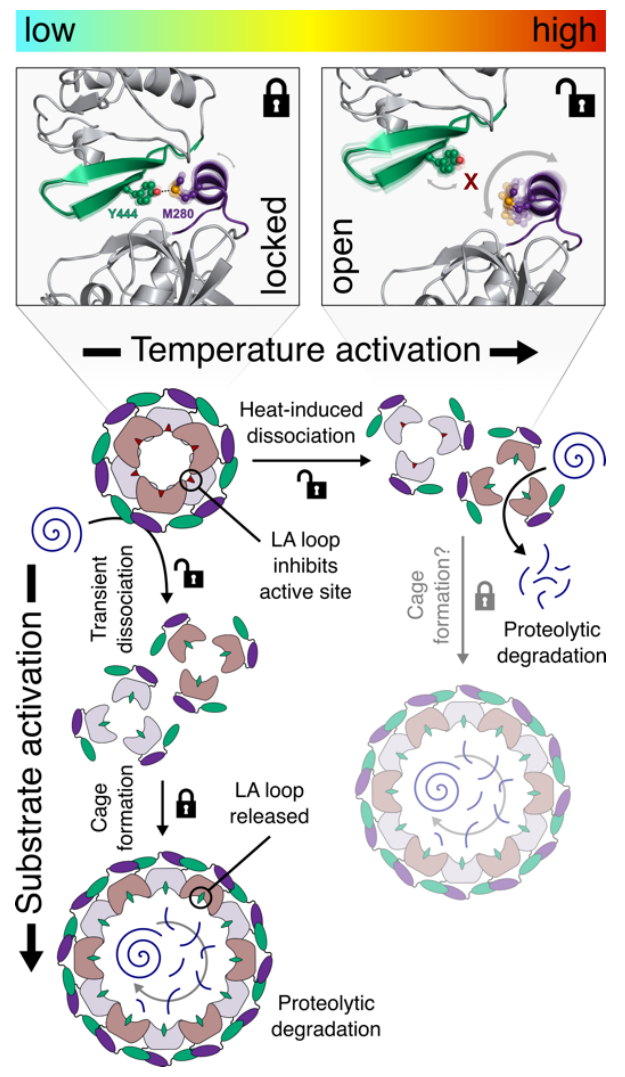

Fig. 9: Temperature activation of the DegP protease mediated by the M280-Y444 interdomain lock. In cellular ground-states at low temperature the dynamics of M280 are reduced to stabilize the PDZ1-PDZ2 interaction via the sulfur- $\pi$ interaction with Y444 (locked state), resulting in an inactive DegP hexamer. Under heat shock conditions, M280 exhibits a large degree of flexibility and the interaction with Y444 is broken (open state), as it cannot compensate the overall increased dynamics and the PDZ1-PDZ2, leading to trimerization of DegP. At low temperatures the protease activity of DegP can be triggered by activating substrates, which mediate the formation of proteolytic (12/24-meric) cages via a transient trimerization through interactions with the PDZ1 domain. Upon temperature activation the M280-Y444 lock mediates the transformation of DegP from the locked inactive hexameric state to an open trimeric state, primed for the proteolytic degradation of substrates, but still requiring activation through substrate binding. Under heat-shock conditions, the structural basis for cate formation remains unclear, even though DegP is still able to form cages under these conditions (23).

\section{Supplementary Materials}

Figs. S1 to S11 


\section{Supplementary Materials for}

\section{Structural basis of DegP-protease temperature-dependent activation}

Darius Šulskis, Johannes Thoma, Björn M. Burmann*

*Corresponding author. Email: bjorn.marcus.burmann@gu.se

This PDF file includes:

Figs. S1 to S11

Tables S1 to S3 
A

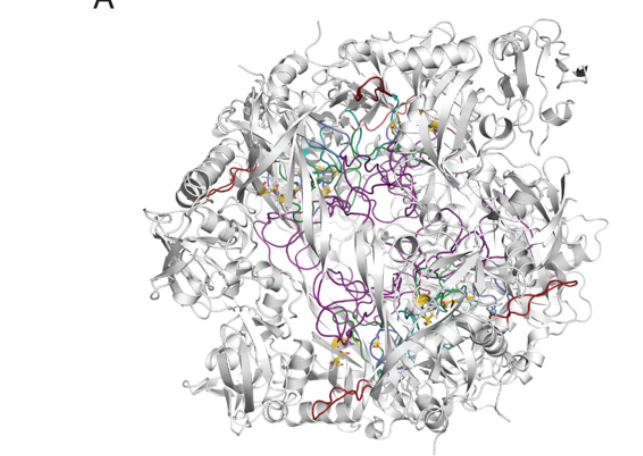

B

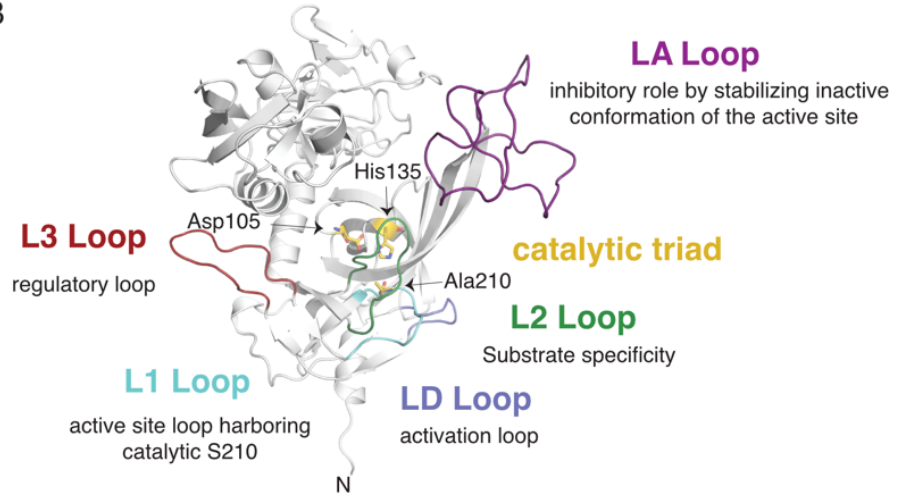

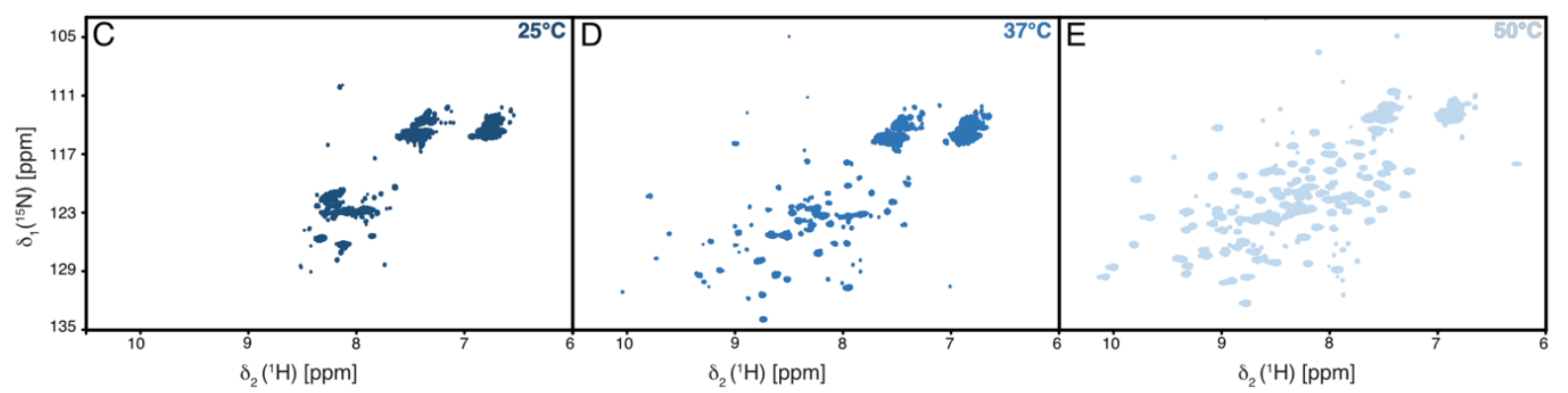

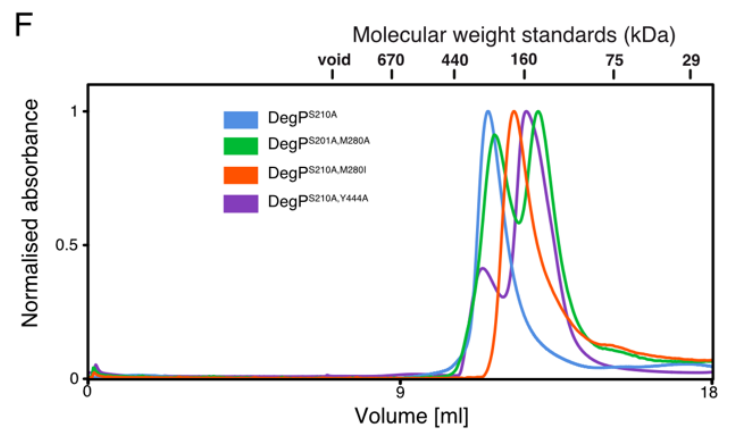

G
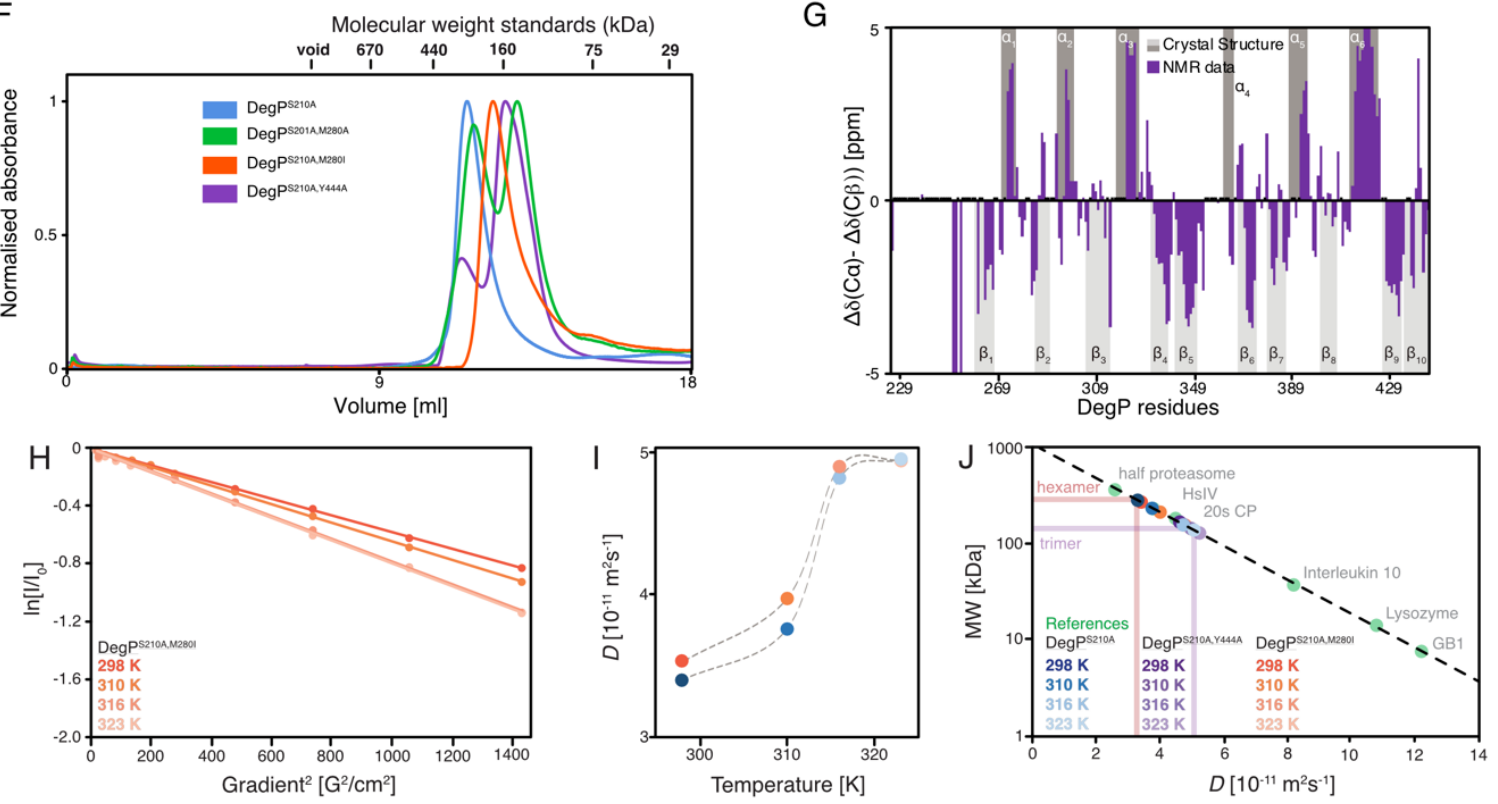

Fig. S1. Solution studies of full-length DegP.

(A) Structural model of the DegP $\mathrm{P}^{\mathrm{S} 10 \mathrm{~A}}$ in its inactive hexameric form highlighting the different regulatory loops involved in its proteolytic function. Based on the structural model developed by Figaj et al. (18). (B) Zoom on a DegP $\mathrm{P}^{\mathrm{S} 10 \mathrm{~A}}$ monomer with the highlighted regulatory loops together with the catalytic triad and their respective function. (C-E) $2 \mathrm{D}\left[{ }^{15} \mathrm{~N},{ }^{1} \mathrm{H}\right]-\mathrm{NMR}$ spectrum of $\left[U_{-}{ }^{2} \mathrm{H},{ }^{15} \mathrm{~N}\right]-\mathrm{DegP}{ }^{\mathrm{S} 210 \mathrm{~A}}$ measured at the indicated temperatures. (F) Gel elution profiles of different full-length DegP ${ }^{\mathrm{S} 210 \mathrm{~A}}$ variants as indicated. Recorded at $8^{\circ} \mathrm{C}$ in NMR-buffer on a Superdex 
S200increase 10/300 column (GE Healthcare). The column void volume and the molecular weights of a standard calibration curve are indicated. (G) Secondary backbone ${ }^{13} \mathrm{C}$ chemical shifts in solution of the full-length $\mathrm{DegP}^{\mathrm{S} 210 \mathrm{~A}, \mathrm{Y} 444 \mathrm{~A}}$ protein variant compared to the hexameric X-ray structure (PDB-ID: 1KY9). Positive values indicate $\alpha$-helix whereas negative values $\beta$-sheet secondary structure elements. (H) Measurement of the molecular diffusion constants with a ${ }^{13} \mathrm{C}$ methyl-filtered diffusion experiment for $\operatorname{DegP}^{\mathrm{S} 210 \mathrm{~A}, \mathrm{M} 280 \mathrm{I}}$. The logarithm of the signal intensity is plotted against the squared gradient strength of the applied pulsed-field gradients. $\left[U-{ }_{-}^{2} \mathrm{H}, \mathrm{Ile}-\delta_{1}-\right.$ $\left.{ }^{13} \mathrm{CH}_{3}\right]-\mathrm{DegP} \mathrm{P}^{\mathrm{S} 210 \mathrm{~A}, \mathrm{M} 280 \mathrm{I}}$ was measured at different temperatures as indicated. Solid lines are a linear fit to the data. (I) Obtained molecular diffusion constants for $\operatorname{DegP}^{\mathrm{S} 210 \mathrm{~A}}$ (blue; data also shown in Fig. $1 \mathrm{~F}$ ) and $\mathrm{DegP}^{\mathrm{S} 210 \mathrm{~A}, \mathrm{M} 280 \mathrm{I}}$ (orange) plotted against the temperature. The broken lines serve as a guide to the eyes only. (J) Calibration curve for estimating the molecular weight based on the determined molecular diffusion constants. Linear correlation of the molecular weight (MW: logarithmic scale) plotted against the molecular diffusion constants. Published diffusion constants of proteins with known molecular weight are indicated in green (see Methods for details). Temperature dependent data for DegP ${ }^{\mathrm{S} 210 \mathrm{~A}}$, DegP $\mathrm{P}^{\mathrm{S} 210 \mathrm{~A}, \mathrm{Y} 444 \mathrm{~A}}$, and $\mathrm{DegP}^{\mathrm{S} 210 \mathrm{~A}, \mathrm{M} 280 \mathrm{I}}$ are shown as blue, purple or orange gradients, respectively, as indicated. 
A

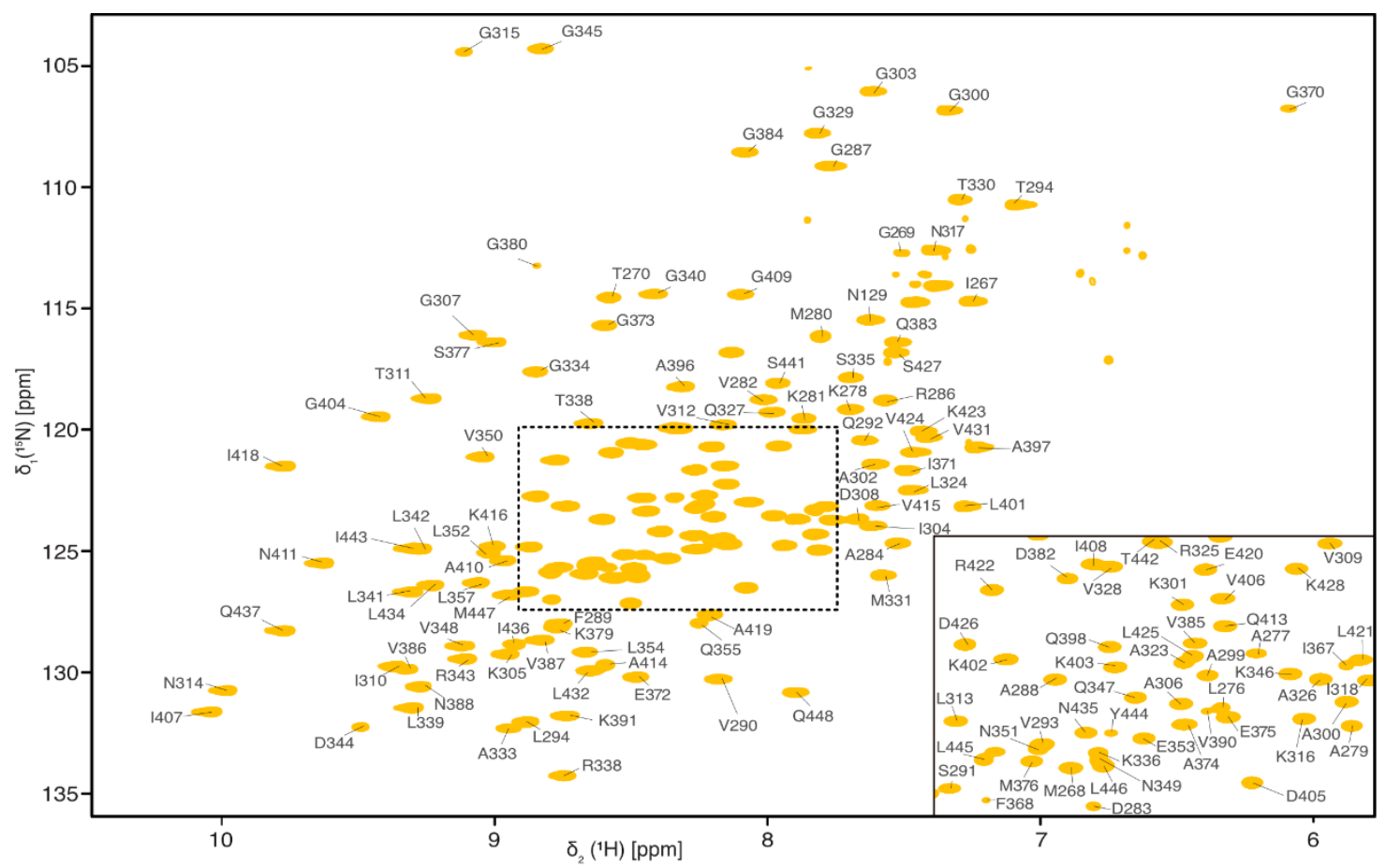

B

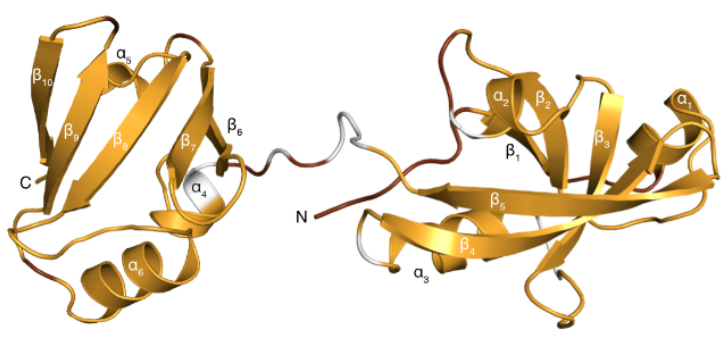

C

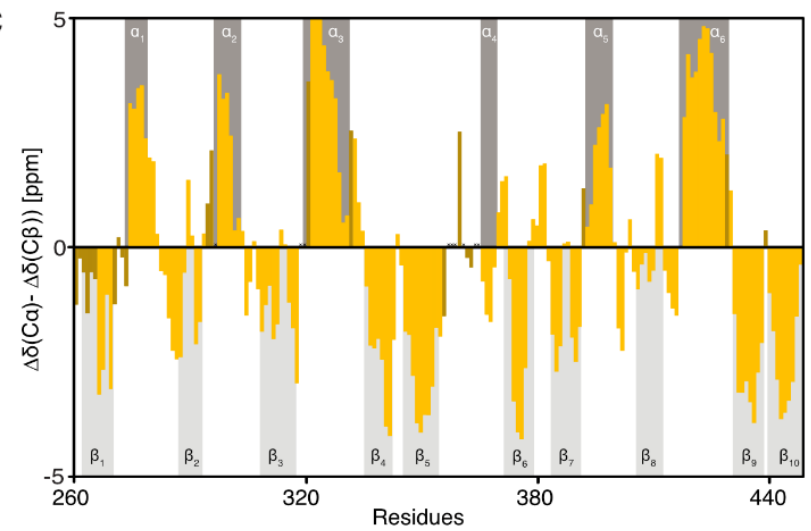

D

$\mathrm{E}$ $117.68117 .93125 .75126 .37119 .81131 .51114 .48126 .74124 .95129 .50 \leftarrow[\mathrm{ppm}]$
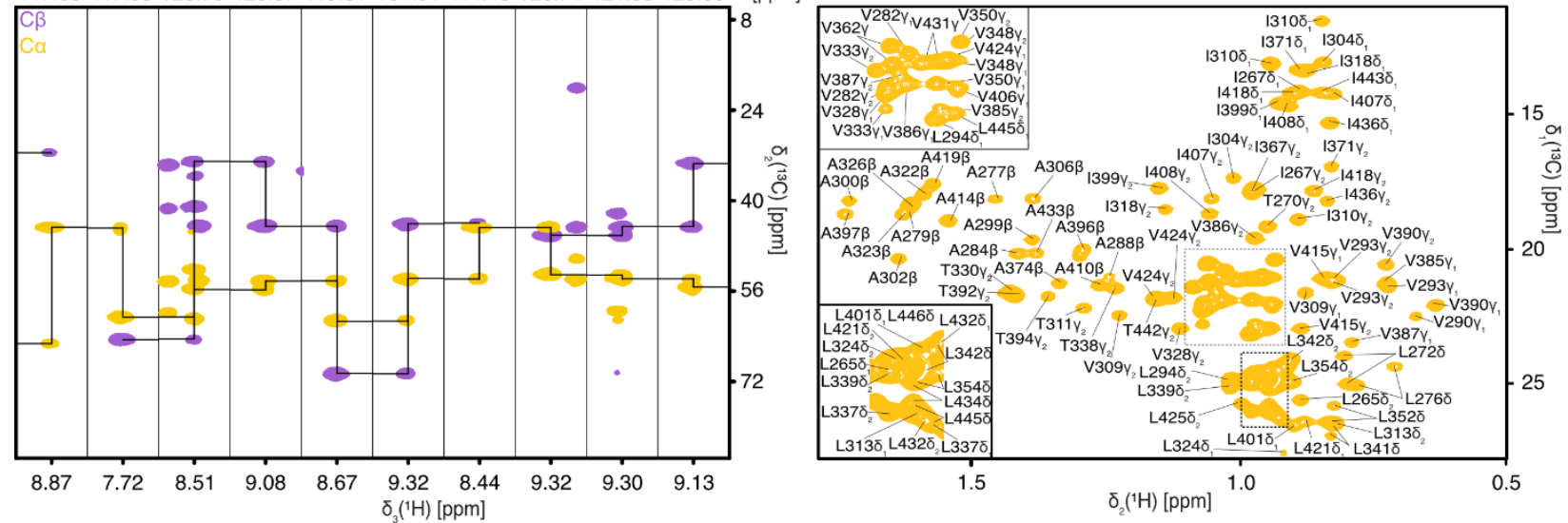
Fig. S2. The isolated PDZ1-PDZ2 domain construct in solution.

(A) $2 \mathrm{D}\left[{ }^{15} \mathrm{~N},{ }^{1} \mathrm{H}\right]-\mathrm{NMR}$-spectrum of $\left[U_{-}{ }^{15} \mathrm{~N},{ }^{13} \mathrm{C}\right]-\mathrm{PDZ} 1-\mathrm{PDZ} 2$. The sequence-specific resonance assignment obtained from 3D triple-resonance experiments is indicated. (B) Cartoon representation of the crystal structure of the PDZ1-PDZ2 domains (PDB-ID: 3OU0) with the assigned resonances highlighted in orange and unassigned residues in white. (C) Secondary backbone ${ }^{13} \mathrm{C}$ chemical shift analysis plotted against the PDZ1-PDZ2 residues. Dark shaded bars present residues experiencing line-broadening in $\left[{ }^{15} \mathrm{~N},{ }^{1} \mathrm{H}\right]-\mathrm{NMR}$-spectra that could be assigned unambiguously via 2D $\left[{ }^{13} \mathrm{C},{ }^{1} \mathrm{H}\right]$-NMR-spectra based TOCSY-type 3D experiments. The secondary structure elements derived from the crystal structure (PDB-ID: 3OU0) are highlighted in grey. (D) Representative strips for residues G74-L83 from a 3D HNCACB spectrum of the PDZ1PDZ2-domains. (E) Methyl-region of a $\left[{ }^{13} \mathrm{C},{ }^{1} \mathrm{H}\right]-\mathrm{NMR}$-spectrum of $\left[U_{-}{ }^{15} \mathrm{~N},{ }^{13} \mathrm{C}\right]-\mathrm{PDZ} 1-\mathrm{PDZ} 2$ with the assignment of the methyl side-chain resonances indicated. 

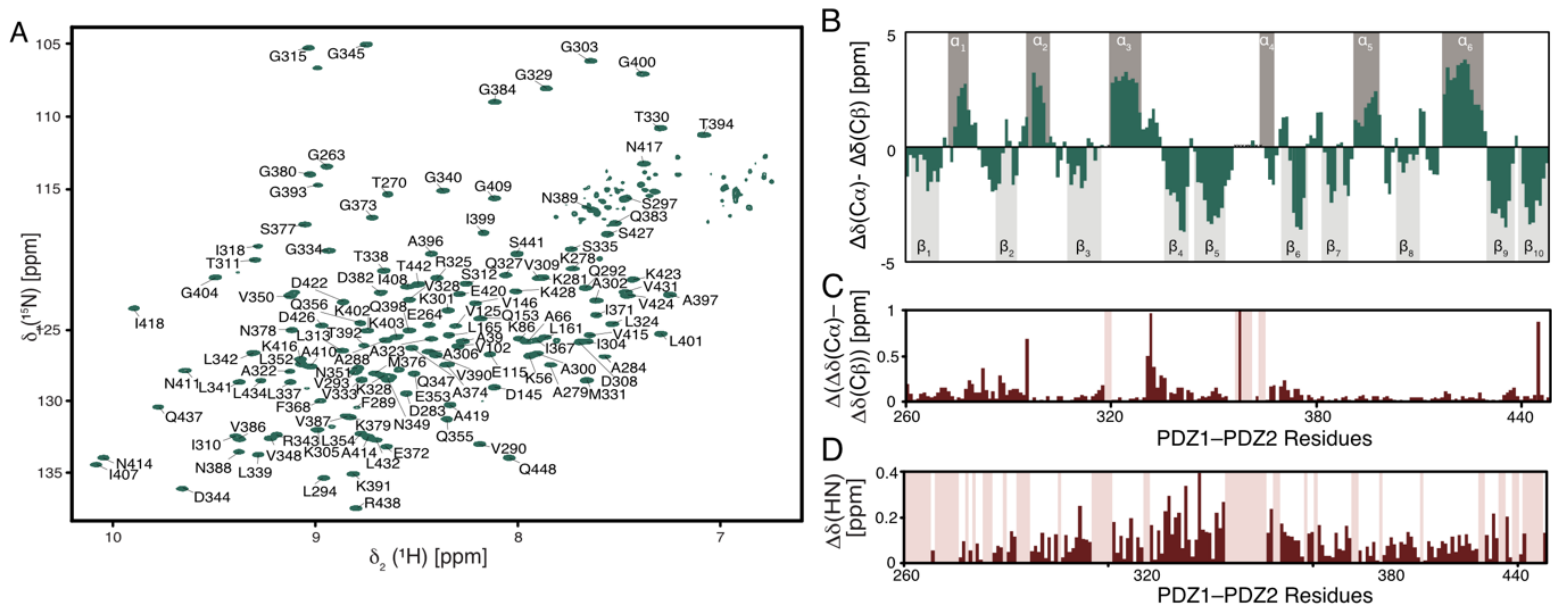

Fig. S3. The isolated PDZ1-PDZ2 domain construct in solution at low temperature.

(A) $2 \mathrm{D}\left[{ }^{15} \mathrm{~N},{ }^{1} \mathrm{H}\right]-\mathrm{NMR}$-spectrum of $\left[U_{-}{ }^{15} \mathrm{~N},{ }^{13} \mathrm{C}\right]-\mathrm{PDZ} 1-\mathrm{PDZ} 2$ at $25^{\circ} \mathrm{C}$. The sequence-specific resonance assignment obtained from 3D triple-resonance experiments is indicated. (B) Secondary backbone ${ }^{13} \mathrm{C}$ chemical shift analysis plotted against the PDZ1-PDZ2 residues. The secondary structure elements derived from the crystal structure (PDB-ID: 3OU0) are highlighted in grey. (C) The difference of the secondary backbone ${ }^{13} \mathrm{C}$ chemical shifts at the different temperatures $\left(\Delta\left(\Delta \delta\left({ }^{13} \mathrm{C} \alpha\right)-\Delta \delta\left({ }^{13} \mathrm{C} \beta\right)\right)\right.$ are shown in dark red. (D) Combined chemical shift differences of the amide moieties plotted versus the PDZ1-PDZ2 amino acid residue number. In panels, C and D broadened residues are indicated by the red shading. 
A

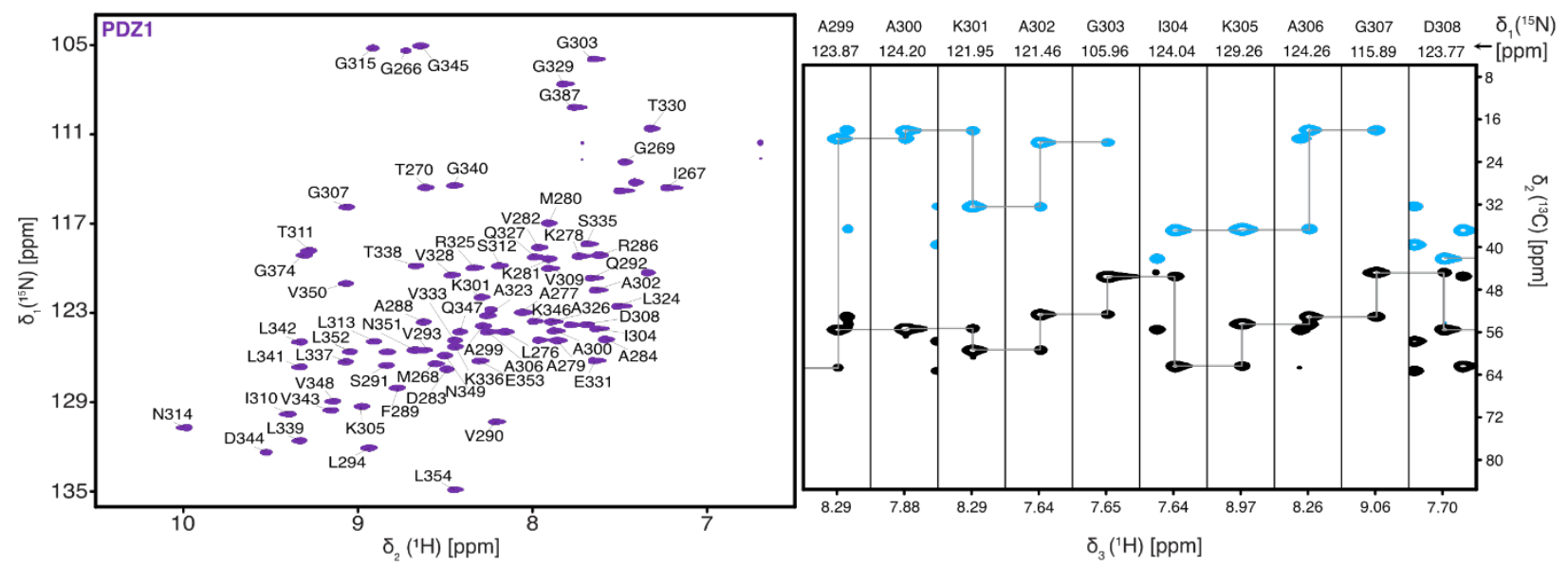

C

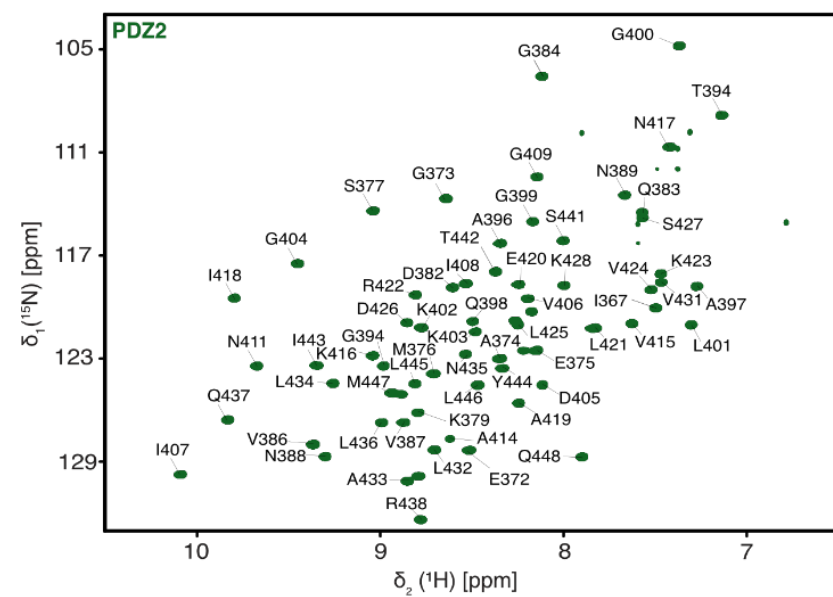

D

E

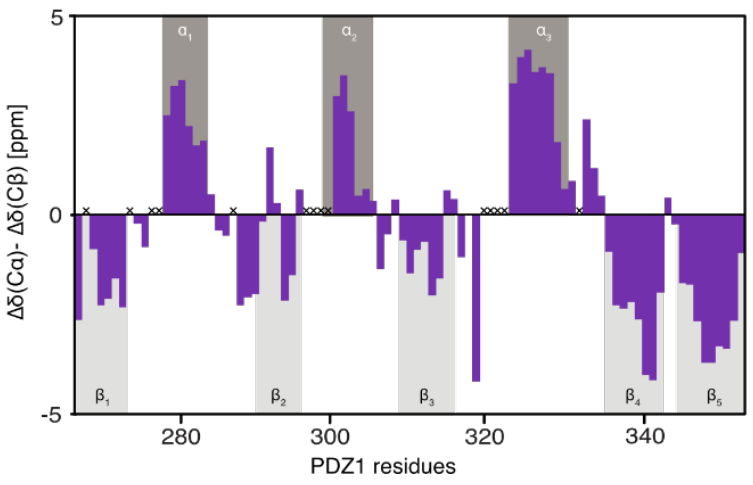

$\begin{array}{lllllllllll}\text { A398 } & \text { A399 } & \text { Q400 } & \text { L401 } & \text { G402 } & \text { L403 } & \text { K404 } & \text { K405 } & \text { G406 } & \text { D407 } & \delta_{1}\left({ }^{15} \mathrm{~N}\right)\end{array}$

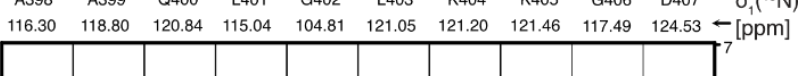

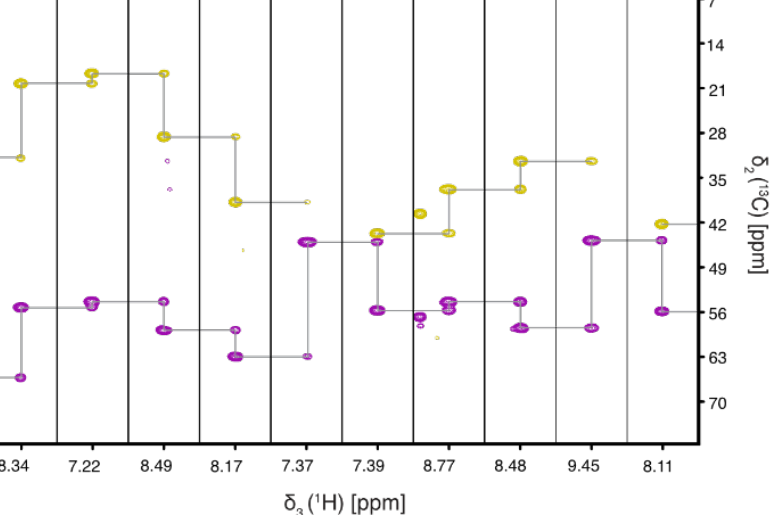

$\mathrm{F}$

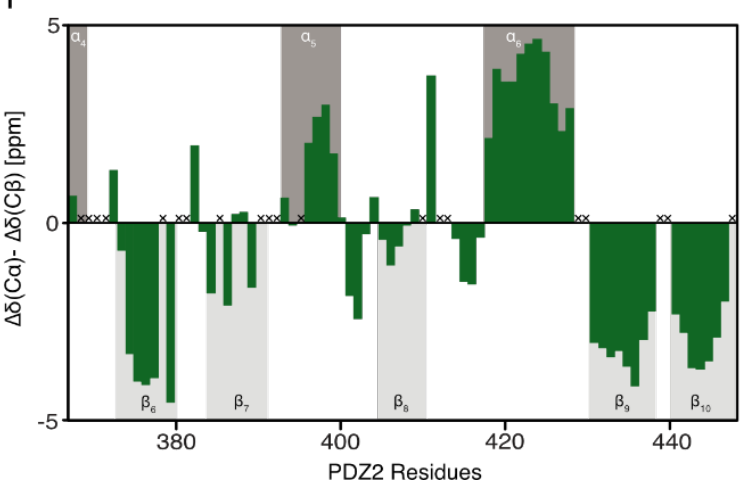

Fig. S4. The isolated PDZ1 and PDZ2 domains in solution.

(A) 2D $\left[{ }^{15} \mathrm{~N},{ }^{1} \mathrm{H}\right]-\mathrm{NMR}$-spectrum of $\left[U-{ }^{15} \mathrm{~N},{ }^{13} \mathrm{C}\right]-\mathrm{PDZ1}$. The sequence-specific resonance assignment obtained from 3D triple-resonance experiments is indicated. (B) Representative strips for residues A299-D308 from a 3D HNCACB spectrum of the PDZ1-domain. (C) $2 \mathrm{D}\left[{ }^{15} \mathrm{~N},{ }^{1} \mathrm{H}\right]$ NMR-spectrum of $\left[U_{-}{ }^{15} \mathrm{~N},{ }^{13} \mathrm{C}\right]-\mathrm{PDZ} 1$. The sequence-specific resonance assignment obtained from 3D triple-resonance experiments is indicated. (D) Representative strips for residues A398-D407 
from a 3D HNCACB spectrum of the PDZ1-domain. (E, F) Secondary backbone ${ }^{13} \mathrm{C}$ chemical shift analysis plotted against the PDZ1 (E) and PDZ2 (F) residues. The secondary structure elements derived from the crystal structure are highlighted in grey. 
A
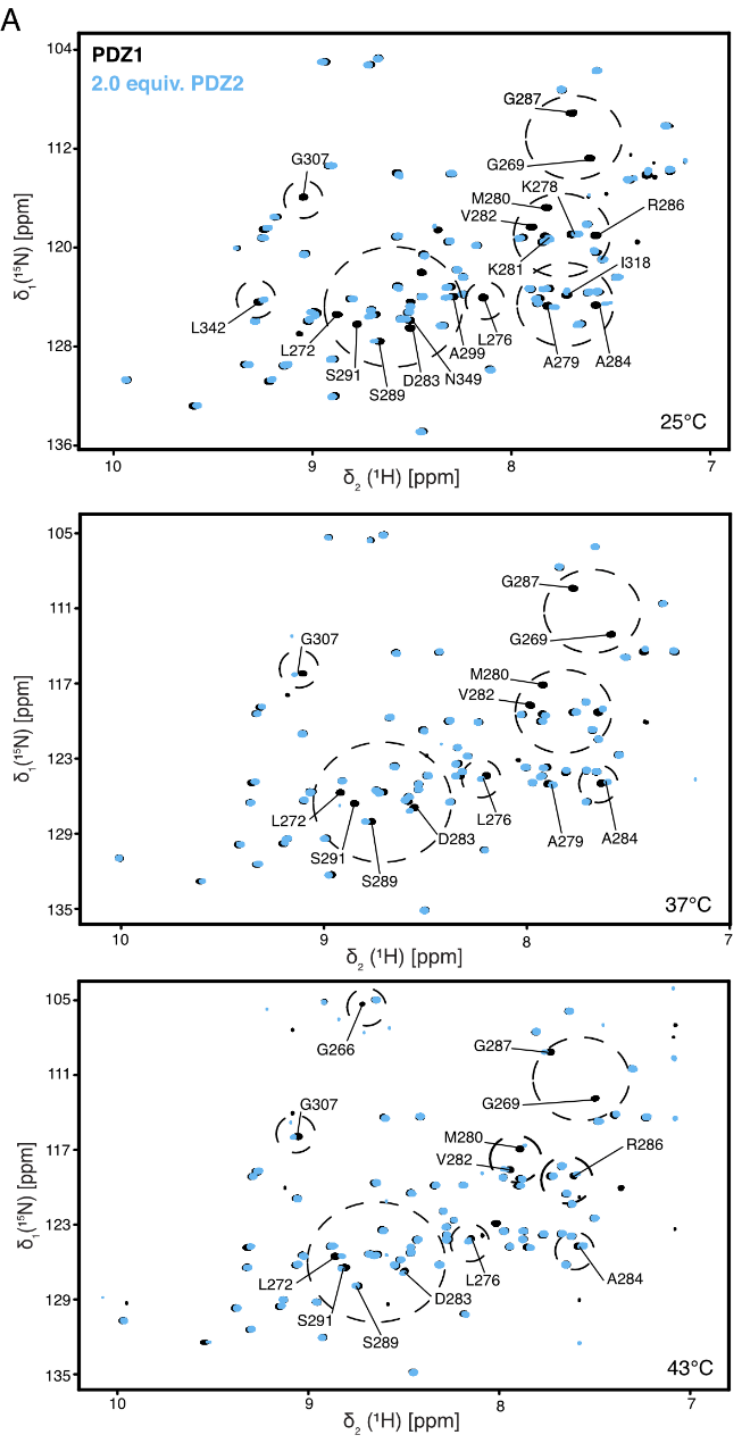

C

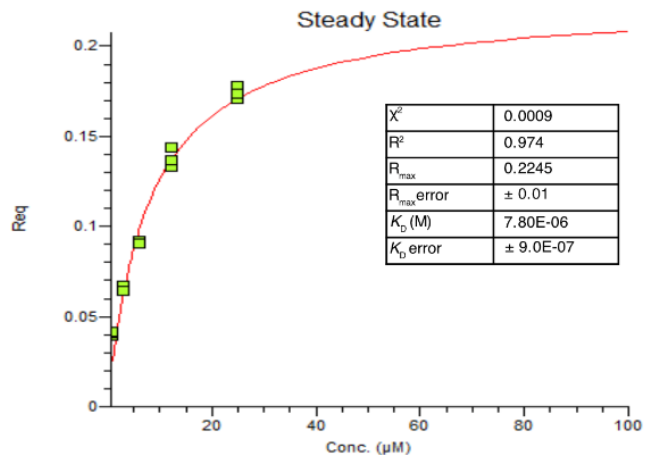

B
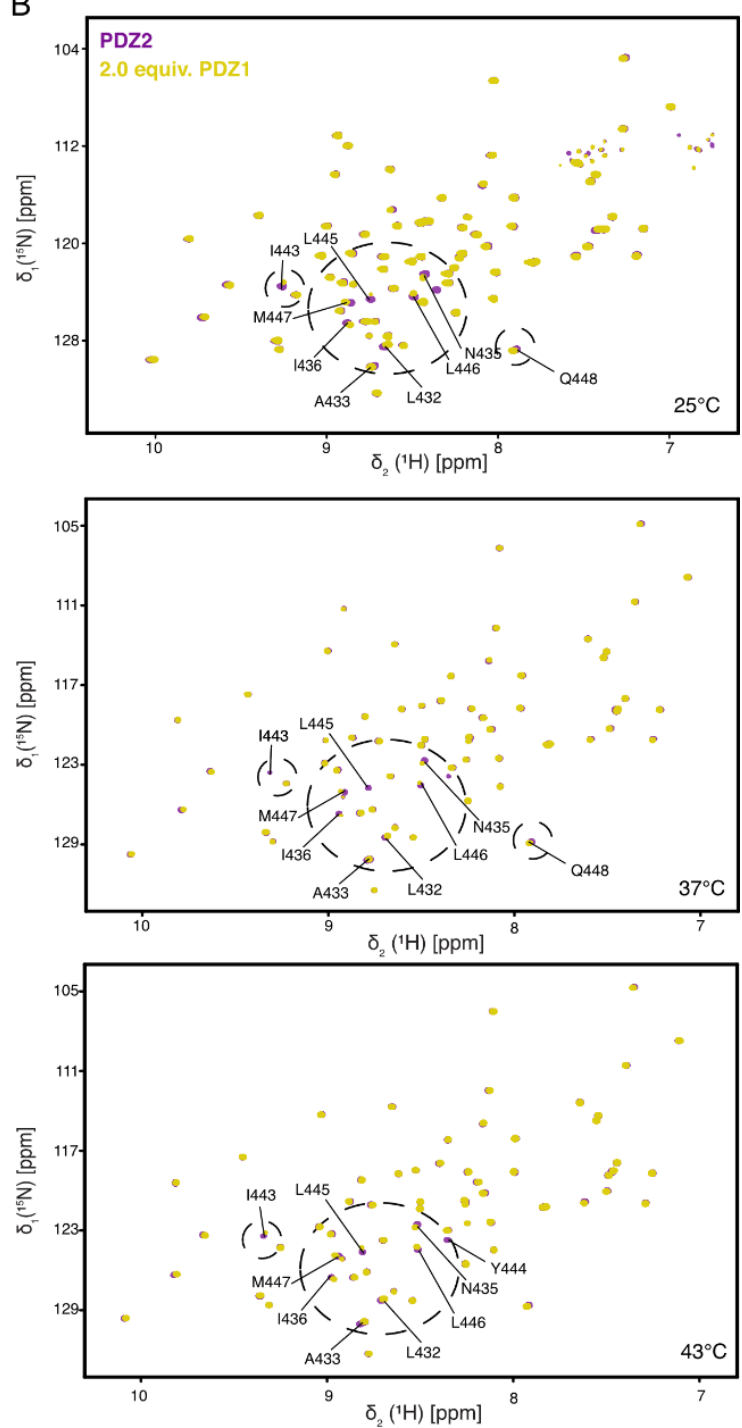

C

Fig. S5. Temperature dependence of the PDZ1:PDZ2 interaction.

(A, B) 2D $\left[{ }^{15} \mathrm{~N},{ }^{1} \mathrm{H}\right]-\mathrm{NMR}$ spectra of $\left[U_{-}{ }^{15} \mathrm{~N}\right]-\mathrm{PDZ} 1$ (A, purple) and $\left[U_{-}{ }^{15} \mathrm{~N}\right]-\mathrm{PDZ} 2$ (B, black) as well as after the addition of two molar equivalents of the respective other domain. Titrations were 
measured at $25^{\circ} \mathrm{C}, 37^{\circ} \mathrm{C}$, and $43^{\circ} \mathrm{C}$, as indicated. (C) Steady-state analysis of the BLI-curves shown in Fig. 2F. Curves were measured and analyzed in triplicates (green data points). The red curve is the least-squares fit to the data. The resulting $K_{\mathrm{D}}$ and indicators for the fitting quality $\left(\mathrm{R}^{2}\right.$, $\left.\chi^{2}\right)$ are indicated. 

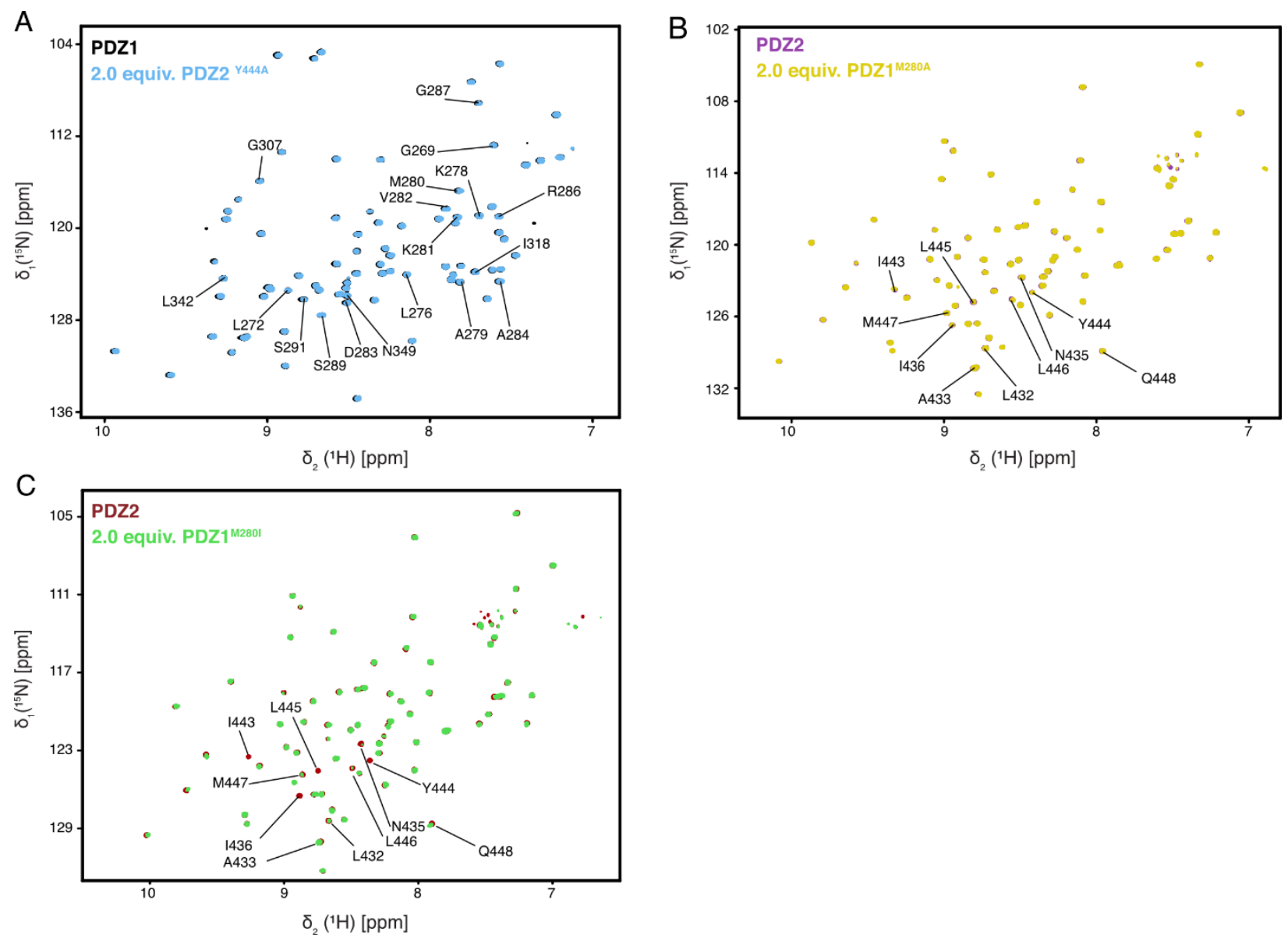

Fig. S6. Interactions of the PDZ1 ${ }^{\mathrm{M} 280 \mathrm{~A}}$, PDZ1 ${ }^{\mathrm{M} 280 \mathrm{I}}$, and $\mathrm{PDZ2}^{\mathrm{Y444A}}$ mutants.

(A, B, C), 2D [ $\left.{ }^{15} \mathrm{~N},{ }^{1} \mathrm{H}\right]-\mathrm{NMR}$ spectra of $\left[U_{-}{ }^{15} \mathrm{~N}\right]-\mathrm{PDZ} 1$ (A, black), $\left[U_{-}{ }^{15} \mathrm{~N}\right]-\mathrm{PDZ} 2$ (B, black, $\mathbf{C}$, red) as well as after addition of two molar equivalents of the respective other domain carrying the indicated single-point mutation. Titrations were measured at $25^{\circ} \mathrm{C}$. 
$\mathrm{A}=298 \mathrm{~K}=310 \mathrm{~K}=316 \mathrm{~K}=323 \mathrm{~K}$

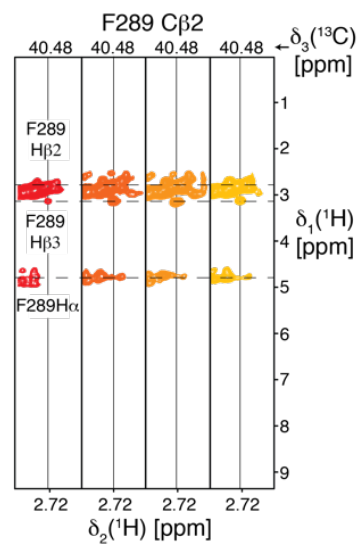

C

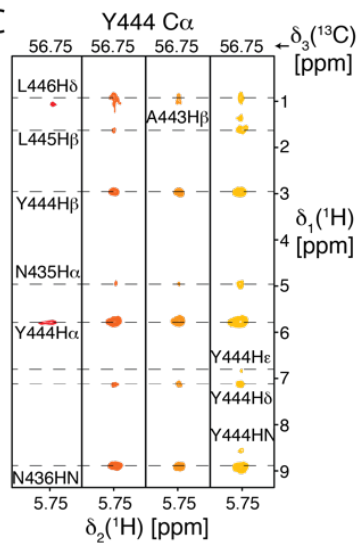

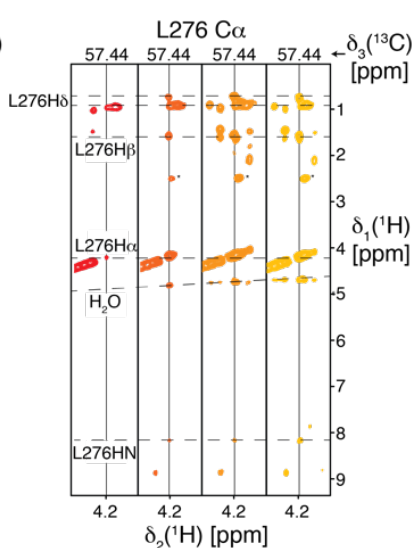
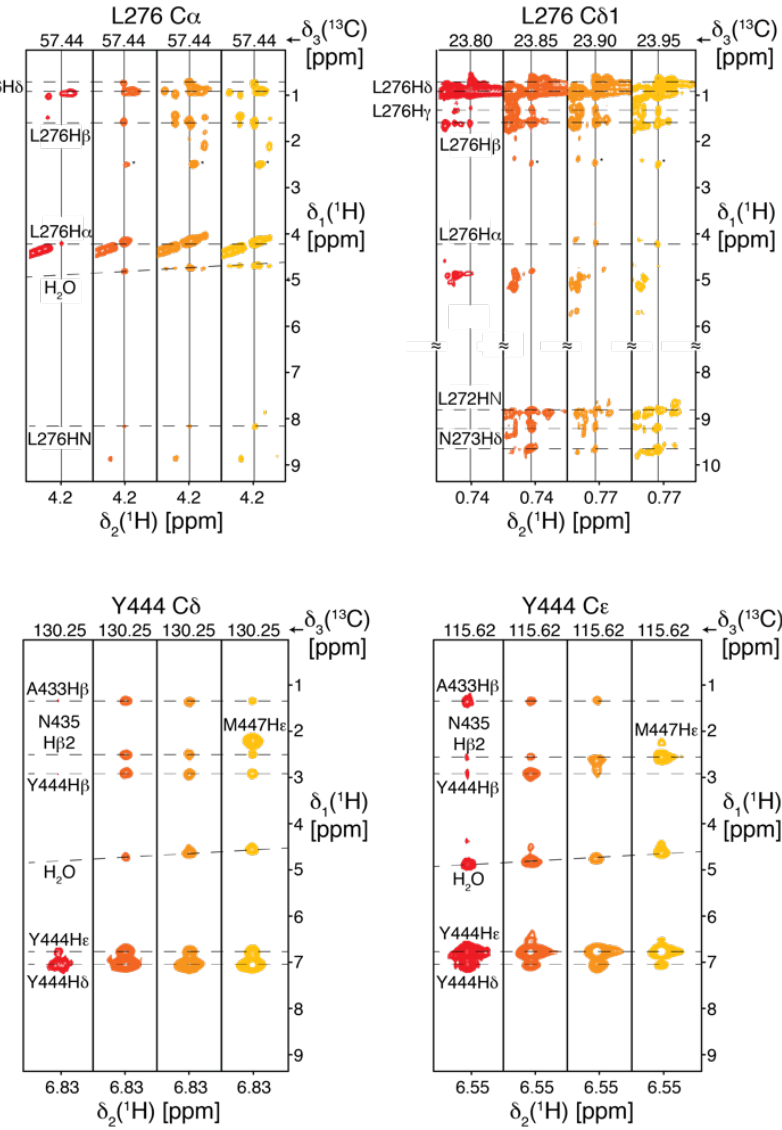

B
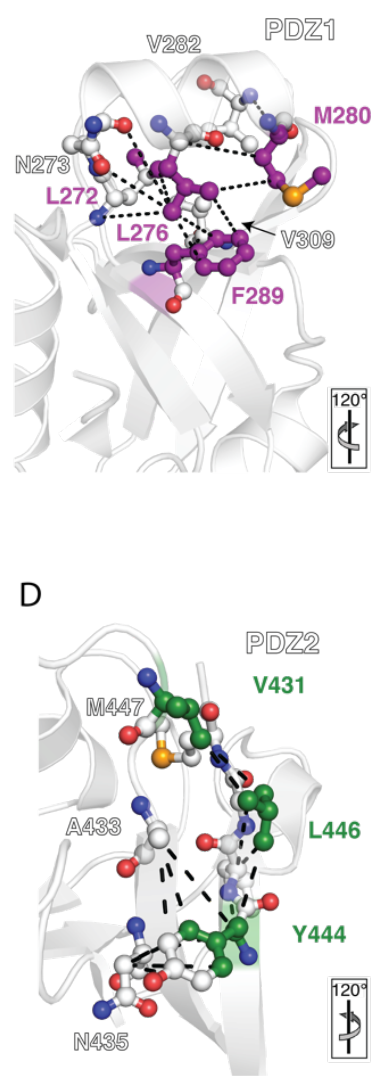

Fig. S7. Temperature-dependent analysis of the NOE-network stabilizing the PDZ1-PDZ2 interface

(A) Representative NOE strips from NOESY experiments at the indicated temperatures. Intramolecular NOE cross-peaks showing parts of the NOE-network on PDZ1 stabilizing the interaction regions around M280 is indicated. (B) Visualization of the detected intramolecular NOEs (dashed lines) on the structure of PDZ1. (C) Representative NOE strips from NOESY experiments at the indicated temperatures. Intramolecular NOE cross-peaks showing parts of the NOE-network on PDZ2 stabilizing the interaction regions around Y444 is indicated. (D) Visualization of the detected intramolecular NOEs (dashed lines) on the structure of PDZ2. (B, D) Broadened residues upon domain interaction at low temperature are indicated in purple (PDZ1) and green (PDZ2) as shown in Fig. 3H as well as the respective orientation. 

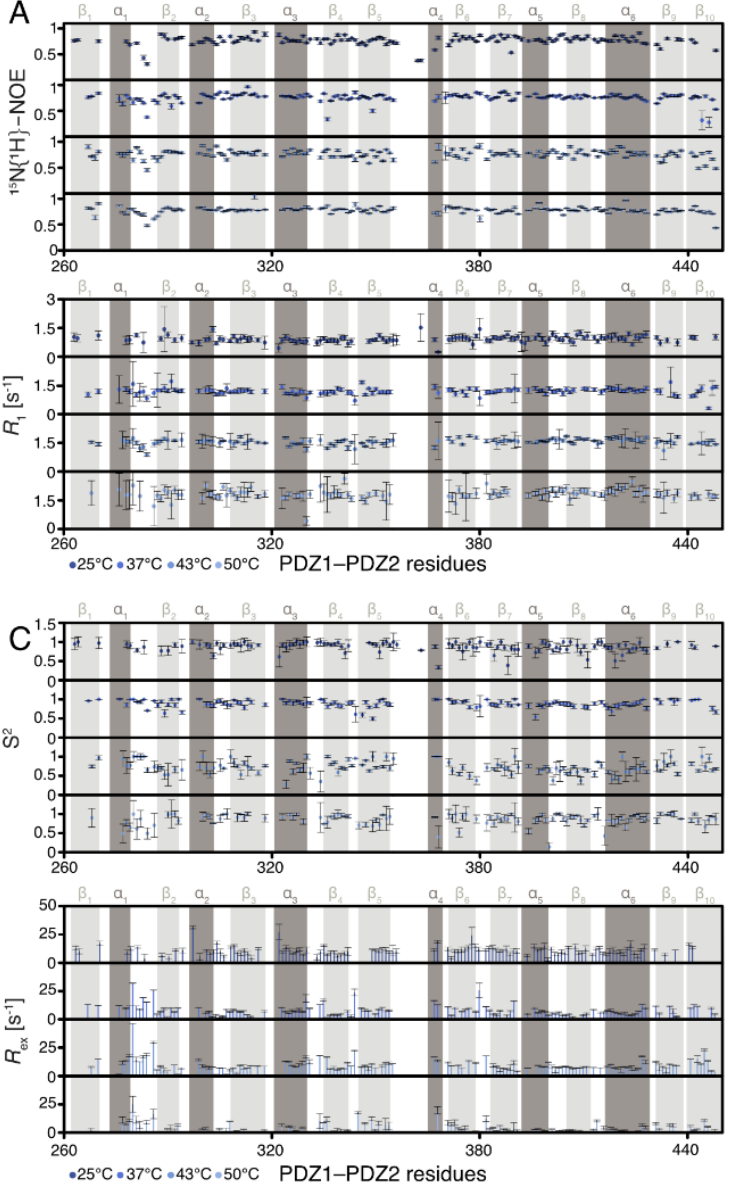
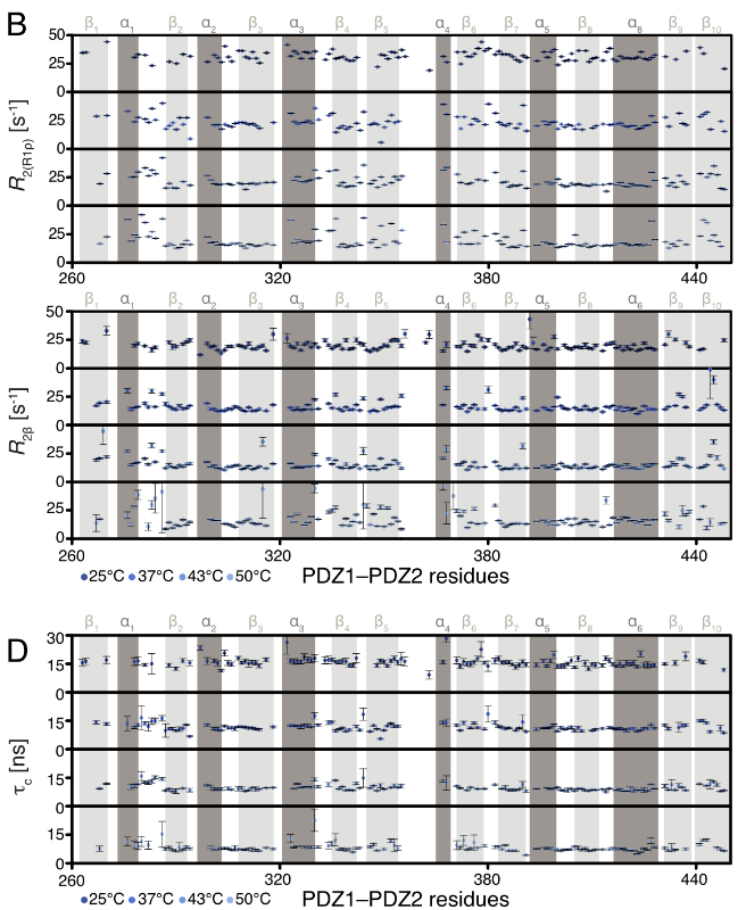

Fig. S8. Temperature dependence of the PDZ1-PDZ2 backbone dynamics.

(A) Local backbone dynamics on the pico- to nanosecond timescale probed by hetNOE and $R_{1}$ measurements. (B) Obtained transversal relaxation rates $\left(R_{2 \beta}\right.$ and $\left.R_{2(\mathrm{R} 1 \rho)}\right)$ reporting on micro- to millisecond motions. (C) Temperature dependence of the sub-nanosecond order parameter $\mathrm{S}^{2}$ and the exchange rate $R_{\mathrm{ex}}$, reporting on possible conformational exchange contributions on the microto millisecond timescale, calculated using the Lipari-Szabo model-free approach. (D) Rotational correlation time $\left(\tau_{\mathrm{c}}\right)$ is determined from the ratio of $R_{1}$ and $R_{2(\mathrm{R} 1 \rho)}$. All data are plotted against the $\mathrm{PDZ1}-\mathrm{PDZ} 2$ residues at the indicated temperatures ranging from $25-50^{\circ} \mathrm{C}$. 

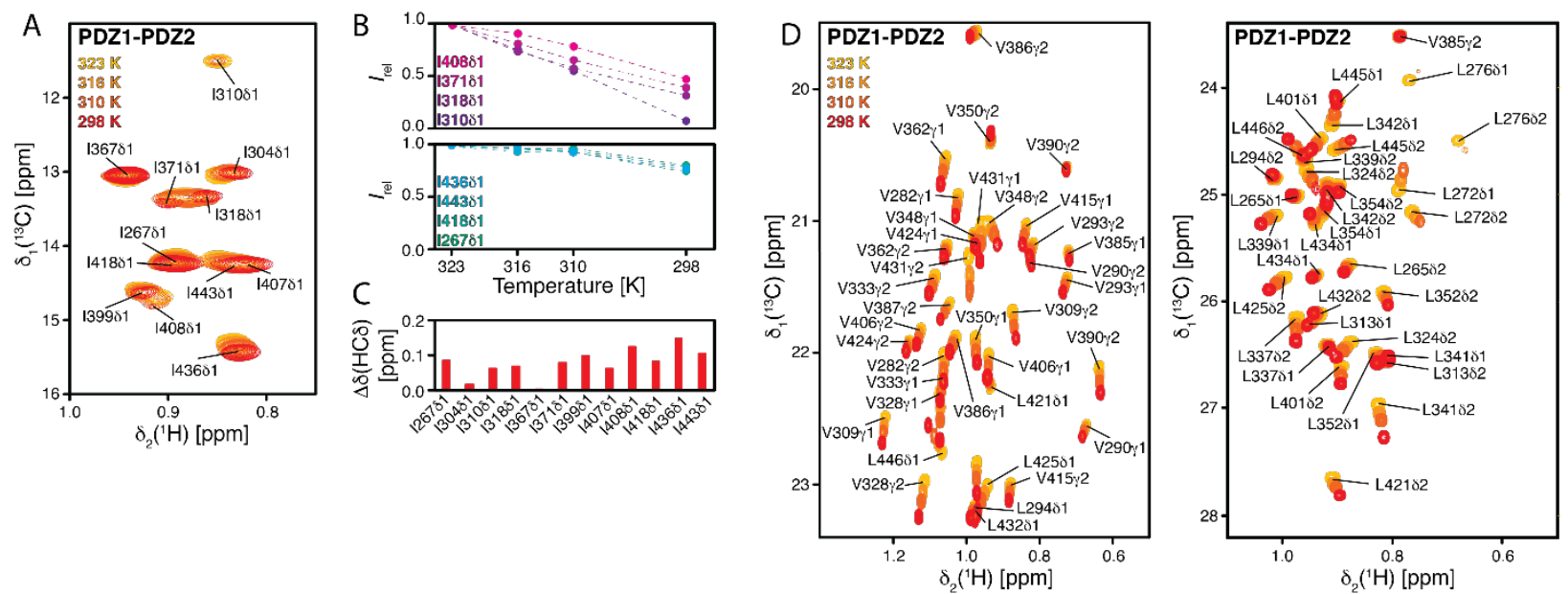

E

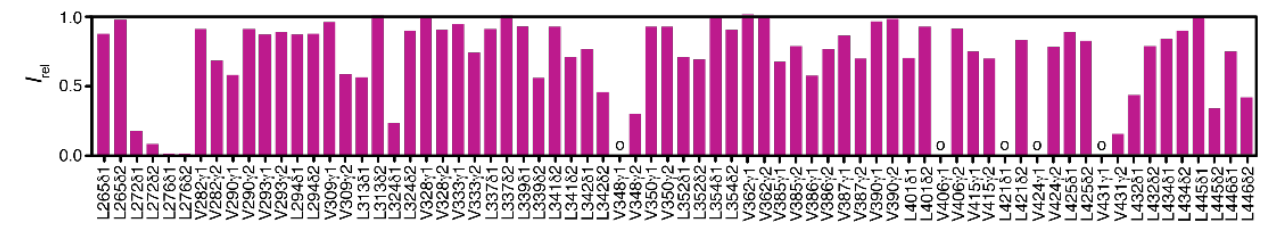

$\mathrm{F}$
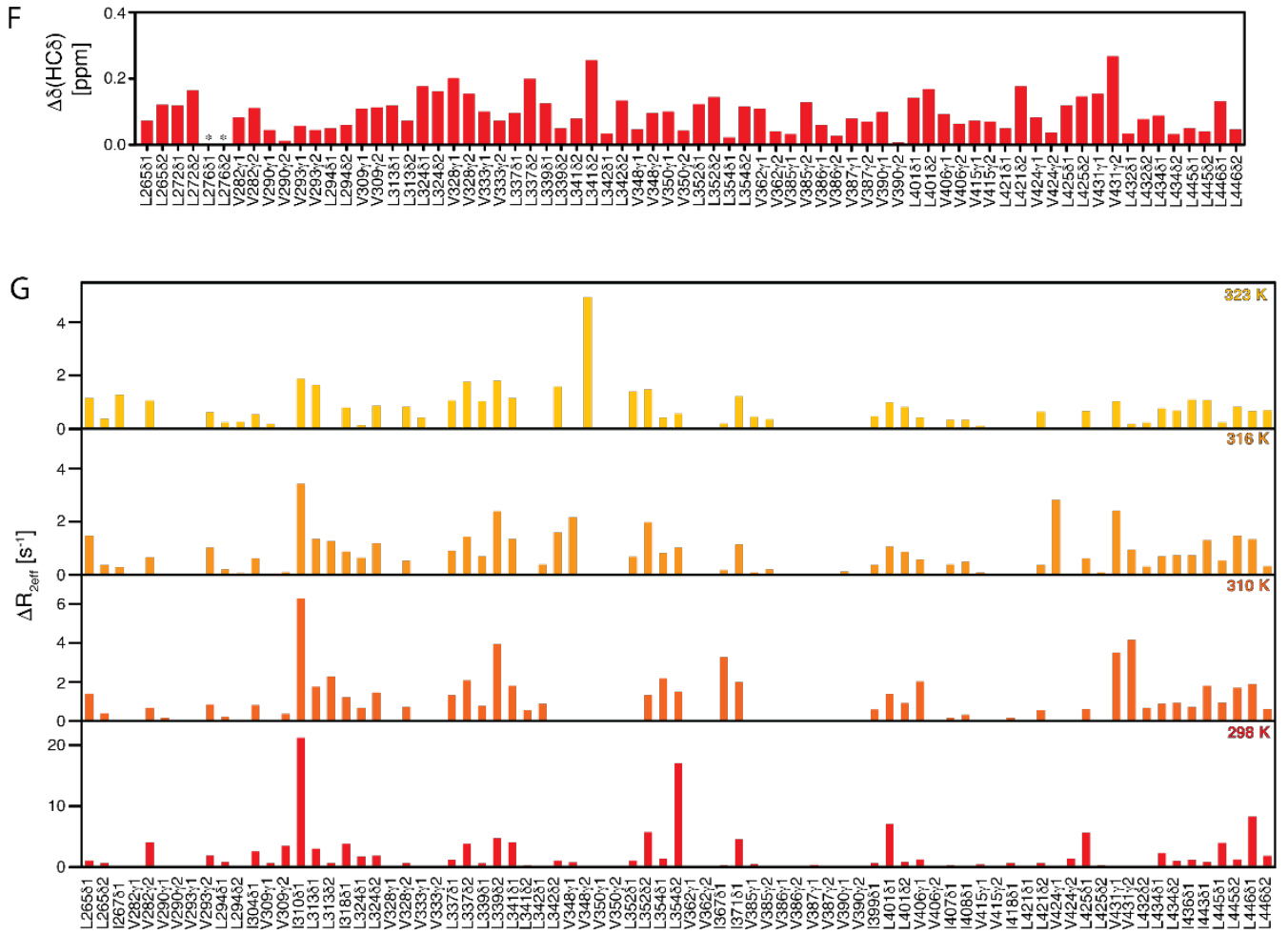

Fig. S9. Methyl group dynamics.

(A) Isoleucine methyl region of a $2 \mathrm{D}\left[{ }^{13} \mathrm{C},{ }^{1} \mathrm{H}\right]-\mathrm{NMR}$ spectrum of $\left[U_{-}{ }^{13} \mathrm{C},{ }^{15} \mathrm{~N}\right]-\mathrm{PDZ} 1-\mathrm{PDZ} 2$ at different temperatures as indicated. $(\mathbf{B}, \mathbf{C})$ The temperature dependence of the isoleucine signal intensities (B) and chemical shift changes (C) for the PDZ1-PDZ2 construct. The broken lines in panel $\mathbf{B}$ serve as guide to the eyes only. (D) Leucine and valine methyl region of a $2 \mathrm{D}\left[{ }^{13} \mathrm{C},{ }^{1} \mathrm{H}\right]-$ 
NMR spectrum of $\left[U_{-}{ }^{2} \mathrm{H}\right.$, Leu- $\delta_{1,2}$-Val- $\left.\gamma_{1,2}{ }^{13} \mathrm{CH}_{3}\right]-\mathrm{PDZ} 1-\mathrm{PDZ} 2$ at different temperatures as indicated. (E, F) The temperature dependence of the leucine/valine signal intensities (E) and chemical shift changes (F) for the PDZ1-PDZ2 construct. o in panel $\mathbf{E}$ indicates overlapping peaks, whereas $*$ in panel $\mathbf{F}$ indicates severe line-broadening beyond detection. $(\mathbf{G}) \Delta R_{2 \text { eff }}$ values for isoleucine, leucine, and valine methyl groups, obtained from the difference of $R_{2 \mathrm{eff}}$ at the lowest and highest CPMG frequency $\mathrm{UCPMG}_{\mathrm{CPM}}$ at the indicated temperatures. 

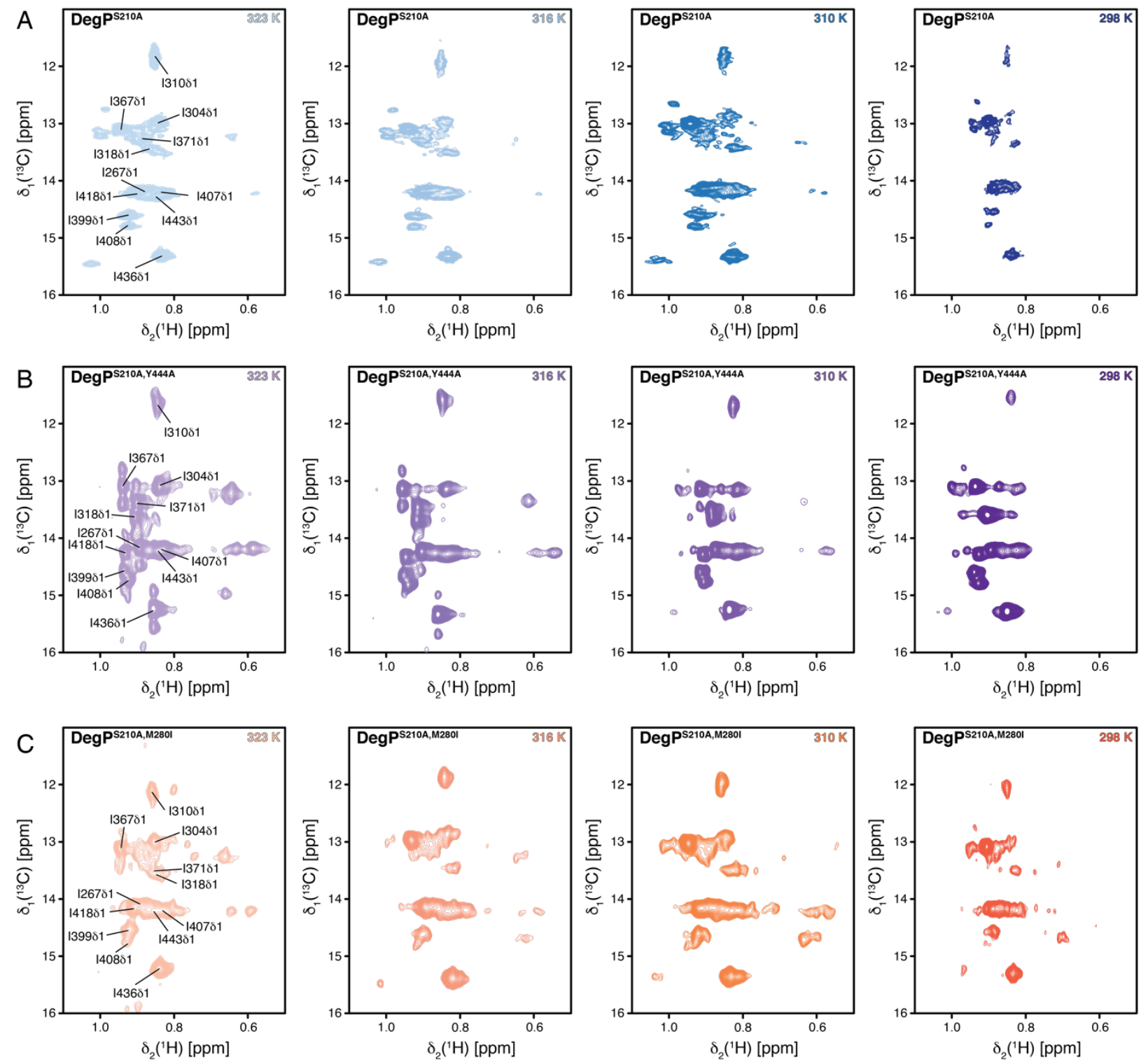

Fig. S10. Isoleucine spectra of full-length $\operatorname{DegP}^{\mathrm{S210A}}$-variants

(A-C) $2 \mathrm{D}\left[{ }^{13} \mathrm{C},{ }^{1} \mathrm{H}\right]-\mathrm{NMR}$ spectra of $\left[U_{-}{ }^{2} \mathrm{H}\right.$, Ile- $\left.\delta_{1-}{ }^{13} \mathrm{CH}_{3}\right]-\operatorname{DegP} \mathrm{P}^{\mathrm{S} 10 \mathrm{~A}}(\mathbf{A}),\left[U_{-}{ }^{2} \mathrm{H}, \mathrm{Ile}-\delta_{1-}{ }^{13} \mathrm{CH}_{3}\right]-$ $\operatorname{DegP}{ }^{\mathrm{S} 210 \mathrm{~A}, \mathrm{Y} 444 \mathrm{~A}}(\mathbf{B})$, and $\left[U_{-}{ }^{2} \mathrm{H}\right.$, Ile- $\left.\delta_{1}{ }^{-1}{ }^{13} \mathrm{CH}_{3}\right]-\mathrm{DegP}^{\mathrm{S} 210 \mathrm{~A}, \mathrm{M} 280 \mathrm{I}}(\mathbf{C})$ measured at the indicated temperatures. The sequence-specific resonance assignment of selected isoleucine resonances derived from the isolated PDZ1-PDZ2 domain are indicated. 
A

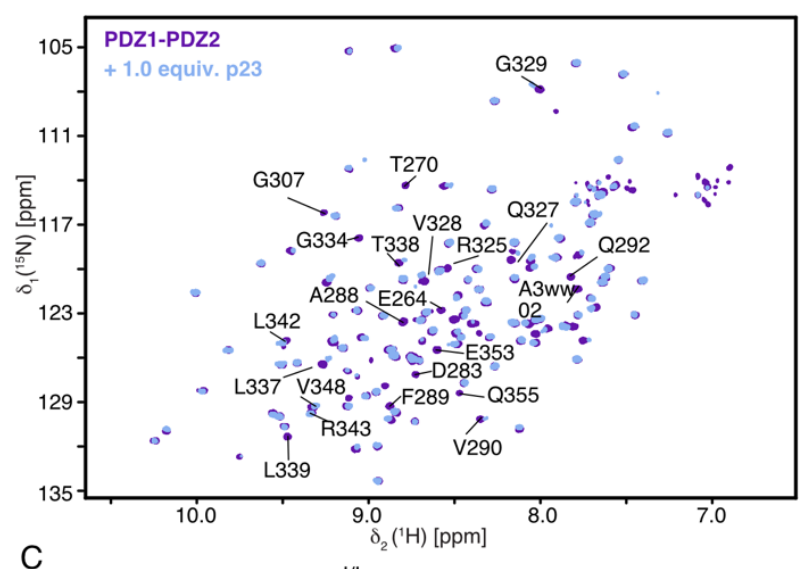

C

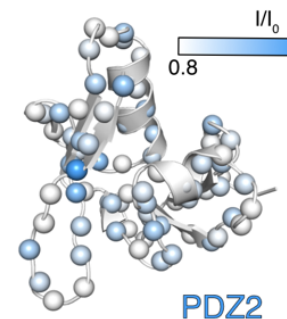

PDZ2

PDZ1

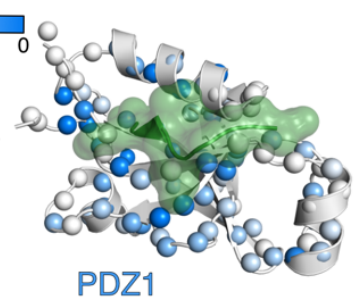

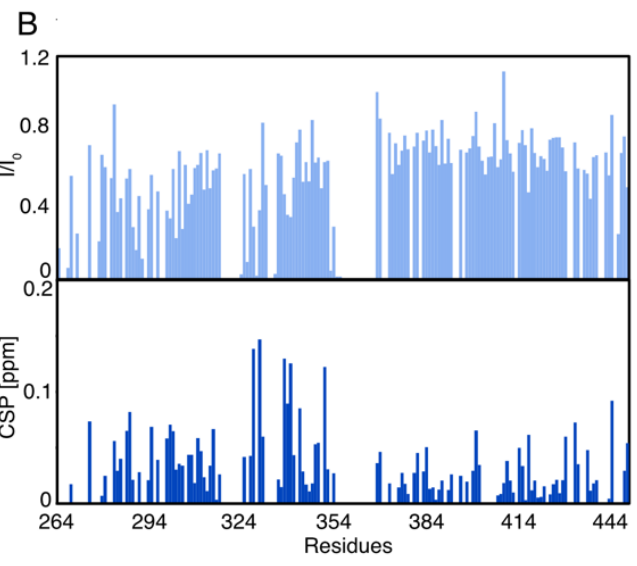

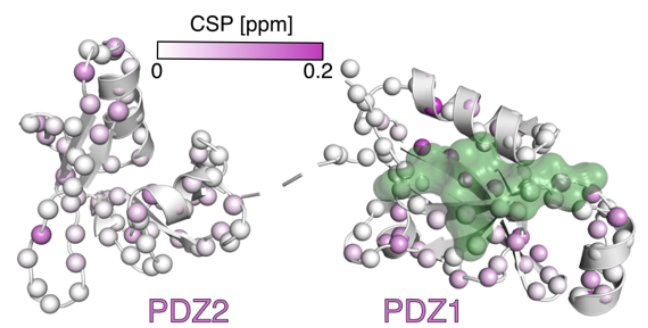

Lysozyme C18.58: GTGDNYRGYSLGNWVSAAKFESNFNTQATNRNTDGSTDYGILQI

D

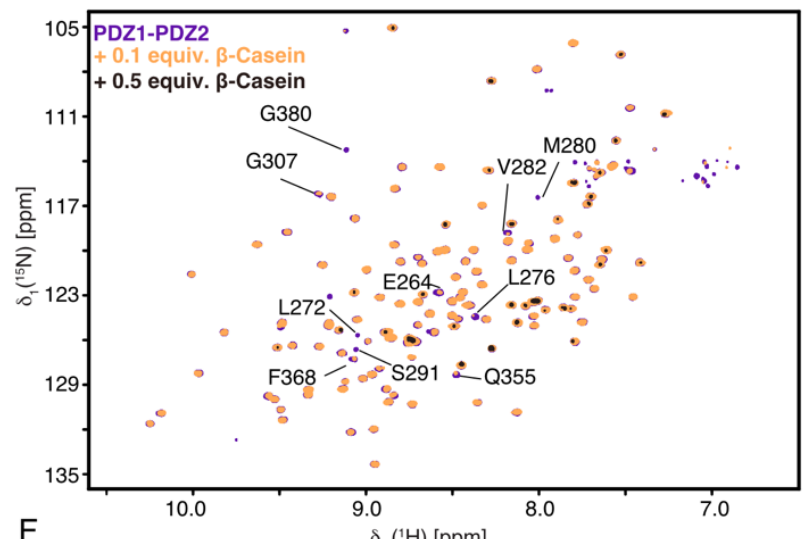

F

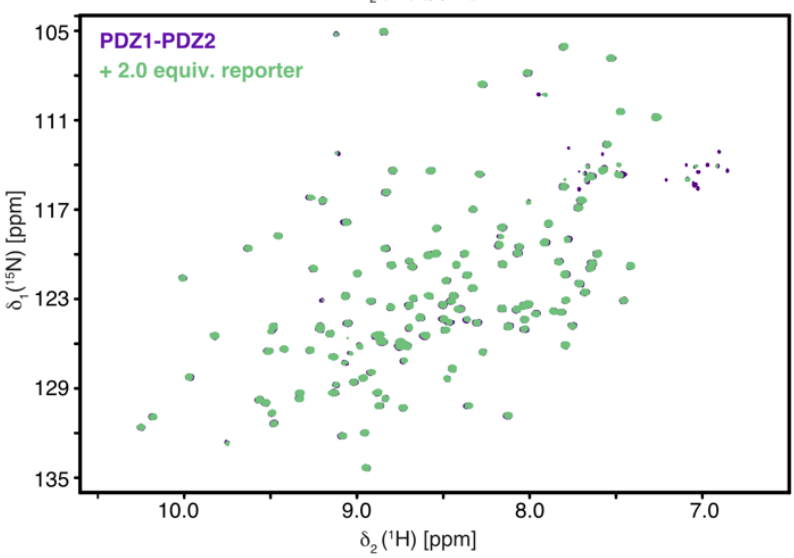

\section{E}
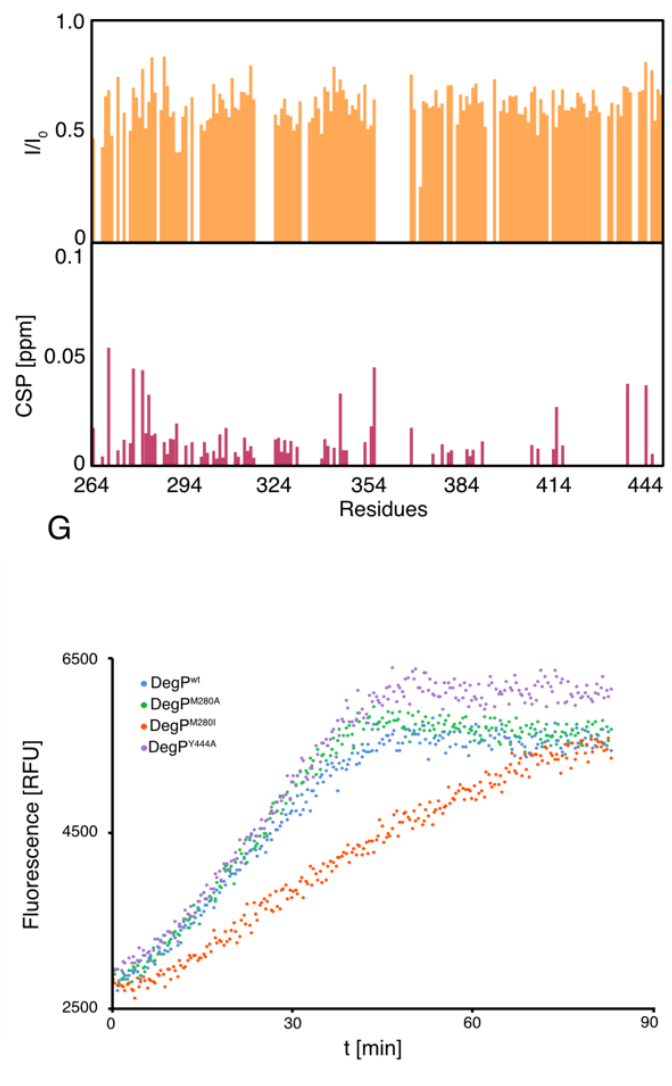


\section{Fig. S11. PDZ1-PDZ2 construct interactions with different substrates.}

(A) $2 \mathrm{D}\left[{ }^{15} \mathrm{~N},{ }^{1} \mathrm{H}\right]-\mathrm{NMR}$ spectra of $\left[U_{-}{ }^{15} \mathrm{~N}\right]-\mathrm{PDZ} 1-\mathrm{PDZ} 2$ (purple) and after the addition of 1 molar equivalent of p23 (blue). All NMR titrations were measured at $37^{\circ} \mathrm{C}$. (B) Residue-resolved backbone amide NMR signal attenuation $\left(\mathrm{I} / \mathrm{I}_{0}\right)$ and detected signal chemical shift perturbations (CSP) of the p23 titration. (C) Observed p23 titration effects plotted on the previously reported crystal structure of the DegP:Lysozyme $\mathrm{C}^{15-58}$ (green) complex (3OTP) (14). The amide moieties of the PDZ1-PDZ2 construct are shown as spheres. Signal attenuation values are indicated by the white to blue and CSP values by the white to the purple gradient. Inset: Sequence alignment of Lysozyme $\mathrm{C}^{15-58}$ and p23 for the visible residues highlighted in green. (D) $2 \mathrm{D}\left[{ }^{15} \mathrm{~N},{ }^{1} \mathrm{H}\right]-\mathrm{NMR}$ spectra of $\left[U_{-}^{15} \mathrm{~N}\right]-\mathrm{PDZ} 1-\mathrm{PDZ} 2$ (purple) and after the addition 0.1 (orange) and 0.5 (black) molar equivalents of $\beta$-Casein. (E) Residue-resolved backbone amide NMR signal attenuation $\left(\mathrm{I} / \mathrm{I}_{0}\right)$ and detected signal chemical shift perturbations (CSP) of the $\beta$-Casein titration (0.1 equivalents). (F) $2 \mathrm{D}\left[{ }^{15} \mathrm{~N},{ }^{1} \mathrm{H}\right]-\mathrm{NMR}$ spectra of $\left[U_{-}{ }^{15} \mathrm{~N}\right]-\mathrm{PDZ} 1-\mathrm{PDZ} 2$ (purple) and after the addition 2 molar equivalents of reporter peptide. $(\mathbf{G})$ Proteolysis of p23 $(7.5 \mu \mathrm{M})$ by DegP and its variants $(0.2 \mu \mathrm{M}$ of monomer concentration) at $25^{\circ} \mathrm{C}$. 
A

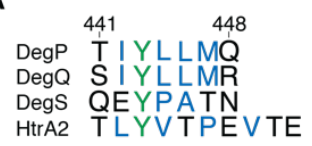

B

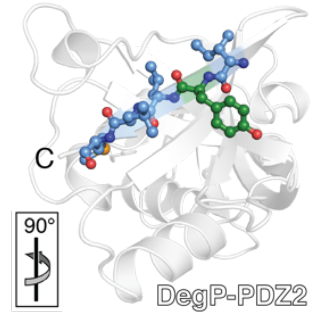

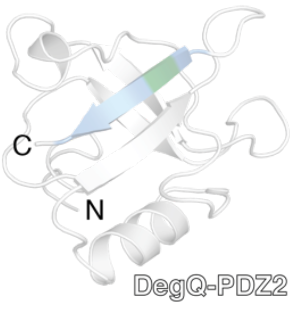

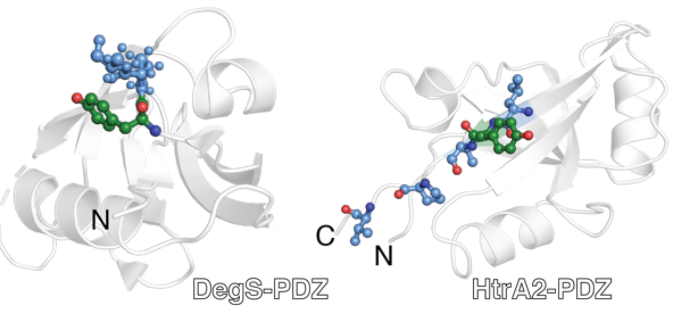

C
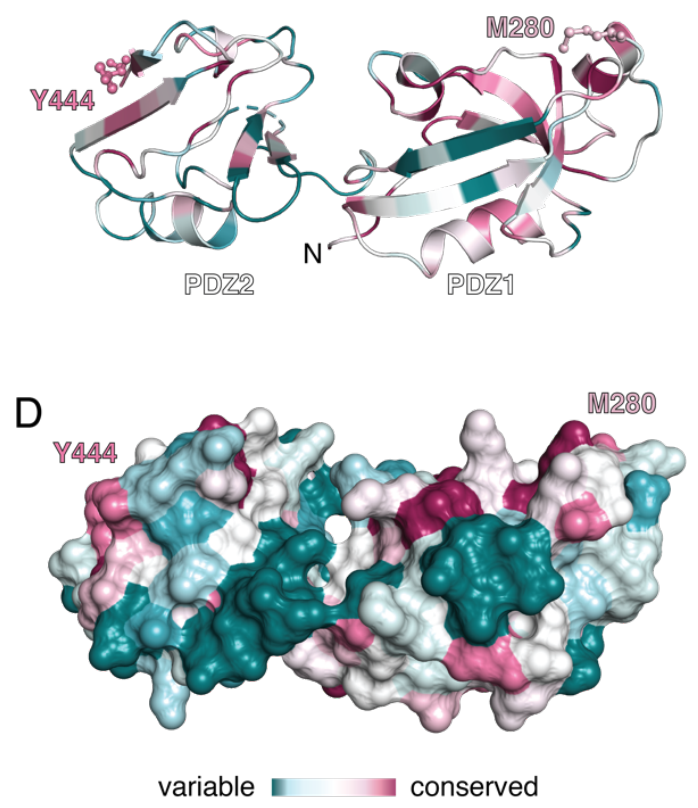

Fig. S12. Sequence conservation analysis of the interdomain lock.

(A) Sequence comparison of the $\beta_{10}$-strand containing Y444 in the PDZ of DegP with corresponding domains of related bacterial periplasmic DegQ and DegS as well as human mitochondrial HtrA2. (B) Cartoon representation of the DegP-PDZ2 (PDB-ID: 3OU0) with focus on Y444 and adjacent hydrophobic residues forming a hydrophobic patch facilitating the interdomain lock (23). For the DegQ-PDZ2 only a medium resolution structure at $7.5 \AA$ (PDB-ID: 4A8C) is available without any side-chain information (22). In contrast to DegP and DegQ, DegS has only a single PDZ-domain (PDB-ID: 4RQY). Similarly, human mitochondrial HtrA2 bears also a single PDZ-domain (PDB-ID: 1LCY), for which recently the involvement of the highlighted tyrosine in oligomeric resting state stabilization could be shown (21). (C, D) Cartoon (C) and surface (D) representation of the DegP PDZ1-PDZ2 domains displaying the degree of conservation with the indicated gradient ranging from 0 (variable) to 9 (conserved). Positions of M280, 7/9 conservation score, and Y444, 8/9 conservation score are indicated. Analysis was performed via the ConSurf (Tel Aviv University, Israel) server (78, 79). 
Table S1. Summary of the obtained diffusion coefficients

\begin{tabular}{|c|c|c|c|}
\hline Temperature & $\operatorname{DegP} P^{S 210 A}$ & DegP ${ }^{\text {S210A,Y444A }}$ & DegP $P^{\$ 210 A, M 280 I}$ \\
\hline $25^{\circ} \mathrm{C}$ & $3.41 \cdot 10^{-7} \mathrm{~cm}^{2} \mathrm{~s}^{-1}$ & $4.64 \cdot 10^{-7} \mathrm{~cm}^{2} \mathrm{~s}^{-1}$ & $3.53 \cdot 10^{-7} \mathrm{~cm}^{2} \mathrm{~s}^{-1}$ \\
\hline $37^{\circ} \mathrm{C}$ & $3.81 \cdot 10^{-7} \mathrm{~cm}^{2} \mathrm{~s}^{-1}$ & $4.81 \cdot 10^{-7} \mathrm{~cm}^{2} \mathrm{~s}^{-1}$ & $3.97 \cdot 10^{-7} \mathrm{~cm}^{2} \mathrm{~s}^{-1}$ \\
\hline $43^{\circ} \mathrm{C}$ & $4.83 \cdot 10^{-7} \mathrm{~cm}^{2} \mathrm{~s}^{-1}$ & $4.96 \cdot 10^{-7} \mathrm{~cm}^{2} \mathrm{~s}^{-1}$ & $4.89 \cdot 10^{-7} \mathrm{~cm}^{2} \mathrm{~s}^{-1}$ \\
\hline $50^{\circ} \mathrm{C}$ & $4.94 \cdot 10^{-7} \mathrm{~cm}^{2} \mathrm{~s}^{-1}$ & $4.99 \cdot 10^{-7} \mathrm{~cm}^{2} \mathrm{~s}^{-1}$ & $4.94 \cdot 10^{-7} \mathrm{~cm}^{2} \mathrm{~s}^{-1}$ \\
\hline
\end{tabular}

Table S2. Summary of the calculated diffusion tensor values

\begin{tabular}{|c|c|c|c|c|c|c|c|}
\hline Temperature & $\boldsymbol{D}_{\mathbf{x}}$ & $\boldsymbol{D}_{\mathbf{y}}$ & $\boldsymbol{D}_{\mathbf{z}}$ & $\boldsymbol{D}_{\| / \perp^{\mathbf{a}}}$ & $\boldsymbol{\alpha}^{\circ}$ & $\boldsymbol{\beta}^{\circ}$ & $\boldsymbol{\gamma}^{\circ}$ \\
\hline $\mathbf{2 5}^{\circ} \mathbf{C}$ & $1.196 \pm 0.039$ & $1.818 \pm 0.041$ & $1.956 \pm 0.414$ & 1.30 & $23.10 \pm 34.25$ & $19.96 \pm 22.02$ & $54.48 \pm 33.97$ \\
\hline & & & & & & \\
\hline $\mathbf{3 7}^{\circ} \mathbf{C}$ & $1.859 \pm 0.038$ & $2.238 \pm 0.041$ & $2.572 \pm 0.043$ & 1.26 & $-27.07 \pm 13.61$ & $22.47 \pm 5.93$ & $55.79 \pm 13.94$ \\
\hline & & & & & & & \\
\hline $\mathbf{4 3}^{\circ} \mathbf{C}$ & $2.249 \pm 0.043$ & $2.768 \pm 0.039$ & $3.165 \pm 0.049$ & 1.26 & $-15.87 \pm 5.21$ & $41.77 \pm 5.21$ & $72.91 \pm 4.09$ \\
\hline & & & & & & & \\
\hline $\mathbf{5 0}^{\circ} \mathbf{C}$ & $2.431 \pm 0.104$ & $3.989 \pm 0.117$ & $4.325 \pm 0.112$ & 1.35 & $18.37 \pm 15.01$ & $-37.93 \pm 25.15$ & $34.38 \pm 15.35$ \\
& & & & & & \\
\hline
\end{tabular}

Principle values of the diffusion tensor $\left(10^{-8} \mathrm{~s}^{-1}\right)$ as determined for axially symmetric diffusion tensors with Tensor2 (65). Relaxation data determined at a proton Larmor frequency of $700 \mathrm{MHz}(16.4 \mathrm{~T})$ was used with standard values for the length of the N-H bond, $r_{\mathrm{N}-\mathrm{H}}$ of $1.02 \AA$, and the chemical shift anisotropy (CSA) of $-172 \mathrm{ppm}$. In addition, the refined high resolution DegP structure was used (PDB: 3OU0). $D_{\| / \perp}$ was calculated as follows: $D_{\|}=(D \mathrm{x}+\mathrm{Dy}) / 2$ and $D_{\perp}=D_{\mathrm{z}}$ 
Table S3. Plasmids and respective primers used in this study.

\begin{tabular}{|c|c|c|}
\hline Plasmid & Primer & Sequence \\
\hline $\begin{array}{l}\text { pDS5 (6xHis-DegP }{ }^{\mathrm{S} 210 \mathrm{~A}, \mathrm{Y444A}} \text { ) } \\
\text { pDS37 (6xHis-SUMO-PDZ2 } \\
\left.\text { pDS45 (6xHis-DegP }{ }^{\mathrm{Y} 444 \mathrm{~A}}\right)\end{array}$ & $\begin{array}{l}\text { DegP_Y444A_frw } \\
\text { DegP_Y444A_rev }\end{array}$ & $\begin{array}{l}\text { 5'-GATTACTGCATTAACAGGGCGATGGTGCTGTCGCCGCG-3' } \\
\text { 5'-CGCGGCGACAGCACCATCGCCCTGTTAATGCAGTAATC-3' }\end{array}$ \\
\hline $\begin{array}{l}\left.\text { pDS41 (6xHis-DegP }{ }^{\mathrm{S} 210 \mathrm{~A}, \mathrm{M} 280 \mathrm{~A}}\right) \\
\text { pDS44(6xHis-DegP } \\
\text { pDS28A }) \\
\text { pDS39 (6xHis-SUMO-PDZ1- } \\
\left.\text { PDZ2 }^{\mathrm{M} 280 \mathrm{~A}}\right)\end{array}$ & $\begin{array}{l}\text { DegP_M280A_frw } \\
\text { DegP_M280A_rev }\end{array}$ & $\begin{array}{l}\text { 5'-CTTTCGCCGCTTTCGCCAGTTCGGAGTTCAG-3' } \\
\text { 5'-CTTTCGCCGCTTTCGCCAGTTCGGAGTTCAG-3' }\end{array}$ \\
\hline $\begin{array}{l}\left.\text { pDS52 (6xHis-DegP } \mathrm{P}^{\mathrm{M} 280 \mathrm{I}}\right) \\
\text { pDS46 (6xHis-DegP } \\
\text { S210A,M280I }\end{array}$ & $\begin{array}{l}\text { DegP_M280I_frw } \\
\text { DegP_M280I_rev }\end{array}$ & $\begin{array}{l}\text { 5'-CTTTAATCGCTTTCGCCAGTTCGGAGTTCAG-3' } \\
\text { 5'-GCGATTAAAGTTGACGCCCAGCGCGGTGC-3' }\end{array}$ \\
\hline pDS35(6xHis-DegP) & & \\
\hline pDS10(6xHis-SUMO-PDZ1) & $\begin{array}{l}\text { pET15_5206_Fwd } \\
\text { SUMO_PDZ1PDZ2_fwd } \\
\text { SUMO_PDZ1PDZ2_rev } \\
\text { PDZ1_XhoI_Rev }\end{array}$ & $\begin{array}{l}\text { 5'-ATCGAGATCTCGATCCCGCG-3' } \\
\text { 5'-GATTGGCGGTAAACGCGGTGAGCTGGG-3' } \\
\text { 5'-CACCGCGTTTACCGCCAATCTGTTCCAG-3' } \\
\text { 5'-GTGCTCGAGTTACAGTTCCAGGTTCACG-3' }\end{array}$ \\
\hline pDS11(6xHis-SUMO-PDZ2) & $\begin{array}{l}\text { pET15_5206_Fwd } \\
\text { SUMO_PDZ2_Fwd } \\
\text { SUMO_PDZ2_Rev } \\
\text { PDZ1PDZ2_XhoI_Rev }\end{array}$ & $\begin{array}{l}\text { 5'-ATCGAGATCTCGATCCCGCG-3' } \\
\text { 5'-GATTGGCGGTCAGAATCAGGTTGATTCCAG-3' } \\
\text { 5'-CTGATTCTGACCGCCAATCTGTTCCAG-3' } \\
\text { 5'-GTGCTCGAGTTACTGCATTAACAGGTAGATG-3' }\end{array}$ \\
\hline $\begin{array}{l}\text { pDS12(6xHis-SUMO-PDZ1- } \\
\text { PDZ2) }\end{array}$ & $\begin{array}{l}\text { pET15_5206_Fwd } \\
\text { PDZ1PDZ2_XhoI_Rev } \\
\text { SUMO_PDZ1PDZ2_fwd } \\
\text { PDZ1PDZ2_XhoI_Rev }\end{array}$ & $\begin{array}{l}\text { 5'-ATCGAGATCTCGATCCCGCG-3' } \\
\text { 5'-GTGCTCGAGTTACTGCATTAACAGGTAGATG-3' } \\
\text { 5'-GATTGGCGGTAAACGCGGTGAGCTGGG-3' } \\
\text { 5'-GTGCTCGAGTTACTGCATTAACAGGTAGATG-3' }\end{array}$ \\
\hline
\end{tabular}

